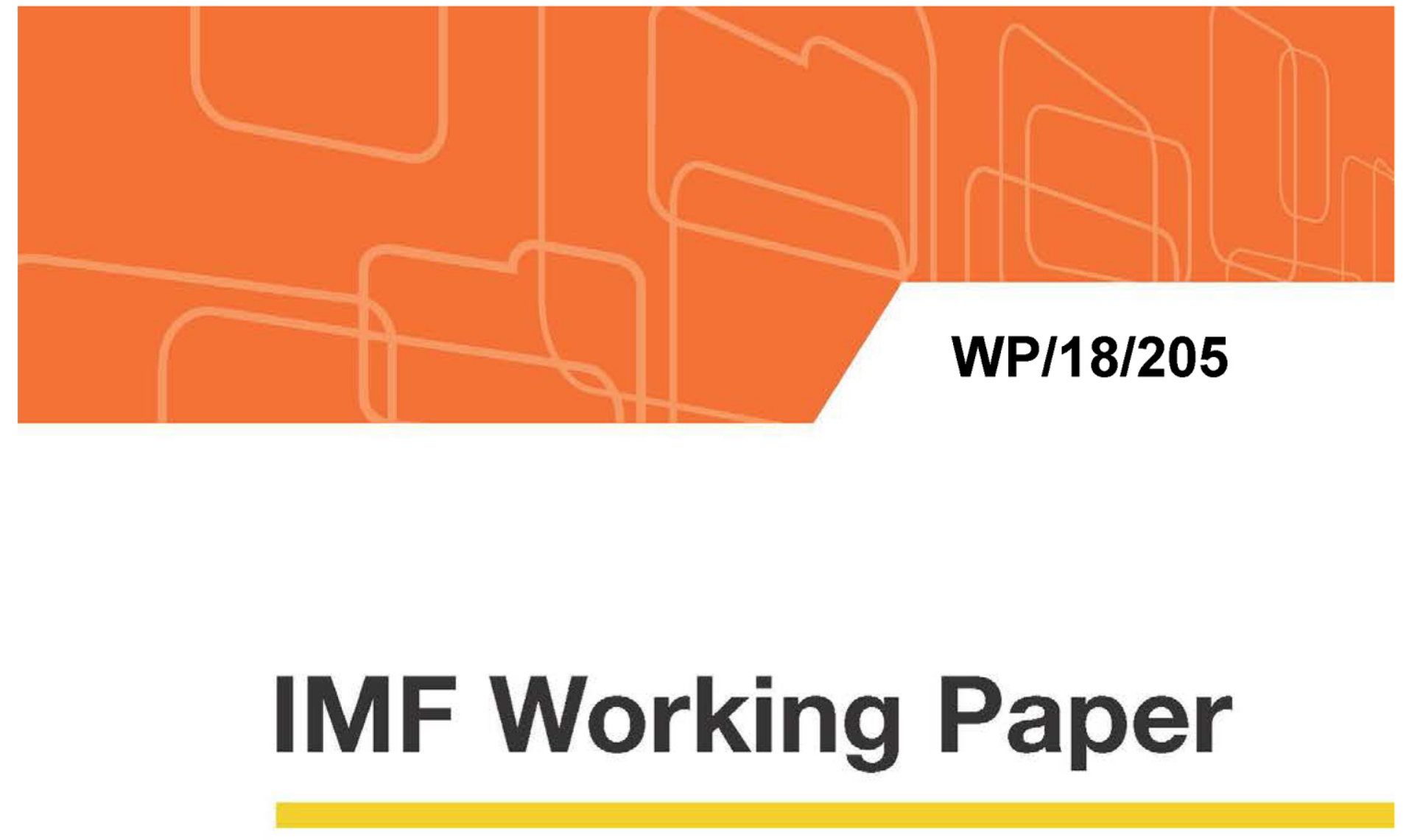

\title{
An Imperfect Financial Union With Heterogeneous Regions
}

by Filippo Balestrieri and Suman S. Basu

IMF Working Papers describe research in progress by the author(s) and are published to elicit comments and to encourage debate. The views expressed in IMF Working Papers are those of the author(s) and do not necessarily represent the views of the IMF, its Executive Board, or IMF management. In addition, the views expressed in this paper do not necessarily reflect those of the Analysis Group.

$$
\text { I N T ER N A T I O N A L MON ETAR Y FU N D }
$$




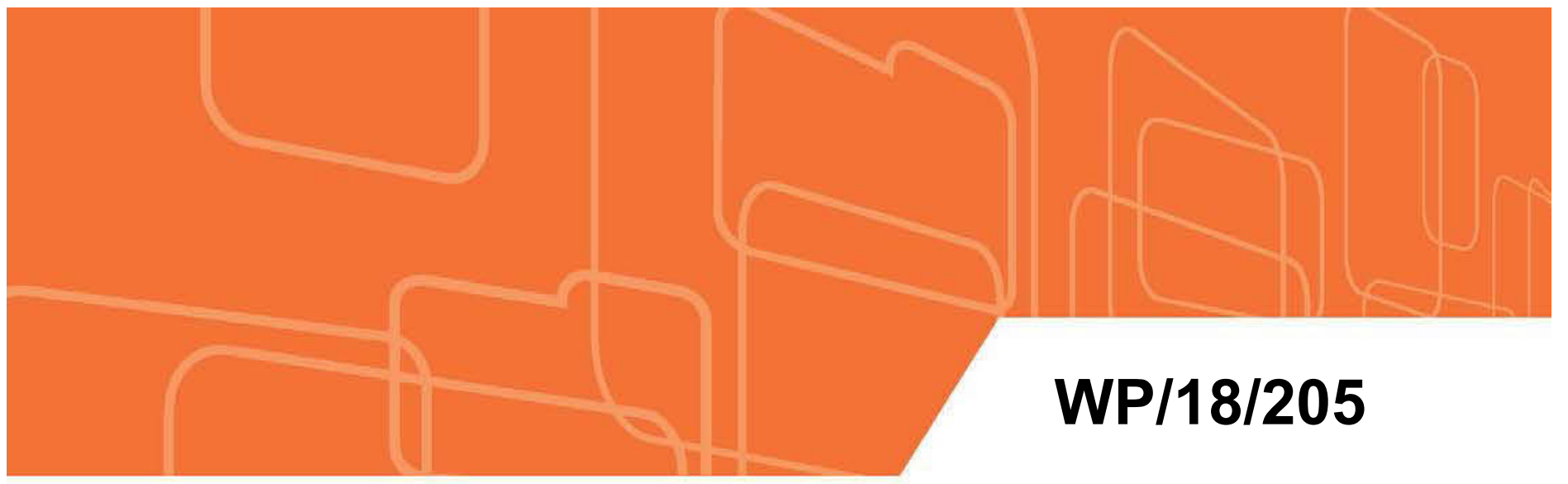

\title{
IMF Working Paper
}

\section{An Imperfect Financial Union With Heterogeneous Regions}

\author{
by Filippo Balestrieri and Suman S. Basu
}

IMF Working Papers describe research in progress by the author(s) and are published to elicit comments and to encourage debate. The views expressed in IMF Working Papers are those of the author(s) and do not necessarily represent the views of the IMF, its Executive Board, or IMF management. In addition, the views expressed in this paper do not necessarily reflect those of the Analysis Group. 


\title{
IMF Working Paper
}

\author{
Research Department
}

\section{An Imperfect Financial Union with Heterogeneous Regions* \\ Prepared by Filippo Balestrieri and Suman S. Basu}

Authorized for distribution by Marcos Chamon

September 2018

\begin{abstract}
IMF Working Papers describe research in progress by the author(s) and are published to elicit comments and to encourage debate. The views expressed in IMF Working Papers are those of the author(s) and do not necessarily represent the views of the IMF, its Executive Board, or IMF management.
\end{abstract}

\begin{abstract}
We analyze a union of financially-integrated yet politically-sovereign countries, where households in the Northern core of the union lend to those in the Southern periphery in a unified debt market subject to a borrowing constraint. This constraint generates sudden stops throughout the South, depresses the intra-union interest rate, and reduces Northern welfare below its unconstrained level, while having ambiguous effects on Southern welfare. During sudden stops, Pareto improvements can be achieved using North-to-South governmental loans if Southern governments have the capacity to commit to repay, or using a combination of Southern debt relief and budget-neutral taxes and subsidies if they do not. From the pre-crisis perspective, it is Pareto-improving to allow loans and debt relief to be negotiated in later sudden-stop periods as long as the regions in the union are sufficiently heterogeneous to begin with. We show that our results are robust to production and to limited financial openness of the union.
\end{abstract}

JEL Classification Numbers: E44, F36, F42

Keywords: Capital flows, sudden stop, financial union, heterogeneous regions

Authors' E-Mail Addresses: Filippo.Balestrieri@analysisgroup.com; SBasu2@imf.org

\footnotetext{
* This paper was previously presented as "Heterogeneous Countries in a Financial Union.” For helpful discussions, we thank Olivier J. Blanchard, Marcos Chamon, Atish R. Ghosh, Francesco Giavazzi, Bernardo Huberman, Subir Lall, Alberto Martin, Jonathan D. Ostry, Vania Stavkareva, and presentation attendees at the Latin American and Caribbean Economic Association 2014, the North American Meetings of the Econometric Society 2015, the Royal Economic Society 2015, the Society for the Advancement of Economic Theory 2015, and the European Economic Association 2015. All errors remaining are our own.
} 


\section{Contents}

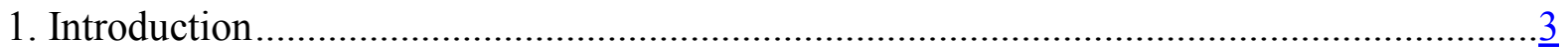

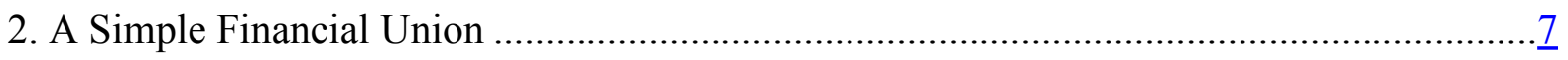

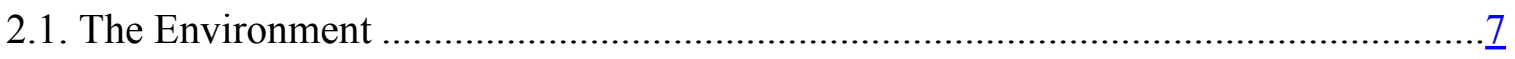

2.2. Pareto Efficiency of the Laissez-Faire Equilibrium..................................................11

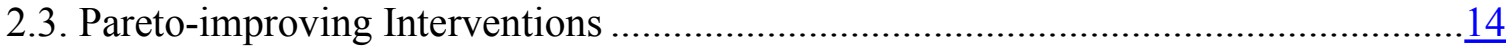

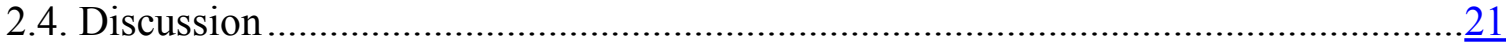

3. Pre-crisis Heterogeneity and Institutional Design ..................................................

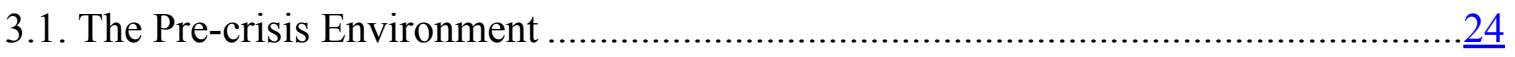

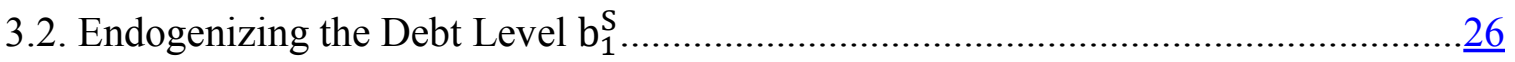

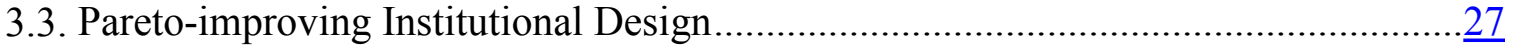

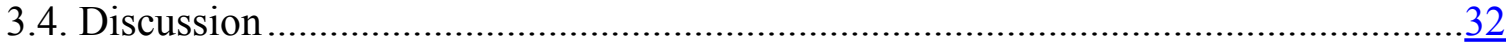

4. A More Elaborate Financial Union ........................................................................

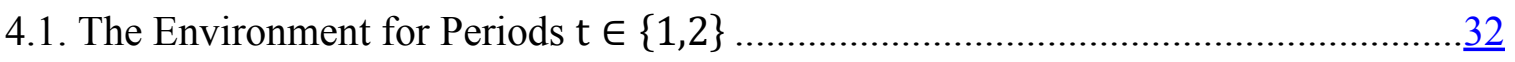

4.2. Pareto Efficiency of the Laissez-Faire Equilibrium........................................... 37

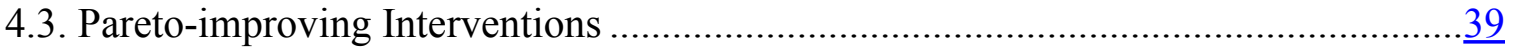

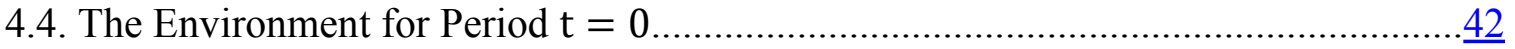

4.5. Pareto-improving Institutional Design........................................................... 44

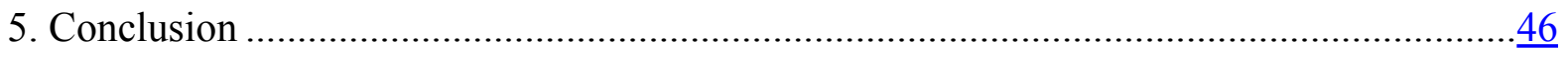

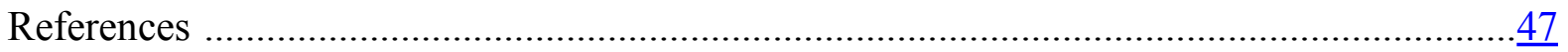

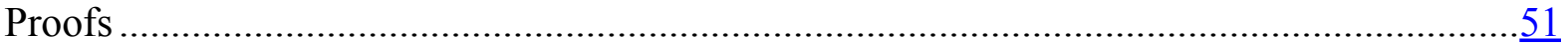

Figures

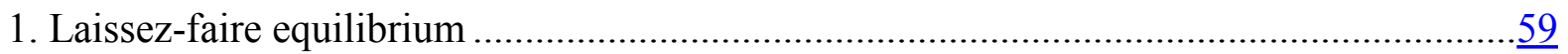

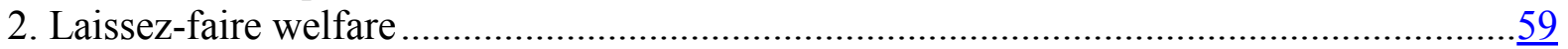

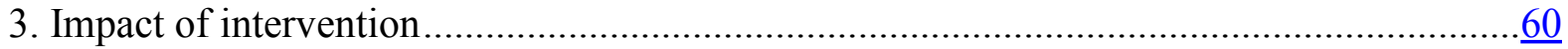

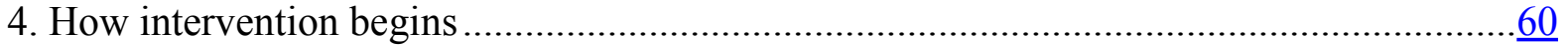

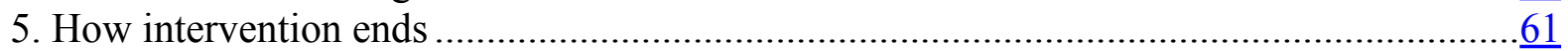

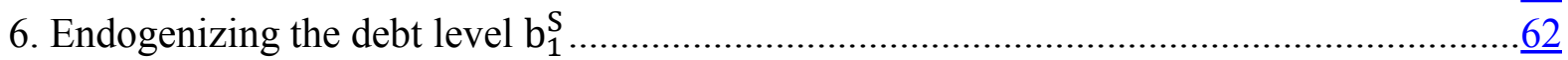

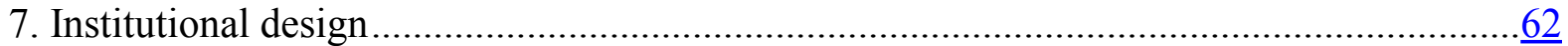

8. Laissez-faire equilibrium with $R O W$ and production ............................................63

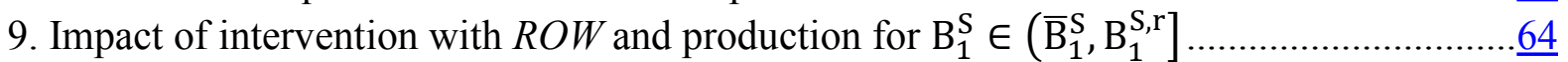

10. Simulation: impact of constraint on pre-crisis welfare ........................................... $\frac{65}{65}$

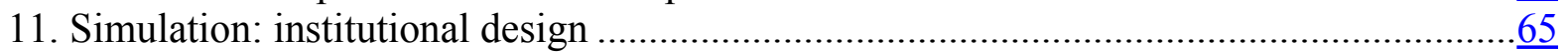




\section{Introduction}

European integration in the post-WW2 era began with greater openness in goods markets and proceeded over time to the liberalization of markets in services, labor, and the particular focus of our paper, finance. Capital market integration in Europe in the early 2000s took the form of a Northern "core" of economies intermediating debt purchases, from their own savers and from the rest of the world, to help a Southern "periphery" of economies finance their large current account deficits with respect to the rest of the world (Chen et al., 2012). ${ }^{1}$

But financial integration came with financial frictions. As Europe slid into crisis from 2009 onwards, there was a substantial reversal in North-to-South lending, as the value of the collateral backing the lending was downgraded: firstly, as Giavazzi and Spaventa (2010) observed, tradable output in periphery economies had not kept pace with external debt repayment needs ${ }^{2}$ and secondly, the price of collateralizable nontradable assets in the periphery, such as housing, also declined. As a result, the periphery's current account deficits shrank and turned into surpluses. Using the Calvo et al. (2004) methodology, Merler and Pisani-Ferry (2012) established that the decline in private capital flows into the periphery was severe enough to be classified a "sudden stop." 3 Subsequent analyses using structural models by Martin and Philippon (2014) and Gourinchas et al. (2016) have supported this finding. The impact of financial constraints in the periphery was partially cushioned by low interest rates, the Target 2 mechanism, and new debt-repurchase facilities introduced by the European Central Bank, and by sovereign bailouts from the International Monetary Fund and European supranational institutions.

In this paper, we draw on Europe's experience to build a model of an "imperfect financial union" - a group of politically-sovereign countries whose debt markets are integrated but suffer from a collateral-based repayment friction. ${ }^{4}$ These countries are divided into core and periphery regions, with the former lending to the latter because of heterogeneity: the periphery begins with higher inherited debt and/or lower initial endowments. We show that

\footnotetext{
${ }^{1}$ Specifically, the authors find that a large portion of this financing occurred through cross-border interbank lending and purchases of securities issued by governments and financial institutions.

${ }^{2}$ In an early analysis of the large current account deficits of Greece and Portugal, Blanchard and Giavazzi (2002) interpreted them as a by-product of beneficial financial integration, while cautioning that nontradable goods prices would fall when external debt was eventually repaid. Taking stock eight years later, Giavazzi and Spaventa (2010) warned that the external debt repayment problem would be more severe than had been expected: in their view, capital inflows into the periphery had been used for the consumption of tradable goods and the production of nontradable goods, rather than for investment in the tradable goods sector.

${ }^{3}$ Using monthly data, Calvo et al. (2004) define a sudden stop as occurring when year-on-year private capital inflows fall two standard deviations below their mean.

${ }^{4}$ This label is inspired by the terminology of Shambaugh (2012), who calls for the Eurozone to develop into a "financial union" - a union of countries within which imperfections in private financial markets are offset as much as possible by supranational financial institutions (such as Eurozone-wide deposit insurance, common supervisors, and a common risk-free bond). Our approach in this paper is to assume that some financial frictions still remain within the union (hence our addition of the word "imperfect"), and then to examine supranational fiscal policies (e.g., inter-governmental loans, debt relief, and budget-neutral taxes and subsidies) that can help manage such a union.
} 
sudden stops in the periphery depress the intra-union interest rate in general equilibrium, and thereby affect the welfare of both core and periphery regions. The endogeneity of the interest rate creates the potential for supranational fiscal policies to generate welfare improvements in a novel manner. Given the politically sovereignty of countries, we restrict our attention to policies that are Pareto-improving, benefiting each country in both the core and the periphery. We eschew restrictions on intra-union capital flows because we take it as given that financial integration is a pre-existing economic imperative.

The basic mechanism is as follows. Inspired by the literature on sudden stops, we assume that all households in the union have a borrowing limit that is equal to a fraction of the value of their future tradable and nontradable outputs. When households in the periphery wish to issue a high level of debt to the core, and when the periphery's nontradable goods price is low, the periphery's borrowing constraint binds, which we interpret as a union-wide crisis: an entire region is suffering a sudden stop. If the intra-union interest rate is endogenous - for example, the union is financially closed, or households in the core intermediate funds from the rest of the world to the periphery and earn a premium on such lending - it must decline below the unconstrained level when sudden stops occur. Since the core is a lender region, a decline in the interest rate constitutes a decline in the core's intertemporal terms of trade, and reduces the welfare of the core's households relative to the unconstrained allocation. By contrast, periphery households benefit if the constraint is moderately binding, but are worse off if the constraint is severely binding.

Within this environment, there exist Pareto-improving interventions which reverse the constraint-induced declines in interest rates and core-to-periphery lending. We examine two interventions which both accomplish this objective but in rather different ways.

Firstly, a core-to-periphery governmental loan directly increases public capital flows but it also reduces private capital flows (by a smaller amount), because the private sector borrowing limit is tightened as a result of the fall in the nontradable goods price in the period when the loan is repaid. The core is willing to subsidize this governmental loan, because it increases the interest rate on private loans, which in turn benefits the core's households. The implementation of such a loan requires the periphery's governments to have fiscal space, i.e., an ability to commit to repay that gets around the private sector's constraint.

Secondly, we consider an unconventional policy package of debt relief for the periphery today combined with a commitment by the periphery's governments to tax tradable consumption and subsidize nontradable consumption in a budget-neutral manner in the future. The commitment raises the future nontradable goods price and perhaps also nontradable output, and thereby relaxes the private sector borrowing constraint immediately, boosting private core-to-periphery capital flows. The associated increase in the interest rate benefits the core because it is the lender region, and it can afford to share its welfare gains with the periphery by offering the latter debt relief. Such a policy requires no commitment to repay by the periphery's governments, just a commitment to implement future fiscal policies.

C)International Monetary Fund. Not for Redistribution 
In section 2, we construct the simplest possible framework that captures the mechanisms described above. Our financial union is endowment-based and has two periods. It features the two regions North and South, each containing a continuum of countries. A common riskless bond is freely traded within the union, but the union is financially closed to the rest of the world (while being open to goods trade). Households in the Southern periphery start off with some debt owed to the Northern core, and when the inherited debt is high, the borrowing constraint binds throughout the South. In this simple model, both governmental loans and the debt relief package can restore the first-best allocation. Bargaining via regional coalitions is able to exploit all Pareto improvements, since the coalitions internalize the effects of their actions on the interest rate in a way that individual countries do not.

Are crisis-time interventions also Pareto-improving from the perspective of earlier periods, when borrowing constraints have yet to bind? In section 3, we show that the answer to this question depends on the union's degree of heterogeneity in pre-crisis times-i.e., how much more of an endowment the North starts off with relative to the South. If heterogeneity is low, the North rules out beforehand all interventions during crises, because interventions cause higher Southern borrowing and lower Northern consumption in pre-crisis periods. When heterogeneity is moderate or high, however, the ability of interventions to increase the interest rate during crises more than compensates the North for the higher pre-crisis Southern borrowing. Therefore, both regions agree beforehand to establish institutions that can then provide governmental loans and debt relief during regional sudden stops.

How do the optimal policy interventions change when households in the union can borrow from and lend to the rest of the world, and when output is produced instead of endowed? In section 4, we extend our model to address both of these issues.

We show that if both North and South can issue debt to the rest of the world, but there are tight limits on such borrowing, then the equilibrium of the model looks like the environment described in Chen et al. (2012): the North intermediates funds from the rest of the world to the South. In our model, the North earns a riskless premium on such lending, and all of the above results continue to apply because the premium is endogenous.

In an environment where tradable and nontradable goods are produced instead of endowed, both the interventions described above now generate intratemporal distortions. The governmental loan requires a tax on the South's tradable output in the period of repayment, which depresses tradable production, while the tax-and-subsidy portion of the debt relief package causes excessive Southern production of nontradable output. Therefore, the interventions do not restore any first-best allocation, but instead trace out a second-best frontier. Our general result is that both interventions are always used, each until the marginal reduction in the constraint-induced intertemporal distortion is equal to the marginal increase in the policy-induced intratemporal distortion. Deviating from the second-best combination of interventions reduces the welfare gains for both North and South. Excessive use of the governmental loan generates an excessively large union-wide current account surplus, while excessive use of the tax-subsidy intervention has the opposite effect.

CInternational Monetary Fund. Not for Redistribution 
Related Literature. This paper draws on an extensive literature on borrowing constraints and sudden stops in emerging markets. ${ }^{5}$ Closest to our paper are works by Jeanne and Korinek (2013) and Benigno et al. (2013, 2016), which have moved beyond pre-crisis interventions that reduce the risk of crises, ${ }^{6}$ to the kinds of policies that we focus on in this paper: crisis-time interventions that make crises less painful. However, our results diverge from those in the literature because of the change in setting: while most papers to date have focused on an individual country facing an exogenous interest rate, we examine a continuum of countries in a union with an endogenous interest rate. In Benigno et al. (2016), a contemporaneous tax on tradable consumption and subsidy on nontradable consumption improves welfare for a single borrower country facing an exogenous interest rate. In our model, instead, when a continuum of borrower countries commit to implement such taxes in the future, the interest rate increases, and as a result, it may be that lender countries benefit more than borrower countries. For this reason, debt relief must generally be added to the policy package in order to make sure that borrower countries are also better off. ${ }^{7}$

The way in which borrowing constraints depress the interest rate in our model is consistent with a growing body of research on debt deleveraging episodes, encompassing both closed-economy and open-economy frameworks. ${ }^{8,9}$ This literature often assumes that prices are sticky and that there is a zero lower bound on interest rates. In such an environment, fiscal transfers, debt relief, or simply higher fiscal spending in the core, can generate import and export demand spillovers between core and periphery and raise the interest rate above the zero lower bound. Relative to this literature, our use of a flexible-price framework sets aside the zero lower bound issue, and shifts focus from intra-union trade spillovers to intraunion financial spillovers. In our core-periphery model, the interest rate reflects the core's intermediation return from financing consumption in the periphery - even if all of the periphery's imports come from the rest of the world. Pareto improvements then involve raising the interest rate while providing some compensation to the periphery for this change. ${ }^{10}$

${ }^{5}$ In addition to the papers already referenced above, see Dornbusch et al. (1995), Calvo (1998), Caballero and Krishnamurthy (2001), Mendoza (2002, 2006), Mendoza and Smith (2006), Bianchi (2010), Jeanne and Korinek (2010), and Korinek and Mendoza (2014). These papers have introduced a variety of borrowing constraints based on the value of tradable output, nontradable output, and capital.

${ }^{6}$ Such policies include capital inflow taxes, capital controls, and macroprudential measures.

${ }^{7}$ We later emphasize that this tax-and-subsidy policy combination works not because of its support of the real exchange rate per se, but because it supports the price of collateralizable nontradable goods and/or assets in borrower countries.

${ }^{8}$ In the closed-economy literature, an early work with collateral constraints based on housing values is Iacoviello (2005). More recent papers, which have incorporated inter alia the zero lower bound on interest rates, include Guerrieri and Lorenzoni (2011), Midrigan and Phillippon (2011), Eggertsson and Krugman (2012), and Korinek and Simsek (2016).

${ }^{9}$ For open-economy models, including models of countries inside monetary unions, see Benigno and Romei (2012), Dogra (2014), Blanchard et al. (2015), and Fornaro (2016).

${ }^{10}$ Djajić et al. (1998) and Cremers and Sen (2009) show that inter-country transfers may benefit the donor country by increasing the interest rate, under the condition that discount rates and/or elasticities of intertemporal substitution in consumption differ between countries. In our model, by contrast, we show that such transfers can increase the interest rate when preferences are identical between countries, but some 
Our focus on the financial aspects of integration and our assumption of flexible prices separates our work from the literature on optimal currency areas. This substantial body of research, initiated by Mundell (1961) in an era of global trade integration and limited financial flows, focuses on asymmetric shocks to export demand within a currency union that has (implicitly or explicitly) sticky prices. ${ }^{11}$ While exchange rate flexibility is generally enough to restore post-shock Pareto efficiency in that literature, our results in this paper can be interpreted as showing that it is no longer such a powerful instrument when intra-union capital flows are large enough to trigger regional sudden stops. ${ }^{12}$ In this new environment, inter-regional lending and debt relief institutions need to be built.

Finally, this paper is informed by the literature on European capital flows that has emerged since the recent crisis. ${ }^{13}$ While some authors have proposed adding impediments to capital flows, ${ }^{14}$ our work falls instead within the strand of papers which have examined policies to stabilize economic activity while taking higher financial integration as given. ${ }^{15}$

\section{A Simple Financial Union}

The main contribution of this paper is the potential for Pareto-improving policies in a financially-integrated union of countries, when the union is composed of heterogeneous regions and one of those regions is experiencing a sudden stop. In this section, we build the intuition for this result by proving it in a simple two-period financially-closed union containing endowment economies. In later sections, we generalize the result to models with more periods, with financial openness of the union to the rest of the world, and with production. All proofs of lemmas and propositions are contained in the appendix.

\subsection{The Environment}

Our financial union $F$ has two regions $i \in\{N, S\}$, where $N$ is the Northern core and $S$ is the Southern periphery. Each region is composed of a unit measure of countries $j \in[0,1]$, and each country in turn contains a government and a unit measure of identical households who consume tradable and nontradable goods. There also exist unmodeled countries outside the financial union, in the rest of the world $R O W$. There are two periods, $t \in\{1,2\}$.

countries face binding borrowing constraints.

${ }^{11}$ For the early literature, see also McKinnon (1963), Kenen (1969), and Mundell (1973). Later empirical works include Bayoumi and Eichengreen (1993), Bayoumi and Masson (1995), and De Grauwe (1993, 1996). Recent micro-founded theoretical models that are heirs to the optimal currency literature include Beetsma and Jensen (2005), Galí and Monacelli (2008), and Farhi and Werning (2013a). These papers establish that fiscal cushioning, including inter-country transfers, is desirable in currency unions after asymmetric shocks.

${ }^{12}$ Our flexible-price model is isomorphic to a model with sticky prices and a flexible exchange rate.

${ }^{13}$ In addition to the papers already referenced above, see De Grauwe (2012), Lane (2012), Hale (2013), Obstfeld (2013), Waysand et al. (2010), and Reis (2013).

${ }^{14}$ For example, Farhi and Werning (2012) characterize the optimal use of capital controls.

${ }^{15}$ These papers, encompassing a variety of mechanisms, include Bolton and Jeanne (2011), Mendoza et al. (2013), Goyal et al. (2013), Farhi and Werning (2013b), and Broner et al. (2014). 
Households. The representative household in country $j$ of region $i$ has log preferences:

$$
U^{i, j}=\left(\log c_{T 1}^{i, j}+\nu \log c_{N T 1}^{i, j}\right)+\left(\log c_{T 2}^{i, j}+\nu \log c_{N T 2}^{i, j}\right),
$$

where $c_{T t}^{i, j}$ and $c_{N T t}^{i, j}$ are respectively the consumption of tradable and nontradable goods in country $j$ of region $i$ in period $t$, and $\nu$ captures the taste for nontradable goods. Tradable goods can be transported costlessly within the union and outside it, while nontradable goods are country-specific. Households face the following budget and borrowing constraints:

$$
\begin{gathered}
c_{T 1}^{i, j}+p_{1}^{i, j} c_{N T 1}^{i, j}+\frac{\left(1+\tau^{i, j}\right) c_{T 2}^{i, j}+\left(1-\eta^{i, j}\right) p_{2}^{i, j} c_{N T 2}^{i, j}}{r_{2}^{i, j}} \leq-b_{1}^{i, j}+y_{T 1}+p_{1}^{i, j} y_{N T 1}+x^{i, j}+\frac{y_{T 2}+p_{2}^{i, j} y_{N T 2}+z^{i, j}}{r_{2}^{i, j}} \\
b_{2}^{i, j} \equiv r_{2}^{i, j}\left(c_{T 1}^{i, j}+p_{1}^{i, j} c_{N T 1}^{i, j}+b_{1}^{i, j}-y_{T 1}-p_{1}^{i, j} y_{N T 1}-x^{i, j}\right) \leq \phi\left(y_{T 2}+p_{2}^{i, j} y_{N T 2}+z^{i, j}\right),
\end{gathered}
$$

where tradable goods are the numeraire, $p_{t}^{i, j}$ is the (flexible) relative price of nontradable goods in country $j$ of region $i$ in period $t, y_{T t}$ and $y_{N T t}$ are respectively the endowments of tradable and nontradable goods common to all countries in period $t, b_{t}^{i, j}$ is the inherited debt of each household in country $j$ of region $i$ at the beginning of period $t, r_{2}^{i, j}$ is the interest rate on borrowing and lending faced by that household between periods 1 and $2, \phi \in(0,1)$ is the fraction of period-2 endowments that is pledgable as collateral against borrowing in period $1, x^{i, j}$ and $z^{i, j}$ are the lump-sum transfers or taxes (depending on the sign) provided by the government to each household under its authority in periods 1 and 2 respectively, and $\tau^{i, j}$ and $\eta^{i, j}$ are respectively a tax on the consumption of tradable goods and a subsidy on the consumption of nontradable goods imposed by the government in period 2 .

Households begin period 1 with inherited debt $b_{1}^{i, j}$. The borrowing constraint (3) on $b_{2}^{i, j}$, based on the value of future tradable and nontradable endowments, is inspired by the sudden stops literature. ${ }^{16}$ When this constraint is binding for a country in our model, we say that the country is experiencing a sudden stop. The potential for government policies to generate Pareto improvements depends on the form of this constraint.

The household's first-order conditions are:

$$
\begin{gathered}
\left(1+\tau^{i, j}\right) c_{T 2}^{i, j} \geq r_{2}^{i, j} c_{T 1}^{i, j} \\
\nu c_{T 1}^{i, j}=p_{1}^{i, j} c_{N T 1}^{i, j} \\
\left(1+\tau^{i, j}\right) \nu c_{T 2}^{i, j}=\left(1-\eta^{i, j}\right) p_{2}^{i, j} c_{N T 2}^{i, j} .
\end{gathered}
$$

The intertemporal Euler condition (4) holds with equality when the borrowing constraint

\footnotetext{
${ }^{16}$ Bianchi (2011), Korinek (2011), and Benigno et al. (2016) use a borrowing constraint related to the current-period value of tradable and nontradable goods, arguing that future income may not be seizable by lenders because of fraud by borrowers. In the context of European integration, the future value seems more reasonable to include in the borrowing constraint, firstly because debt-recovery institutions in advanced economies are superior to those in emerging markets, and secondly because we wish to study how expectations about future nontradable prices may constrain lending today.
} 
(3) is slack, but with inequality when the constraint is strictly binding. The intratemporal conditions (5) and (6) hold irrespective of whether the borrowing constraint is binding.

Government. Each government is benevolent. It can tax or subsidize the households in its own country and exchange goods with other countries' governments.

We assume that all households in each country are treated identically, so that governments do not make transfers between different households inside the same country. Then the implementation of lump-sum transfers and taxes requires coordinated domestic and foreign actions: if $x^{i, j}$ or $z^{i, j}$ are greater than zero, the government provides identical transfers to all domestic households using funds collected from foreign governments; while if $x^{i, j}$ or $z^{i, j}$ are less than zero, the government imposes domestic lump-sum taxes and uses the revenues to fund transfers to foreign governments.

By contrast, we assume that taxes and subsidies on consumption are budget-neutral within each country:

$$
\tau^{i, j} c_{T 2}^{i, j}=\eta^{i, j} p_{2}^{i, j} c_{N T 2}^{i, j}
$$

We can use the tools $\left\{x^{i, j}, z^{i, j}, \tau^{i, j}, \eta^{i, j}\right\}_{i \in\{N, S\}, j \in[0,1]}$ to design two policy packages - which we call "interventions" - requiring different degrees of commitment by the government.

- Governmental loans: lump-sum taxes and transfers $\left\{x^{i, j}, z^{i, j}\right\}_{i \in\{N, S\}, j \in[0,1]}$, whereby some governments provide funds to others in period 1 and get repaid in period 2. This intervention requires the recipient governments in period 1 to be able to commit to repay in period 2 , getting around the private sector's borrowing constraint (3).

- Tax-subsidy with debt relief: lump-sum taxes and transfers in period 1 which are not repaid, but are followed by budget-neutral taxes and subsidies on consumption in period $2,\left\{x^{i, j}, \tau^{i, j}, \eta^{i, j}\right\}_{i \in\{N, S\}, j \in[0,1]}$. This intervention requires governments in period 1 to be able to commit to undertake specific fiscal policy actions in period 2 , but not to be able to commit to repay.

Imperfect financial union. The financial union $F$ is defined such that within it, there is a common riskless bond and no government-imposed restrictions on capital flows. Therefore, households in all countries inside the union borrow and lend at the same interest rate:

$$
r_{2}^{i, j}=r_{2} \text { for all } i, j .
$$

Nevertheless, as we have seen above, financial integration is not perfect because of the borrowing constraint (3), which reflects the limited pledgability of future endowments.

In this section, our financial union is both financially and politically closed to the rest of the world. Financial closure means that although households can exchange exports and imports with the rest of the world, they cannot borrow or lend outside the union. Political closure means that government transfers cannot be financed using resources from outside the union. These two notions of closure give rise respectively to the following two conditions: 


$$
\begin{gathered}
\sum_{i \in\{N, S\}} \int_{0}^{1} b_{t}^{i, j} d j=0 \text { for all } t \\
\sum_{i \in\{N, S\}} \int_{0}^{1} x^{i, j} d j=\sum_{i \in\{N, S\}} \int_{0}^{1} z^{i, j} d j=0 .
\end{gathered}
$$

Now we can characterize the market-clearing conditions for the financial union. Firstly, by definition, the market for nontradable goods must clear within each country $j$ :

$$
c_{N T t}^{i, j}=y_{N T t} \text { for all } i, j, t
$$

Secondly, combining equations (2) and (7)-(11), we establish that even if countries inside the union import and export tradable goods from and to the rest of the world $R O W$, it must be that the total tradable consumption equals the total tradable endowments within the union in each period $t \in\{1,2\}$ :

$$
\sum_{i \in\{N, S\}} \int_{0}^{1} c_{T t}^{i, j} d j=2 y_{T t} \text { for all } t .
$$

Heterogeneous regions. A region $i \in\{N, S\}$ is defined such that within each region $i$, the inherited debt levels are common across all countries $j$ :

$$
b_{1}^{i, j}=b_{1}^{i} \text { for all } i, j .
$$

Therefore, at the beginning of period 1, one region owes all of its inherited debt to the other region. We assume that the Southern periphery is the borrower region:

$$
b_{1}^{S}=-b_{1}^{N} \in\left(0,\left(b_{1}^{S}\right)^{\max }\right)
$$

where $\left(b_{1}^{S}\right)^{\max }$ is the highest value of inherited debt consistent with non-negative Southern consumption in period 1 . Since all countries within the same region are identical, we focus on interventions such that all governments within the same region follow identical policies:

$$
x^{i, j}=x^{i}, z^{i, j}=z^{i}, \tau^{i, j}=\tau^{i}, \text { and } \eta^{i, j}=\eta^{i} \text { for all } i, j .
$$

We are interested in interventions such that the Northern core provides transfers to the Southern periphery in period 1, followed either by transfers in the reverse direction in period 2, or by taxes and subsidies on Southern consumption in period 2:

$$
x^{S}=-x^{N}>0, z^{S}=-z^{N} \leq 0, \text { and } \tau^{S}, \eta^{S} \geq 0, \tau^{N}=\eta^{N}=0 .
$$

Substituting conditions (8), (13), and (15) into the household's optimization problem establishes that the equilibrium variables are identical for all countries $j$ within each region $i$ :

$$
c_{T t}^{i, j}=c_{T t}^{i}, c_{N T t}^{i, j}=c_{N T t}^{i}=y_{N T t}, \text { and } p_{t}^{i, j}=p_{t}^{i} \text { for all } i, j, t
$$


Therefore, we suppress country superscripts in favor of regional superscripts below. This notational choice keeps the focus on regional heterogeneity, while in the background we keep in mind that each region is composed of a continuum of countries who do not have any market power on their own.

Competitive equilibrium allocations. A rational expectations equilibrium is a set of prices and allocations $\left\{r_{2}^{i, j},\left\{p_{t}^{i, j}, c_{T t}^{i, j}, c_{N T t}^{i, j}\right\}_{t \in\{1,2\}}\right\}_{i \in\{N, S\}, j \in[0,1]}$ which satisfy the households' constraints and first-order conditions, (2)-(6), the government's budget constraint (7), the nontradable goods market clearing condition (11), and the financial-integration and market-clearing conditions for the union, (8) and (12), subject to the set of inherited debt levels and government policies $\left\{b_{1}^{i, j}, x^{i, j}, z^{i, j}, \tau^{i, j}, \eta^{i, j}\right\}_{i \in\{N, S\}, j \in[0,1]}$ defined by equations (13)-(16).

Our problem simplifies to characterizing the prices and allocations $\left\{r_{2}, p_{2}^{S}, c_{T 1}^{S}, c_{T 2}^{S}, c_{T 1}^{N}\right\}$ as a function of $\left\{b_{1}^{S}, x^{S}, z^{N}, \tau^{S}\right\}$, using the following equations:

$$
\begin{gathered}
2 c_{T 1}^{N}=b_{1}^{S}+y_{T 1}-x^{S}+\frac{y_{T 2}+z^{N}}{r_{2}} \\
c_{T 1}^{S}+\frac{c_{T 2}^{S}}{r_{2}}=-b_{1}^{S}+y_{T 1}+x^{S}+\frac{y_{T 2}-z^{N}}{r_{2}} \\
R_{2}^{S} \equiv \frac{c_{T 2}^{S}}{c_{T 1}^{S}} \geq \frac{r_{2}}{1+\tau^{S}} \\
b_{2}^{S} \equiv r_{2}\left(c_{T 1}^{S}+b_{1}^{S}-y_{T 1}-x^{S}\right) \leq \phi\left(y_{T 2}+p_{2}^{S} y_{N T 2}-z^{N}\right) \\
p_{2}^{S} y_{N T 2}=\left(\nu+\tau^{S}+\nu \tau^{S}\right) c_{T 2}^{S} \\
c_{T 1}^{S}+c_{T 1}^{N}=2 y_{T 1},
\end{gathered}
$$

and then backing out the implicit variables $\left\{\left\{p_{1}^{i}=\frac{\nu c_{T 1}^{i}}{y_{N T 1}}\right\}_{i \in\{N, S\}}, p_{2}^{N}=\frac{\nu c_{T 2}^{N}}{y_{N T 2}}, c_{T 2}^{N}=r_{2} c_{T 1}^{N}\right.$, $\left.\eta^{S}=\frac{\tau^{S} c_{T 2}^{S}}{p_{2}^{S} y_{N T 2}}\right\}$. Equations (20) and (21) hold with complementary slackness, and Walras' Law allows us to ignore the market-clearing condition for tradable goods in period 2 .

$R_{2}^{S}$ is the shadow interest rate on borrowing in the South. It will serve as an indicator of the distortion in equilibrium allocations arising from the borrowing constraint.

\subsection{Pareto Efficiency of the Laissez-Faire Equilibrium}

First best. The first-best allocation maximizes $\sum_{i \in\{N, S\}} \int_{0}^{1} \lambda^{i, j} U^{i, j} d j$ subject to the marketclearing conditions (11) and (12) and the Pareto weights $\left\{\lambda^{i, j}\right\}_{i \in\{N, S\}, j \in[0,1]}$, ignoring the borrowing constraint (3). We assume that the Pareto weights are identical for all countries $j$ within each region $i$ :

$$
\lambda^{i, j}=\lambda^{i} \text { for all } i, j \text {. }
$$

Lemma 1 (First-best allocation) Irrespective of $\left\{\lambda^{i}\right\}_{i \in\{N, S\}}$, the first-best allocation features $\frac{c_{T 2}^{i}}{c_{T 1}^{i}}=\frac{y_{T 2}}{y_{T 1}}$ for all $i$. 
As the Pareto weights change, the relative levels of tradable consumption in the North and South change, but for all countries in both regions, the ratio of consumption between the two periods remains fixed at $\frac{y_{T 2}}{y_{T 1}}$ (which means in particular that the condition $R_{2}^{S}=\frac{y_{T 2}}{y_{T 1}}$ is satisfied). Nontradable consumption is simply fixed by the endowments $\left\{y_{N T t}\right\}_{t \in\{1,2\}}$.

Laissez faire. The laissez-faire equilibrium follows equations (18)-(23), setting $x^{S}=z^{N}=$ $\tau^{S}=0$. The resulting allocations are parameterized by the inherited debt level $b_{1}^{S}$, and are shown by the solid lines in figure 1. For comparison, the dashed lines in the figure represent the unconstrained equilibrium, i.e., the equilibrium calculated ignoring condition (21).

In the absence of the borrowing constraint (21), the interest rate is fixed at $R_{2}^{S}=r_{2}=\frac{y_{T 2}}{y_{T 1}}$, and the unconstrained tradable consumption levels in the North and South follow:

$$
c_{T 1}^{N *}=\frac{1}{2}\left(b_{1}^{S}+2 y_{T 1}\right), c_{T 1}^{S *}=\frac{1}{2}\left(-b_{1}^{S}+2 y_{T 1}\right), \text { and } c_{T 2}^{i *}=\frac{y_{T 2}}{y_{T 1}} c_{T 1}^{i *} \text { for all } i .
$$

So the higher the inherited debt level of the South $b_{1}^{S}$, the lower the consumption of the South in both periods. But the borrowing constraint (21), combined with equations (19) and (22), imposes a lower bound on Southern consumption in period 2:

$$
c_{T 2}^{S} \geq \bar{c}_{T 2}^{S}=y_{T 2} \frac{1-\phi}{1+\phi \nu}
$$

As shown in panel I of the figure, the unconstrained level of $c_{T 2}^{S}$ violates this bound once the inherited debt $b_{1}^{S}$ is high enough:

$$
b_{1}^{S}>\bar{b}_{1}^{S}=2 y_{T 1} \frac{\phi(1+\nu)}{1+\phi \nu} .
$$

For these levels of debt, there is a union-wide crisis, because the constraint triggers a sudden stop throughout the Southern periphery. Southern consumption follows instead the expression:

$$
c_{T 1}^{S, C}=\frac{1+3 \phi+4 \phi \nu}{1+2 \phi+3 \phi \nu} y_{T 1}-\frac{1+\phi+2 \phi \nu}{1+2 \phi+3 \phi \nu} b_{1}^{S} \text { and } c_{T 2}^{S, C}=\bar{c}_{T 2}^{S},
$$

which is defined for $b_{1}^{S}$ up to $\left(b_{1}^{S}\right)^{\text {max }}=\frac{1+3 \phi+4 \phi \nu}{1+\phi+2 \phi \nu} y_{T 1}$. Panel II shows that the interest rate $r_{2}$ dips below $\frac{y_{T 2}}{y_{T 1}}$, while the shadow rate $R_{2}^{S}$ rises above it. Such a result is consistent with the research on debt deleveraging episodes (e.g., Guerrieri and Lorenzoni, 2011, Eggertsson and Krugman, 2012, and Fornaro, 2015). In our model, the binding constraint in the Southern periphery of a financial union reduces North-to-South private capital flows $\left(c_{T 1}^{S}+b_{1}^{S}-y_{T 1}\right)$ and the South's eventual debt position $b_{2}^{S}$ (as shown in panel III of the figure), below their unconstrained levels.

Panel IV shows that the effect of the borrowing constraint on welfares in the North and South $\left\{U^{i, j}=U^{i}\right\}_{i \in\{N, S\}, j \in[0,1]}$, relative to the welfares in the absence of the constraint $\left\{U^{i *}\right\}_{i \in\{N, S\}}$, is more complicated. The Southern constraint unambiguously reduces the welfare of Northern households. By contrast, Southern households benefit relative to the 
unconstrained allocation if the inherited debt is moderately above $\bar{b}_{1}^{S}$ (even though the entire South is experiencing a sudden stop!), but they are worse off if the inherited debt is very high. All the above results are summarized in the proposition below.

Proposition 1 (Laissez-faire equilibrium) The laissez-faire equilibrium is a first-best allocation for some Pareto weights $\left\{\lambda^{i}\right\}_{i \in\{N, S\}}$ when $b_{1}^{S} \in\left[0, \bar{b}_{1}^{S}\right]$, but lies in the interior of the first-best frontier when $b_{1}^{S}>\bar{b}_{1}^{S}$. In the latter region, $c_{T 2}^{S, C}=\bar{c}_{T 2}^{S}$ and $R_{2}^{S}>\frac{y_{T 2}}{y_{T 1}}>r_{2}$. Defining $\widehat{b}_{1}^{S}=6 y_{T 1} \frac{\phi(1+\nu)}{1+2 \phi+3 \phi \nu}\left(<\left(b_{1}^{S}\right)^{\max }\right)$, welfare levels follow:

$$
U^{N}\left\{\begin{array} { c c } 
{ = U ^ { N * } } & { \text { for } b _ { 1 } ^ { S } \in [ 0 , \overline { b } _ { 1 } ^ { S } ] } \\
{ < U ^ { N * } } & { \text { for } b _ { 1 } ^ { S } > \overline { b } _ { 1 } ^ { S } }
\end{array} \text { and } U ^ { S } \left\{\begin{array}{cc}
=U^{S *} & \text { for } b_{1}^{S} \in\left[0, \bar{b}_{1}^{S}\right] \\
>U^{S *} & \text { for } b_{1}^{S} \in\left(\bar{b}_{1}^{S}, \widehat{b}_{1}^{S}\right) \\
<U^{S *} & \text { for } b_{1}^{S}>\widehat{b}_{1}^{S} .
\end{array}\right.\right.
$$

This welfare result comes from the endogeneity of the interest rate. We can understand the conceptual mechanism in a graphical fashion using two steps: firstly, choose any fixed value of $b_{1}^{S}>\bar{b}_{1}^{S}$ from panel IV of figure 1 and show how varying the pledgability parameter $\phi$ can take us from the unconstrained to the constrained welfare level; and secondly, apply the lessons of the first step to a variety of levels of $b_{1}^{S}$.

Panel I of figure 2 illustrates the first step. For $b_{1}^{S}>\bar{b}_{1}^{S}$, the constraint is strictly binding at the actual value of $\phi$, but if we raise the parameter to the value $\phi^{J B}$ which makes the constraint just binding, we can recover the unconstrained regional welfare levels. Then we gradually reduce $\phi$ from $\phi^{J B}$ to its actual value and explore how constrained regional welfares change according to the equations (18)-(23). Regional welfares are affected by the associated change in $r_{2}$ :

$$
\begin{gathered}
d r_{2}=\frac{r_{2} y_{T 2}}{\frac{1}{2} y_{T 2}+\left(y_{T 2}-c_{T 2}^{S}\right)} \frac{(1+\nu)}{(1+\phi \nu)^{2}} d \phi \\
d U^{N}=\frac{c_{T 2}^{N}-y_{T 2}}{r_{2}^{2} c_{T 1}^{N}} d r_{2}=\frac{y_{T 2}}{\frac{1}{2} y_{T 2}+\left(y_{T 2}-c_{T 2}^{S}\right)} \frac{c_{T 2}^{N}-y_{T 2}}{c_{T 2}^{N}} \frac{(1+\nu)}{(1+\phi \nu)^{2}} d \phi \\
d U^{S}=\frac{1}{c_{T 1}^{S}}\left[-\frac{y_{T 2}-c_{T 2}^{S}}{r_{2}^{2}} d r_{2}+\frac{y_{T 2}}{r_{2}}\left(1-\frac{r_{2}}{R_{2}^{S}}\right) \frac{(1+\nu)}{(1+\phi \nu)^{2}} d \phi\right] \\
=\frac{y_{T 2}}{r_{2} c_{T 1}^{S}}\left(\frac{\frac{1}{2} y_{T 2}}{\frac{1}{2} y_{T 2}+\left(y_{T 2}-c_{T 2}^{S}\right)}-\frac{r_{2}}{R_{2}^{S}}\right) \frac{(1+\nu)}{(1+\phi \nu)^{2}} d \phi .
\end{gathered}
$$

The interest rate $r_{2}$ declines below $\frac{y_{T 2}}{y_{T 1}}$ when $\phi$ decreases and the constraint begins to bind. The welfare of Northern households is hurt because they are "exporters" of saving $\left(c_{T 2}^{N}-y_{T 2}\right)>0$, and the "intertemporal terms of trade" on this saving, $r_{2}$, is now lower. Southern households benefit from the decline in the interest rate $r_{2}$ because they are "importers" of saving $\left(y_{T 2}-c_{T 2}^{S}\right)>0$, but they are also hurt by the transfer of consumption from period 1 to period 2 , because when $R_{2}^{S}>r_{2}$, consumption is more valuable in period 1 than in period 2 .

CInternational Monetary Fund. Not for Redistribution 
The constraint's impact on Southern welfare depends on how low the actual value of $\phi$ really is. If the actual value of $\phi$ is just below $\phi^{J B}$, the constraint improves Southern welfare, because the "intertemporal terms of trade" effect is the dominant one. Southern constrained welfare continues increasing as $\phi$ decreases to $\phi^{*}$, which occurs when:

$$
R_{2}^{S}=r_{2} \frac{\frac{1}{2} y_{T 2}+\left(y_{T 2}-c_{T 2}^{S}\right)}{\frac{1}{2} y_{T 2}}
$$

Reducing $\phi$ further reduces Southern welfare from its peak, and the constrained welfare falls below the unconstrained level if the actual value of $\phi$ is below $\phi^{L}$.

The second step is to apply the above reasoning to a variety of levels of $b_{1}^{S}$. For all $b_{1}^{S}>\bar{b}_{1}^{S}$, Northern welfare is hurt by the constraint, but the impact on Southern welfare is more complicated. The higher is the level of $b_{1}^{S}$ in panel IV of figure 1 , the higher is $\phi^{J B}$ relative to the actual value of $\phi$ in panel I of figure 2. For $b_{1}^{S}$ just above $\bar{b}_{1}^{S}, \phi^{J B}$ is just above $\phi$, so the South benefits from the constraint. For future use, we define $\widetilde{b}_{1}^{S}$ to be the debt level at which condition (27) is satisfied. When $b_{1}^{S}$ exceeds $\widehat{b}_{1}^{S}\left(>\widetilde{b}_{1}^{S}\right), \phi^{J B}$ is far above $\phi$, so the South's constrained welfare falls below its unconstrained level.

Finally, panel II of figure 2 uses the information in the above proposition to plot the unconstrained and constrained welfare frontiers. The higher is $b_{1}^{S}$, the further up and to the left that the final allocation is located within this panel. The unconstrained allocations (which lie along the dashed first-best frontier) diverge from the constrained allocations (which lie along the solid line) when $b_{1}^{S}>\bar{b}_{1}^{S}$.

\subsection{Pareto-improving Interventions}

Although financial markets are integrated across country borders within the union, individual countries are politically sovereign. Accordingly, we assume that union-wide policy interventions must be approved through a bargaining process involving all the governments inside the union. Governments bargain as regional coalitions (to support this notion, we show below that coalitions can exhaust the Pareto gains). Each country and coalition is allowed to veto any interventions which make them worse off than the laissez-faire equilibrium, so this equilibrium is the outside option to the bargaining process.

Formally, we start with a debt level $b_{1}^{S}>\bar{b}_{1}^{S}$ and select $\left\{x^{S}, z^{N}, \tau^{S}\right\}$ to maximize the Nash product over indirect utility functions:

$$
\prod_{i \in\{N, S\}}\left(U^{i}\left(x^{S}, z^{N}, \tau^{S}\right)-U^{i}(0,0,0)\right)^{\gamma^{i}},
$$

subject to the equations (18)-(23), with the bargaining powers of each regional coalition

$\left\{\gamma^{i}\right\}_{i \in\{N, S\}}$ satisfying $\gamma^{N}=1-\gamma^{S} \in[0,1]$. Only policies that make all countries better off relative to the laissez-faire equilibrium-i.e., Pareto-improving interventions - are implementable, and which final allocation is chosen depends on the bargaining powers. 
Governmental loan. The first intervention involves $\left\{x^{S}>0, z^{N}>0, \tau^{S}=0\right\}$ and assumes that the governments of the South have the ability to commit in period 1 to repay in period 2 despite the private sector borrowing constraint (21) being binding. Because of the constraint, the intervention cannot be completely undone by the private sector, and it does affect the allocation. When the constraint binds, Southern variables in period 2 satisfy:

$$
c_{T 2}^{S}=\left(y_{T 2}-z^{N}\right) \frac{1-\phi}{1+\phi \nu} \text { and } p_{2}^{S} y_{N T 2}=\nu c_{T 2}^{S} .
$$

To see how the competitive equilibrium alters in response to a governmental loan, first consider small changes in the intervention, $d x^{S}>0$ and $d z^{N}>0$. Since Northern households are unconstrained while the Southern borrowing constraint is binding, the change in the total consumption of tradable goods in the union in period 2 is:

$$
d\left(c_{T 2}^{N}+c_{T 2}^{S}\right)=-\frac{1}{2} r_{2} d x^{S}+\left(\frac{1}{2}-\frac{1-\phi}{1+\phi \nu}\right) d z^{N}+\frac{\frac{1}{2}\left(y_{T 2}+z^{N}\right)+\left(y_{T 2}-z^{N}-c_{T 2}^{S}\right)}{r_{2}} d r_{2} .
$$

In period 2, the consumption of the North decreases by half the interest-compounded value of the extra transfer $d x^{S}$ and increases by half the extra repayment $d z^{N}$, while the consumption of the South decreases by the fraction $\frac{1-\phi}{1+\phi \nu}$ of the extra repayment $d z^{N}$. Absent a change in the interest rate $r_{2}$ on private sector loans, the change in total consumption may be positive or negative. To restore market clearing, $r_{2}$ must adjust so that Northern households optimally tilt their consumption schedule in a manner consistent with the constrained consumption of Southern households:

$$
d r_{2}=\frac{r_{2}}{\frac{1}{2}\left(y_{T 2}+z^{N}\right)+\left(y_{T 2}-z^{N}-c_{T 2}^{S}\right)}\left[\frac{1}{2} r_{2} d x^{S}-\left(\frac{1}{2}-\frac{1-\phi}{1+\phi \nu}\right) d z^{N}\right] .
$$

Welfares in the North and South are affected directly by the transfers and indirectly by the associated change in the interest rate $r_{2}$ :

$$
\begin{gathered}
d U^{N}\left(x^{S}, z^{N}, 0\right)=\frac{1}{c_{T 1}^{N}}\left[-d x^{S}+\frac{1}{r_{2}} d z^{N}+\frac{y_{T 2}-z^{N}-c_{T 2}^{S}}{r_{2}^{2}} d r_{2}\right] \\
d U^{S}\left(x^{S}, z^{N}, 0\right)=\frac{1}{c_{T 1}^{S}}\left[d x^{S}+\left\{-\frac{1}{r_{2}}+\frac{1}{r_{2}}\left(1-\frac{r_{2}}{R_{2}^{S}}\right) \frac{1-\phi}{1+\phi \nu}\right\} d z^{N}-\frac{y_{T 2}-z^{N}-c_{T 2}^{S}}{r_{2}^{2}} d r_{2}\right],
\end{gathered}
$$

where $y_{T 2}-z^{N}-c_{T 2}^{S}>0$. Northern households are hurt by the higher transfer $d x^{S}$, but they benefit from the higher repayment $d z^{N}$ and any increase in the interest rate $d r_{2}$. Southern households experience changes in welfare in the opposite direction. But crucially, the South's pain from the repayment is mitigated because $d z^{N}$ occurs in period 2 , when consumption is less valuable at the margin than it is in period 1 .

Because $R_{2}^{S}>r_{2}$ in the constrained equilibrium, Pareto improvements are possible. Any increase in the private market interest rate, $d r_{2}>0$, generated by a governmental loan benefits the North and hurts the South by shifting consumption in period 2 from the South 
to the North. The North can compensate the South by transferring extra tradable goods to the South in period 1. $R_{2}^{S}>r_{2}$ means that the South values each extra unit of consumption more than the North does in period 1, so the North finds it possible to raise the welfare of the South through period 1 transfers, while remaining better off itself.

Formally, combining the above equations:

$$
\left.d U^{i}\left(x^{S}, z^{N}, 0\right)\right|_{d U^{-i}\left(x^{S}, z^{N}, 0\right)=0}=\frac{1}{c_{T 1}^{i}} \frac{1}{r_{2}}\left(1-\frac{r_{2}}{R_{2}^{S}}\right) \frac{1-\phi}{1+\phi \nu} d z^{N} \text { for all } i,
$$

which establishes that Pareto-improving governmental loans are possible for $R_{2}^{S}>r_{2}$. Within the set of such interventions:

$$
d r_{2}=\rho^{x z}\left(\gamma^{N}\right) \cdot \frac{1-\phi}{1+\phi \nu} \frac{r_{2}}{\frac{1}{2}\left(y_{T 2}+z^{N}\right)+\frac{1}{2}\left(y_{T 2}-z^{N}-c_{T 2}^{S}\right)} d z^{N},
$$

where $\rho^{x z}\left(\gamma^{N}\right) \in\left[\frac{1}{2}\left(1+\frac{r_{2}}{R_{2}^{S}}\right), 1\right]>0$ and $\frac{d \rho^{x z}}{d \gamma^{N}}<0$. Therefore, the intervention is designed so that the interest rate $r_{2}$ increases - although the less so the higher is the North's bargaining power. Figure 3 shows the effects of a Pareto-improving loan, indexing the loan size by $z^{N}$. As $z^{N}$ increases, the South's consumption in period 1 increases and its consumption in period 2 decreases. The interest rate $r_{2}$ increases, and the shadow rate $R_{2}^{S}$ decreases, toward $\frac{y_{T 2}}{y_{T 1}}$.

Panel III shows that the North-to-South governmental loan causes a contraction in the South's private debt position $b_{2}^{S}$ with respect to the North. The repayment $z^{N}$ reduces the South's available tradable goods and depresses the price of its nontradable goods in period 2. Both of these effects tighten the private sector borrowing constraint (21) in period 1:

$$
d p_{2}^{S}<0 \text { and } d b_{2}^{S}<0 .
$$

We can now illustrate how a Pareto-improving intervention begins and ends. The intervention begins as a small loan from the starting point $b_{1}^{S}>\bar{b}_{1}^{S}$ and $x^{S}=z^{N}=0$. Defining the interest rate on the governmental loan as $r^{N S} \equiv \frac{z^{N}}{x^{S}}$ (which for a small intervention is equal to $\frac{d z^{N}}{d x^{S}}$ ), we can show in panel I of figure 4 the minimum interest rate the North is willing to accept, $r_{\min }^{N S}$, and the maximum interest rate the South is willing to pay, $r_{\max }^{N S}$ :

$$
\begin{gathered}
r_{\min }^{N S}=r_{2} \frac{\frac{1}{2} y_{T 2}+\frac{1}{2}\left(y_{T 2}-c_{T 2}^{S}\right)}{\frac{1}{2} y_{T 2}+\left(\frac{1}{2}+\frac{1-\phi}{1+\phi \nu}\right)\left(y_{T 2}-c_{T 2}^{S}\right)} \\
<r_{\max }^{N S}=r_{2} \frac{\frac{1}{2} y_{T 2}+\frac{1}{2}\left(y_{T 2}-c_{T 2}^{S}\right)}{\left(\frac{1}{2}-\frac{1}{2}\left(1-\frac{r_{2}}{R_{2}^{S}}\right) \frac{1-\phi}{1+\phi \nu}\right) y_{T 2}+\left(\frac{1}{2}+\frac{r_{2}}{R_{2}^{S}} \frac{1-\phi}{1+\phi \nu}\right)\left(y_{T 2}-c_{T 2}^{S}\right)} .
\end{gathered}
$$

$r_{\min }^{N S}$ is downward-sloping and lower than $r_{2}$ : the Northern coalition is willing to subsidize the governmental loan because it increases the private market interest rate $r_{2}$, which benefits the North's (saver) households. The upward-sloping dashed line representing $r_{\max }^{N S}$ is lower than $r_{2}$ for $b_{1}^{S} \in\left(\bar{b}_{1}^{S}, \widetilde{b}_{1}^{S}\right)$ (when $R_{2}^{S}$ is below the value required for condition (27)) and higher 
than $r_{2}$ for $b_{1}^{S}>\widetilde{b}_{1}^{S}$ (when $R_{2}^{S}$ is above the required value).

In this panel, we can see why we assumed that governments bargain via regional coalitions. Coalitions internalize the effects of their actions on the union-wide interest rate $r_{2}$, which individual countries do not. If the coalitions were to ignore their effects on the unionwide interest rate $r_{2}$, then the Northern coalition would only accept interest rates above $r_{2}$, while the Southern coalition would accept any interest rate below $R_{2}^{S}$. If such loans are agreed, they would not in general lead to Pareto improvements, because the resulting increase in $r_{2}$ itself would shift too much of the welfare gains to the North at the expense of the South. Only in the blue region of the graph would Pareto improvements be achieved. On the other hand, when coalitions internalize the effects of their actions on $r_{2}$, they can achieve Pareto improvements in both the pink and blue regions.

Panels I and II of figure 5 illustrate in shaded gray the zone of Pareto-improving actions in the $\left(x^{S}, z^{N}\right)$ space for any $b_{1}^{S}>\bar{b}_{1}^{S}$. The values of $r^{N S}$ derived above for the beginning of the intervention determine the upper slope $\left(r_{\max }^{N S}\right.$, representing $\left.\gamma^{N}=1\right)$ and lower slope $\left(r_{\min }^{N S}\right.$, representing $\left.\gamma^{N}=0\right)$ of the gray zone at the origin $(0,0)$. Pareto-improving interventions are possible as long as $R_{2}^{S}>r_{2}$, and the intervention continues until all Pareto gains are exhausted. The blue line represents the final interventions that solve (28) subject to (18)(23), indexed by $\gamma^{N} \in[0,1]$ :

$$
x^{S}=b_{1}^{S}-2 y_{T 1} \frac{\phi(1+\nu)}{1+\phi \nu}-z^{N} \frac{y_{T 1}}{y_{T 2}} \frac{(1-\phi)-\phi(1+\nu)}{1+\phi \nu} .
$$

Panel I assumes that $\phi<\frac{1}{2+\nu} \Leftrightarrow(1-\phi)-\phi(1+\nu)>0$, while panel II assumes the opposite sign for the inequality. ${ }^{17}$ Along the blue line, the intertemporal ratio of consumption is fixed at $\frac{c_{T 2}^{i}}{c_{T 1}^{i}}=R_{2}^{S}=r_{2}=\frac{y_{T 2}}{y_{T 1}}$ for all $i$, i.e., the allocations are along the first-best frontier. The bargaining power of the North $\gamma^{N}$ determines which point on the line is chosen, and thereby the levels of consumption in each region. For both panels, the higher is $\gamma^{N}$, the larger the period-2 repayment to the North, $z^{N}$, the higher is the interest rate $r^{N S} \equiv \frac{z^{N}}{x^{S}}$ on the governmental loan, and the more that the South's private debt position $b_{2}^{S}$ declines relative to the laissez-faire equilibrium. The upper and lower ends of the blue line represent respectively the allocations for $\gamma^{N}=1$ and $\gamma^{N}=0$ :

$$
\begin{gathered}
c_{T 1}^{S, \gamma^{N}=1}=y_{T 1} \sqrt{\left(\frac{1+3 \phi+4 \phi \nu}{1+2 \phi+3 \phi \nu}-\frac{1+\phi+2 \phi \nu}{1+2 \phi+3 \phi \nu} \frac{b_{1}^{S}}{y_{T 1}}\right) \frac{1-\phi}{1+\phi \nu}} \text { and } c_{T 2}^{S, \gamma^{N}=1}=\frac{y_{T 2}}{y_{T 1}} c_{T 1}^{S, \gamma^{N}=1} \\
c_{T 1}^{S, \gamma^{N}=0}=2 y_{T 1}-y_{T 1} \sqrt{\left(\frac{1+\phi+2 \phi \nu}{1+2 \phi+3 \phi \nu}+\frac{1+\phi+2 \phi \nu}{1+2 \phi+3 \phi \nu} \frac{b_{1}^{S}}{y_{T 1}}\right) \frac{1+\phi+2 \phi \nu}{1+\phi \nu}} \text { and } c_{T 2}^{S, \gamma^{N}=0}=\frac{y_{T 2}}{y_{T 1}} c_{T 1}^{S, \gamma^{N}=0} .
\end{gathered}
$$

\footnotetext{
${ }^{17}$ The blue line moves gradually from downward-sloping to upward-sloping as $\phi$ increases. $\phi<\frac{1}{2+\nu}$ is equivalent to $\frac{1-\phi}{1+\phi \nu}>\frac{1}{2}$, which means that setting $d x^{S}=0$, an increase in the repayment $d z^{N}$ increases the interest rate. This sign of the inequality is justified in section 3 .
} 
If Northern governments have a limited ability to tax in period 1, i.e., $x^{S} \leq\left(x^{S}\right)^{\text {max }}$, or if Southern governments have a limited ability to repay in period 2, i.e., $z^{N} \leq\left(z^{N}\right)^{\max }$, then Pareto gains may not be exhausted for some values of $\gamma^{N}$, and the final intervention lies instead along the dashed red line. ${ }^{18}$ The proposition below summarizes the above results.

Proposition 2 (Governmental loan) When $b_{1}^{S}>\bar{b}_{1}^{S}$, a governmental loan achieves a Pareto improvement relative to the laissez-faire equilibrium. When the loan size is unlimited, bargaining between North and South achieves an allocation on the first-best frontier satisfying (29) and $z^{N} \in\left[z^{N, \gamma^{N}=0}, z^{N, \gamma^{N}=1}\right]$, where $z^{N, \gamma^{N}=0}<z^{N, \gamma^{N}=1}$ and $\frac{d z^{N}}{d \gamma^{N}}>0$. $b_{2}^{S}$ is lower than in the laissez-faire equilibrium. When the loan size is limited, the frontier of achievable allocations is a piecewise combination of the first-best frontier and the relevant constraint.

Taking stock, we have shown how an intervention of any size (whether unlimited or not) achieves a Pareto improvement, by tracing out the intervention's effect on the endogenous union-wide interest rate $r_{2}$, the consumption levels in North and South $\left\{c_{T t}^{i}\right\}_{i \in\{N, S\}}$, and the Southern debt position $b_{2}^{S}$ accumulated via North-to-South private debt flows. We have also rationalized region-based coalitional bargaining. If the size of North-to-South governmental loans is unlimited, the financial union is restored to the first-best frontier. These lessons will prove valuable as we consider alternative interventions, and as we extend the model to allow for financial openness of the union and for production.

Tax-subsidy with debt relief. The second intervention involves $\left\{x^{S}>0, z^{N}=0, \tau^{S}>0\right\}$ and assumes that the government of the South has the ability to commit in period 1 to undertake budget-neutral fiscal actions in period 2, but is unable to commit to repay foreigners in period 2. Since the North-to-South transfer $x^{S}$ is never repaid, we label it as debt relief. When the constraint binds, Southern variables in period 2 satisfy:

$$
c_{T 2}^{S}=y_{T 2} \frac{1-\phi}{1+\phi\left(\nu+\tau^{S}+\nu \tau^{S}\right)} \text { and } p_{2}^{S} y_{N T 2}=\left(\nu+\tau^{S}+\nu \tau^{S}\right) c_{T 2}^{S} .
$$

Again, we first consider small changes in the intervention, $d x^{S}>0$ and $d \tau^{S}>0$. The total consumption of tradable goods in the union in period 2 is altered as follows:

$$
d\left(c_{T 2}^{N}+c_{T 2}^{S}\right)=-\frac{1}{2} r_{2} d x^{S}-\frac{c_{T 2}^{S} \phi(1+\nu)}{1+\phi\left(\nu+\tau^{S}+\nu \tau^{S}\right)} d \tau^{S}+\frac{\frac{1}{2} y_{T 2}+\left(y_{T 2}-c_{T 2}^{S}\right)}{r_{2}} d r_{2} .
$$

The tax on the consumption of tradable goods and subsidy on the consumption of nontradable goods in the South in period 2 generates an increase in the price of nontradable goods $p_{2}^{S}$ in that period, which relaxes the private sector borrowing constraint. Southern households are able to borrow more in period 1 and need to repay more in period 2, so the consumption of the South in the latter period falls, as captured by the second term in the above equation. The consumption of the North in period 2 decreases by half the interest-compounded value

\footnotetext{
${ }^{18}$ In panel I, the dashed red line is bounded on both ends. In panel II, only the tighter bound is relevant.
} 
of the debt relief $d x^{S}$. To restore market clearing, the interest rate $r_{2}$ must rise, which affects welfares in the North and South:

$$
\begin{gathered}
d r_{2}=\frac{r_{2}}{\frac{1}{2} y_{T 2}+\left(y_{T 2}-c_{T 2}^{S}\right)}\left[\frac{1}{2} r_{2} d x^{S}+\frac{c_{T 2}^{S} \phi(1+\nu)}{1+\phi\left(\nu+\tau^{S}+\nu \tau^{S}\right)} d \tau^{S}\right] . \\
d U^{N}\left(x^{S}, 0, \tau^{S}\right)=\frac{1}{c_{T 1}^{N}}\left[-d x^{S}+\frac{y_{T 2}-c_{T 2}^{S}}{r_{2}^{2}} d r_{2}\right] \\
d U^{S}\left(x^{S}, 0, \tau^{S}\right)=\frac{1}{c_{T 1}^{S}}\left[d x^{S}+\frac{1}{r_{2}}\left(1-\frac{r_{2}}{R_{2}^{S}}\right) \frac{c_{T 2}^{S} \phi(1+\nu)}{1+\phi\left(\nu+\tau^{S}+\nu \tau^{S}\right)} d \tau^{S}-\frac{y_{T 2}-c_{T 2}^{S}}{r_{2}^{2}} d r_{2}\right],
\end{gathered}
$$

where $y_{T 2}-c_{T 2}^{S}>0$. Northern households are hurt by the higher transfer $d x^{S}$, but they benefit from the higher interest rate $d r_{2}$. Southern households experience changes in welfare in the opposite direction. Crucially, they also benefit from the relaxation of the constraint: $d \tau^{S}>0$ allows consumption to be moved from period 2 to period 1 , when it is more valuable.

Again, because $R_{2}^{S}>r_{2}$ in the constrained equilibrium, Pareto improvements are possible. The increase in the interest rate, $d r_{2}>0$, generated by the tax-subsidy policy shifts consumption in period 2 from the South to the North and raises period-1 consumption in the South. If the South is worse off after this change, the North can compensate the South by transferring tradable goods as debt relief to the South in period 1, while remaining better off itself. Combining the above equations, we formally confirm this result and we derive the bounds for the increase in the interest rate:

$$
\begin{gathered}
\left.d U^{i}\left(x^{S}, 0, \tau^{S}\right)\right|_{d U^{-i}\left(x^{S}, 0, \tau^{S}\right)=0}=\frac{1}{c_{T 1}^{i}} \frac{1}{r_{2}}\left(1-\frac{r_{2}}{R_{2}^{S}}\right) \frac{c_{T 2}^{S} \phi(1+\nu)}{1+\phi\left(\nu+\tau^{S}+\nu \tau^{S}\right)} d \tau^{S} \text { for all } i \\
d r_{2}=\rho^{x \tau}\left(\gamma^{N}\right) \cdot \frac{r_{2}}{\frac{1}{2} y_{T 2}+\frac{1}{2}\left(y_{T 2}-c_{T 2}^{S}\right)} \frac{c_{T 2}^{S} \phi(1+\nu)}{1+\phi\left(\nu+\tau^{S}+\nu \tau^{S}\right)} d \tau^{S}
\end{gathered}
$$

where $\rho^{x \tau}\left(\gamma^{N}\right) \in\left[\frac{1}{2}\left(1+\frac{r_{2}}{R_{2}^{S}}\right), 1\right]>0$ and $\frac{d \rho^{x \tau}}{d \gamma^{N}}<0$. Figure 3 shows the effects of a Paretoimproving tax-subsidy policy with debt relief, indexing the size of the intervention by $\tau^{S}$. As the intervention size increases, Southern consumption in period 1 increases at the expense of its consumption in period 2 , the interest rate $r_{2}$ increases, and the shadow rate $R_{2}^{S}$ decreases. Panel III shows that in contrast to the governmental loan intervention, a tax-subsidy policy with debt relief causes an expansion in the South's private debt position $b_{2}^{S}$ with respect to the North:

$$
d p_{2}^{S}>0 \text { and } d b_{2}^{S}>0
$$

Next, we illustrate how a Pareto-improving intervention begins and ends. The intervention begins with $b_{1}^{S}>\bar{b}_{1}^{S}$ and $x^{S}=\tau^{S}=0$. Defining the debt relief coefficient $g^{N S} \equiv \frac{x^{S}}{\tau^{S}}$ as the debt relief per unit of promised tax (which for a small intervention is equal to $\frac{d x^{S}}{d \tau^{S}}$ ), we show in panel II of figure 4 the minimum debt relief coefficient the South is willing to accept, $g_{\min }^{N S}$, and the maximum coefficient the North is willing to offer, $g_{\max }^{N S}$ : 


$$
\begin{gathered}
g_{\min }^{N S}=\frac{1}{r_{2}} \frac{\frac{1}{2} y_{T 2}+\left(y_{T 2}-c_{T 2}^{S}\right)}{\frac{1}{2} y_{T 2}+\frac{1}{2}\left(y_{T 2}-c_{T 2}^{S}\right)}\left(\frac{r_{2}}{R_{2}^{S}}-\frac{\frac{1}{2} y_{T 2}}{\frac{1}{2} y_{T 2}+\left(y_{T 2}-c_{T 2}^{S}\right)}\right) \frac{c_{T 2}^{S} \phi(1+\nu)}{1+\phi \nu} \\
<g_{\max }^{N S}=\frac{1}{r_{2}} \frac{\left(y_{T 2}-c_{T 2}^{S}\right)}{\frac{1}{2} y_{T 2}+\frac{1}{2}\left(y_{T 2}-c_{T 2}^{S}\right)} \frac{c_{T 2}^{S} \phi(1+\nu)}{1+\phi \nu} .
\end{gathered}
$$

$g_{\max }^{N S}$ is higher than 0: the North is willing to provide debt relief to the South in period 1, because the South's commitment to a budget-neutral tax-subsidy policy in period 2 increases the market interest rate $r_{2}$, which benefits the North's households. The downward-sloping dashed $g_{\min }^{N S}$ is above 0 for $b_{1}^{S} \in\left(\bar{b}_{1}^{S}, \widetilde{b}_{1}^{S}\right)$ but below 0 for $b_{1}^{S}>\widetilde{b}_{1}^{S}$. In other words, for very high debt levels, the South is willing to undertake the tax-subsidy policy even in the absence of debt relief, because the movement of consumption from period 2 to period 1 owing to the relaxation of the borrowing constraint (21) is very valuable.

Again, region-based coalitional bargaining is helpful to exploit all the Pareto gains. If the coalitions were to ignore their effects on the union-wide interest rate $r_{2}$, then the Northern coalition would be unwilling to provide any debt relief at all, and only the Pareto improvements in the blue region of the graph would be achieved. By contrast, coalitional bargaining that correctly treats $r_{2}$ as endogenous is able to achieve Pareto improvements in both the pink and blue regions.

Panels III, IV, and V of figure 5 illustrate in shaded gray the zone of Pareto-improving actions in $\left(x^{S}, z^{N}\right)$ space, for three different levels of $b_{1}^{S}$ above $\bar{b}_{1}^{S} \cdot{ }^{19}$ The values of $g^{N S}$ derived above for the beginning of the intervention determine the upper slope $\left(g_{\min }^{N S}\right.$, representing $\left.\gamma^{N}=1\right)$ and lower slope $\left(g_{\max }^{N S}\right.$, representing $\left.\gamma^{N}=0\right)$ of the gray zone at the origin $(0,0) .{ }^{20}$ For $b_{1}^{S}>\widetilde{b}_{1}^{S}, g_{\min }^{N S}<0$, so the upper slope is negative. The blue line represents the final interventions that solve (28) subject to (18)-(23), indexed by $\gamma^{N} \in[0,1]$ :

$$
x^{S}=b_{1}^{S}-2 y_{T 1} \frac{\phi\left(1+\nu+\tau^{S}+\nu \tau^{S}\right)}{1+\phi\left(\nu+\tau^{S}+\nu \tau^{S}\right)} .
$$

Along this line, $\frac{c_{T 2}^{i}}{c_{T 1}^{i}}=R_{2}^{S}=r_{2}=\frac{y_{T 2}}{y_{T 1}}$ for all $i$, so the allocations are again along the firstbest frontier - just like for the governmental loan. And the left and right ends of the blue line achieve the same consumption levels as the governmental loan does: equations (30) and (31). The higher the bargaining power of the North $\gamma^{N}$, the smaller the period-1 debt relief for the South, $x^{S}$, and the larger the period-2 tax and subsidy combination imposed by the South, $\tau^{S}$, so the lower is the debt relief coefficient $g^{N S} \equiv \frac{x^{S}}{\tau^{S}}$. The North uses its bargaining power to push the South to implement budget-neutral policies that improve the pledgability of the South's future endowments, so that Northern households can exploit the correspondingly higher interest rate. In fact, the higher is $\gamma^{N}$, the more that the South's

\footnotetext{
${ }^{19}$ The graphs evolve gradually as $b_{1}^{S}$ increases; there is no discrete change in behavior at the thresholds.

${ }^{20}$ To ensure comparability of these panels with those for the governmental loan, we plot $x^{S}$ on the horizontal axis. For any point on the graph, $g^{N S}$ is the reciprocal of the slope from the origin to that point.
} 
private debt position $b_{2}^{S}$ increases relative to the laissez-faire equilibrium.

Notice that for $b_{1}^{S}>\widehat{b}_{1}^{S}, \gamma^{N}=1$ is associated with negative debt relief: $x^{S}<0$. As described above, for very high debt levels, the South is willing to undertake the tax-subsidy policy even without debt relief. Then, for the North to extract all the welfare gains, the South needs to provide a transfer to the North instead.

If Northern governments have a limited ability to provide debt relief in period 1, i.e., $x^{S} \leq\left(x^{S}\right)^{\text {max }}$, or if Southern governments face a maximum politically-acceptable tax rate, i.e., $\tau^{S} \leq\left(\tau^{S}\right)^{\max }$, then Pareto gains are not exhausted, and the final intervention lies instead along the dashed red line. The proposition below summarizes the above results.

Proposition 3 (Tax-subsidy with debt relief) When $b_{1}^{S}>\bar{b}_{1}^{S}$, a tax-subsidy policy with debt relief achieves a Pareto improvement relative to the laissez-faire equilibrium. When the debt relief and tax rate are unlimited, bargaining between North and South achieves an allocation on the first-best frontier satisfying (32) and $\tau^{S} \in\left[\tau^{S, \gamma^{N}=0}, \tau^{S, \gamma^{N}=1}\right]$, where $\tau^{S, \gamma^{N}=0}<\tau^{S, \gamma^{N}=1}$ and $\frac{d \tau^{S}}{d \gamma^{N}}>0 . \quad b_{2}^{S}$ is higher than in the laissez-faire equilibrium. When the debt relief or tax rate are unlimited, the frontier of achievable allocations is a piecewise combination of the first-best frontier and the relevant constraint.

Propositions 2 and 3 are closely related: they establish that each intervention on its own can achieve all the Pareto-improving allocations on the first-best frontier, provided that there are no limits on the intervention sizes. The sets $\left[x^{S, \gamma^{N}=0}, x^{S, \gamma^{N}=1}\right]$ generated by the propositions 2 and 3 are not identical: the debt relief necessary to achieve any given allocation is smaller than the size of the necessary period-1 governmental loan, because the latter's effect on Southern consumption is partially undone by the period-2 repayment $z^{N}$.

Combining the interventions. In this endowment-based financial union, the two interventions described above are substitutes: the analytic work underlying propositions 2 and 3 can be easily combined to establish that in the absence of limits on the tools $\left\{x^{S}, z^{N}, \tau^{S}\right\}$, every Pareto-improving allocation on the first-best frontier can be achieved by using many different combinations of the two interventions. The more that the governmental loan is used relative to the debt relief package within the combination, the higher are public capital flows and the lower are private capital flows within the union.

Therefore, if there are limits on one of the policy tools, then any Pareto gains which remain unexploited by using one intervention alone should be achieved by utilizing the other intervention as well.

\subsection{Discussion}

North-to-South capital flows. The heterogeneous structure of our financial union means that there are capital flows from the lender households of the North to the borrower households of the South. Our Pareto improvements are based on reversing the decline in these capital flows during crisis periods.

CInternational Monetary Fund. Not for Redistribution 
Unlike the monetary union literature, where sticky prices typically underlie the rationale for intervention (e.g., Galí and Monacelli, 2008, and Farhi and Werning, 2013a), our results are strengthened in an environment where prices - specifically, collateral prices $p_{2}^{S}$ - are flexible: sudden stops become more severe when they strike, and Pareto improvements become possible even when fiscal space is lacking. In addition, in contrast to many papers emphasizing the zero lower bound on interest rates (e.g., Dogra, 2014, and Blanchard et al., 2015), our welfare gains do not come from the North and South spending more on each other's goods. Our results hold when all countries in the union only export to and import from the rest of the world; what we need is that the North finances the external deficits of the South, so that the North gains from improvements in the terms of its financing.

Endogeneity of the interest rate is key. When Benigno et al. (2016) consider a contemporaneous tax-subsidy policy by a single borrower country facing an exogenous interest rate, they find that the borrower country is unambiguously better off. By contrast, in our financial union, a promise of future taxes and subsidies in the South raises the interest rate today, which generates welfare gains for the North - so much so that debt relief may need to be added to the policy package in order to make sure that the South is also better off.

Pledgability interpretation. The interventions work by making Southern period-2 endowments more pledgable as collateral against borrowing in period 1. The governmental loan works because in the repayment period, the government transforms the partially pledgable tradable endowments $y_{T 2}$ of Southern households into fully pledgable revenues from lumpsum taxation $z^{N}$. The tax-subsidy intervention works by raising the price of the pledgable nontradable endowments $y_{N T 2}$ of Southern households, while keeping the pledgable value of tradable endowments unchanged.

More precisely, the tax-subsidy intervention works because it raises the price of collateralizable nontradable goods and/or assets. In practice, this should not be interpreted as a generalized real exchange rate support that subsidizes all nontradable goods. To underline this point, let us extend the above model to include an additional non-collateralizable nontradable sector with endowments, consumption levels, and prices $\left\{y_{M t}, c_{M t}^{i, j}, q_{t}^{i, j}\right\}_{i \in\{N, S\}, j \in[0,1], t \in\{1,2\}}$. Then the nontradable goods $\left\{y_{N T t}\right\}_{t \in\{1,2\}}$ can be interpreted as representing housing, which is collateralizable, while $\left\{y_{M t}\right\}_{t \in\{1,2\}}$ represents haircuts, which are not.

Suppose that a subsidy $\theta^{i, j}$ can be provided on the consumption of these new goods, amending each government's budget constraint:

$$
\tau^{i, j} c_{T 2}^{i, j}=\eta^{i, j} p_{2}^{i, j} c_{N T 2}^{i, j}+\theta^{i, j} q_{2}^{i, j} c_{M 2}^{i, j}
$$

The upper bound on $b_{2}^{i, j}$ for each household continues to be tied to $\left\{y_{T 2}, y_{N T 2}\right\}$ only, but the utility function is amended with the additional terms $\sum_{t \in\{1,2\}} \gamma \log c_{M t}^{i, j}$, which results in an additional intra-temporal first-order condition for consumption:

$$
\left(1+\tau^{i, j}\right) \gamma c_{T 2}^{i, j}=\left(1-\theta^{i, j}\right) q_{2}^{i, j} c_{M 2}^{i, j}
$$


Assuming as before that all variables are identical within regions, the system of equations (18)-(23) remains the same, except that equation (22) changes to:

$$
p_{2}^{S} c_{N T 2}^{S}=\left[\left(\nu+\tau^{S}+\nu \tau^{S}\right)-\frac{\theta^{S}}{1-\theta^{S}}\left(\gamma+\gamma \tau^{S}\right)\right] c_{T 2}^{S}
$$

We can show that in this amended setup, a small tax-subsidy intervention with debt relief, beginning at $b_{1}^{S}>\bar{b}_{1}^{S}$ and $x^{S}=\tau^{S}=\theta^{S}=0$, generates:

$$
\left.d U^{i}\right|_{d U^{-i}=0}=\frac{1}{c_{T 1}^{i}} \frac{1}{r_{2}}\left(1-\frac{r_{2}}{R_{2}^{S}}\right) \frac{c_{T 2}^{S}}{1+\phi \nu}\left\{\phi(1+\nu) d \tau^{S}-\gamma \phi d \theta^{S}\right\} \text { for all } i .
$$

Therefore, the government should tax non-collateralizable nontradable goods, and use the revenues to subsidize collateralizable nontradable goods. The following lemma holds.

Lemma 2 (Non-collateralizable nontradable goods) When the policy tools $\left(x^{S}, \tau^{S}\right)$ are unlimited, an additional subsidy $\theta^{S}>0$ does not change the result in proposition 3 that bargaining between North and South achieves an allocation on the first-best frontier. However, when either tool is limited, bargaining will result in $\theta^{S}<0$.

Transfer effect. How does the effect of a pure transfer $d x^{S}>0$ in our model relate to the "transfer effect" highlighted in Keynes (1929) and Ohlin (1929)? They find that the country providing the transfer loses both from the goods no longer in the country and also from a decline in the country's intratemporal terms of trade. Since our model does not have differentiated tradable goods and home bias, we cannot replicate their finding. Instead, our model adds a new countervailing finding into the mix: we demonstrate that in the presence of binding borrowing constraints, a transfer to the set of countries facing such constraints changes the intertemporal terms of trade in a direction that benefits the saver countries providing the transfer - namely, it increases the interest rate $r_{2}$. Therefore, the countries providing the transfer actually recoup some, but not all, of the cost of providing the transfer. This result is summarized in the lemma below, which draws on the previous subsection.

Lemma 3 (Transfer effect) When $b_{1}^{S}>\bar{b}_{1}^{S}$, a pure transfer $d x^{S}>0$ generates $d r_{2}>0$ and $d U^{N}\left(x^{S}, 0,0\right)=\frac{1}{c_{T 1}^{N}}\left[-d x^{S}+\frac{y_{T 2}-c_{T 2}^{S}}{r_{2}^{2}} d r_{2}\right] \in\left(-\frac{1}{c_{T 1}^{N}} d x^{S}, 0\right)$.

Coalitional bargaining. We have used the assumption of a continuum of countries inside each region, rather than a single country in each region, for two purposes. Firstly, we wished to illustrate that even in a union of many small countries, regional bargaining may be beneficial: regional coalitions internalize the effects of their actions on the interest rate $r_{2}$, and as a result, they are able to exhaust the Pareto gains. Secondly, we wanted to give a sense that the process for approval of interventions in a union containing many countries may not be straightforward. Indeed, it may be desirable to set up union-wide institutions before a crisis occurs. In this light, we turn next to pre-crisis institutional design. 


\section{Pre-crisis Heterogeneity and Institutional Design}

Our analysis so far suggests that for Pareto gains to be effectively exploited during crises, the financial union requires institutions which implement governmental loans and debt relief packages, and which help individual countries gather into regional bargaining coalitions. But will such institutions have been set up and made functional by the time that crises arrive? In pre-crisis times, before borrowing constraints bind, all the countries inside the financial union should decide whether to set up these institutions and which values of the bargaining power parameter, $\gamma^{N}=1-\gamma^{S} \in[0,1]$, are acceptable. The institutions are brought into existence if and only if for some values of $\gamma^{N}$, regional bargaining during crises is also Pareto-improving from the pre-crisis perspective.

To tackle this issue, we endogenize $b_{1}^{S}$, the inherited debt of the South in the model of the previous section, as the outcome of a deterministic environment with pre-crisis endowments and consumption decisions. Specifically, we add one pre-crisis period onto the model of section 2, and assume that the North starts off with a higher endowment than the South.

\subsection{The Pre-crisis Environment}

There is one additional period, $t=0$, just before the model in section 2.1. Correspondingly, we need to define some new variables and impose some additional constraints.

Households. The representative household in country $j$ of region $i$ has the amended $\log$ preferences:

$$
V^{i, j}=\left(\log c_{T,-1}^{i, j}+\nu \log c_{N T,-1}^{i, j}\right)+\left(\log c_{T 0}^{i, j}+\nu \log c_{N T 0}^{i, j}\right)+U^{i, j},
$$

where $c_{T t}^{i, j}$ and $c_{N T t}^{i, j}$ are respectively the consumption of tradable and nontradable goods in country $j$ of region $i$ in period $t$, and $U^{i, j}$ follows equation (1). The debt of the household in country $j$ of region $i$ at the beginning of period 1 is pinned down by the household's budget constraint:

$$
b_{1}^{i, j} \equiv r_{1}^{i, j}\left(c_{T 0}^{i, j}+p_{0}^{i, j} c_{N T 0}^{i, j}-e^{i, j}-p_{0}^{i, j} y_{N T 0}\right),
$$

where $e^{i, j}$ is the tradable endowment of each household in country $j$ of region $i$ in period 0 , $y_{N T t}$ is the nontradable endowment common to all countries in period $t, r_{1}^{i, j}$ is the interest rate on borrowing and lending faced by the household between periods 0 and 1 , and $p_{0}^{i, j}$ is the price of nontradable goods in country $j$ of region $i$ in period 0 . The equations (2) and (3) also continue to apply.

In addition to the first-order conditions (4)-(6), the household's consumption choices now also satisfy the following conditions for period 0 :

$$
\begin{gathered}
c_{T 1}^{i, j}=r_{1}^{i, j} c_{T 0}^{i, j} \\
\nu c_{T 0}^{i, j}=p_{0}^{i, j} c_{N T 0}^{i, j} .
\end{gathered}
$$


Imperfect financial union. The interest rates are equalized within the financial union $F$, which means the following additional condition:

$$
r_{1}^{i, j}=r_{1} \text { for all } i, j .
$$

There are no imperfections from borrowing constraints in period 0. Our financial union is still assumed to be financially closed to the rest of world, so the additional market-clearing conditions are:

$$
\begin{gathered}
c_{N T 0}^{i, j}=y_{N T 0} \text { for all } i, j \\
\sum_{i \in\{N, S\}} \int_{0}^{1} c_{T 0}^{i, j} d j=e^{T} .
\end{gathered}
$$

where $e^{T} \equiv \sum_{i \in\{N, S\}} \int_{0}^{1} e^{i, j} d j$ is the total tradable endowment within the union in period 0 .

Heterogeneous regions. A region $i \in\{N, S\}$ is defined such that within each region $i$, the tradable endowment levels are common across all countries $j$ :

$$
e^{i, j}=e^{i} \text { for all } i, j .
$$

We assume that the North starts with a higher tradable endowment than the South, and we define the degree of pre-crisis heterogeneity of the union, $H$, accordingly:

$$
\begin{gathered}
e^{S}=e^{T}-e^{N} \in\left[0, \frac{e^{T}}{2}\right] \\
H \equiv \frac{e^{N}-e^{S}}{e^{T}}=1-2 \frac{e^{S}}{e^{T}} \in[0,1] .
\end{gathered}
$$

Equilibrium variables are again identical for all countries $j$ of each region $i$ : condition (17) holds for all periods. Therefore, as in the previous section, we suppress country superscripts in favor of regional superscripts. Equations (13)-(14) will be continue to apply in our extended model, but this time generated endogenously.

Competitive equilibrium allocations. The rational expectations equilibrium of the model follows a definition similar to that in subsection 2.1. The set of prices and allocations, now expanded to include $\left\{r_{0}^{i, j}, p_{0}^{i, j}, c_{T 0}^{i, j}, c_{N T 0}^{i, j}\right\}_{i \in\{N, S\}, j \in[0,1]}$, satisfies the previous equilibrium conditions as well as equations (34)-(42), subject to the degree of heterogeneity $H$ and the government policies $\left\{x^{i, j}, z^{i, j}, \tau^{i, j}, \eta^{i, j}\right\}_{i \in\{N, S\}, j \in[0,1]}$ defined by equations (15)-(16).

Institutional design. At the beginning of period 0, regional coalitions of Northern and Southern governments must decide whether to set up institutions that make crisis-time bargaining possible:

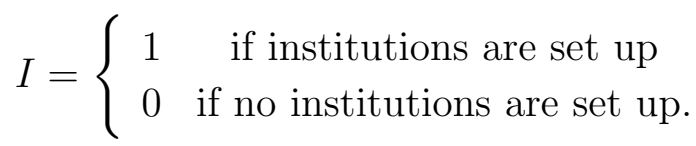

If $I=0$, no crisis-time interventions are allowed: $x^{S}=z^{N}=\tau^{S}=0$. For $I=1$, unlimited interventions using all policy tools $\left\{x^{S}, z^{N}, \tau^{S}\right\}$ are allowed during crisis periods $t \in\{1,2\}$, 
so the North and South must additionally decide in period 0 the value of $\gamma^{N} \in[0,1]$ to be used later on. Then crisis-time bargaining follows the procedure described in subsection 2.3: interventions are negotiated in period 1 taking $b_{1}^{S}$ and the bargaining power $\gamma^{N}$ as given.

\subsection{Endogenizing the Debt Level $b_{1}^{S}$}

Panel I of figure 6 illustrates the endogenous determination of the South's inherited debt level $b_{1}^{S}$. The gray lines summarize the previous section's findings regarding the Southern tradable consumption level as a function of $b_{1}^{S} \cdot c_{T 1}^{S *}$ and $c_{T 1}^{S, C}\left(\equiv c_{T 1}^{S, I=0}\right)$ represent the unconstrained and constrained consumption levels, described respectively by equations (25) and (26). The constrained consumption level falls below the unconstrained value for $b_{1}^{S}>\bar{b}_{1}^{S}$. When interventions are allowed, i.e., $I=1$, the consumption of the South in period 1 increases above its constrained level, with the precise magnitude of the increase depending on the North's bargaining power $\gamma^{N}$. The post-intervention consumption levels are represented by the lines $c_{T 1}^{S, \gamma^{N}=1}$ and $c_{T 1}^{S, \gamma^{N}=0}\left(>c_{T 1}^{S, \gamma^{N}=1}\right)$, based on equations (30)-(31).

To this configuration of graphs we need to add information regarding optimal household decisions and market-clearing in period 0. It turns out that irrespective of $\left\{I, \gamma^{N}\right\}$, the interest rate $r_{1}$ takes a constant value, and households throughout the union optimally choose $\left\{c_{T 0}^{i}\right\}_{i \in\{N, S\}}$ in line with $\left\{c_{T 1}^{i}\right\}_{i \in\{N, S\}}$ :

$$
r_{1}=\frac{2 y_{T 1}}{e^{T}} \text { and } c_{T 0}^{i}=\frac{e^{T}}{2 y_{T 1}} c_{T 1}^{i} \text { for all } i .
$$

Combining with the household budget constraint (34), we derive the new condition:

$$
b_{1}^{S}=2 c_{T 1}^{S}-2 y_{T 1}(1-H) .
$$

This condition is shown as the black upward-sloping line in panel I. Along the line, households' consumption-smoothing decisions cause the debt levels $\left\{b_{1}^{i}\right\}_{i \in\{N, S\}}$ to move in the same direction as $\left\{c_{T 1}^{i}\right\}_{i \in\{N, S\}}$. An increase in $H$, i.e., a reduction in the initial endowments of Southern households, shifts the black line to the right.

The union-wide equilibrium reduces to the set of prices and allocations $\left\{r_{2}, p_{2}^{S}, c_{T 1}^{S}, c_{T 2}^{S}\right.$, $\left.c_{T 1}^{N}\right\}$ as a function of $\left\{H, x^{S}, z^{N}, \tau^{S}\right\}$, subject to the equations (18)-(23) and (44). In graphical terms, the equilibrium is given by the intersection of the black line (indexed by $H$ ) and the appropriate gray line (indexed by $\left\{I, \gamma^{N}\right\}$ ) in panel I of figure 6 .

From the graphs and equations, the borrowing constraint (21) becomes binding, and a regional sudden stop occurs in the South, when the degree of pre-crisis heterogeneity $H$ is high enough:

$$
H>\bar{H}=3 \frac{\phi(1+\nu)}{1+\phi \nu} \Leftrightarrow b_{1}^{S}>\bar{b}_{1}^{S} .
$$

For there to be a possibility of binding constraints in the union, $\bar{H}$ must be less than 1 , which implies that $\phi<\frac{1}{3+2 \nu}$ (our assumption in the previous section that $\phi<\frac{1}{2+\nu}$ is therefore 
justified: it is a necessary condition for $b_{1}^{S}>\bar{b}_{1}^{S}$ to be possible in the first place). Inspecting the graphs yields the following lemma.

Lemma 4 (Inherited debt level) When $H>\bar{H}$, the Southern debt level is affected by the expectation of $\left\{I, \gamma^{N}\right\}$. An expected constraint reduces debt: $b_{1}^{S, C}\left(\equiv b_{1}^{S, I=0}\right)<b_{1}^{S *}$, while an expected intervention increases debt: $b_{1}^{S, \gamma^{N}=0}>b_{1}^{S, \gamma^{N}=1}>b_{1}^{S, C}$ and $\frac{d b_{1}^{S, \gamma^{N}}}{d \gamma^{N}}<0$.

Panel II of figure 6 present the same arguments from the North's perspective, and since the explanatory steps are analogous, we do not repeat them here.

\subsection{Pareto-improving Institutional Design}

Institutions to facilitate interventions are brought into existence if and only if the change in $b_{1}^{S}$ brought about by expected period-1 bargaining (as illustrated in the previous subsection) is associated with a Pareto-improvement from the perspective of period 0, at least for some values of $\gamma^{N}$. We tackle this question next.

First best and laissez faire. A necessary condition for interventions to be useful is that the laissez-faire equilibrium deviates from the first-best frontier. By definition, the firstbest allocation maximizes $\sum_{i \in\{N, S\}} \int_{0}^{1} \lambda^{i, j} V^{i, j} d j$ subject to the market clearing conditions (11)-(12) and (38)-(39), and the Pareto weights $\left\{\lambda^{i, j}=\lambda^{i}\right\}_{i \in\{N, S\}, j \in[0,1]}$. The laissez-faire equilibrium solves equations (18)-(23) and (44) subject to $x^{S}=z^{N}=\tau^{S}=0$. Defining $\left\{V^{i, j}=V^{i}\right\}_{i \in\{N, S\}, j \in[0,1]}$ and $\left\{V^{i *}\right\}_{i \in\{N, S\}}$ as the constrained and unconstrained regional welfare levels, this section's counterparts to lemma 1 and proposition 1 are as follows.

Lemma 5 (First-best allocation) Irrespective of $\left\{\lambda^{i}\right\}_{i \in\{N, S\}}$, the first-best allocation features $\frac{c_{T 1}^{i}}{c_{T 0}^{i}}=\frac{2 y_{T 1}}{e^{T}}$ and $\frac{c_{T 2}^{i}}{c_{T 1}^{i}}=\frac{y_{T 2}}{y_{T 1}}$ for all $i$.

Proposition 4 (Laissez-faire equilibrium) Assume that $\phi$ is sufficiently low, i.e., $\phi \in$ $[0, \widehat{\phi})$ for some $\widehat{\phi}>0$. Then there exists some $\bar{H} \in(0,1)$ such that the laissez-faire equilibrium is a first-best allocation for some Pareto weights $\left\{\lambda^{i}\right\}_{i \in\{N, S\}}$ when $H \in[0, \bar{H}]$, but is located in the interior of the first-best frontier when $H \in(\bar{H}, 1]$. In the latter region, $\frac{c_{T 1}^{i}}{c_{T 0}^{i}}=\frac{2 y_{T 1}}{e^{T}}$ but $c_{T 2}^{S, C}=\bar{c}_{T 2}^{S}$ and $R_{2}^{S}>\frac{y_{T 2}}{y_{T 1}}>r_{2}$. There also exists some $\widehat{H} \in(\bar{H}, 1)$ such that:

$$
V^{N}\left\{\begin{array} { l l } 
{ = V ^ { N * } } & { \text { for } H \in [ 0 , \overline { H } ] } \\
{ < V ^ { N * } } & { \text { for } H \in ( \overline { H } , 1 ] }
\end{array} \text { and } V ^ { S } \left\{\begin{array}{ll}
=V^{S *} & \text { for } H \in[0, \bar{H}] \\
>V^{S *} & \text { for } H \in(\bar{H}, \widehat{H}) \\
<V^{S *} & \text { for } H \in(\widehat{H}, 1]
\end{array}\right.\right.
$$

Pareto-improving institutions. If unlimited interventions $\left\{x^{S}, z^{N}, \tau^{S}\right\}$ can be selected in period 0 , there is no difficulty in generating Pareto improvements from the perspective of period 0 . The following lemma comes from extending the algebra of section 2 . 
Lemma 6 (Pre-crisis policy choice) Suppose that unlimited policies $\left\{x^{S}, z^{N}, \tau^{S}\right\}$ can be selected in period 0 . When $H>\bar{H}$, bargaining between North and South achieves a Paretoimproving (from the period-0 perspective) allocation on the first-best frontier. $b_{1}^{S}$ is higher than in the constrained equilibrium.

The key obstacle that we impose, however, is that only the decisions $\left\{I, \gamma^{N}\right\}$ can be made in period 0 , while the interventions $\left\{x^{S}, z^{N}, \tau^{S}\right\}$ come from bargaining in period 1. We believe that this environment captures more accurately the institutional design problem faced by financial unions such as the Eurozone, and it captures real-world fears of moral hazard, i.e., that the expectation of future interventions may stimulate a level of Southern "overborrowing" that the North cannot offset. This obstacle removes the guarantee that the post-intervention equilibrium is Pareto-improving from the period-0 perspective.

The economic manifestation of this obstacle in our model takes the form of an externality in both regions mediated by the endogenous interest rate $r_{2}$. As shown in subsection 3.2, households make their pre-crisis borrowing decisions based on $\left\{I, \gamma^{N}\right\}$, because the latter pins down their expectations of union-wide policies $\left\{x^{S}, z^{N}, \tau^{S}\right\}$. But households are too small to internalize that their period-0 decisions actually determine the regional debt level $b_{1}^{S}$ (which pins down the outside options in (28)), and thereby affect the period-1 choice of $\left\{x^{S}, z^{N}, \tau^{S}\right\}$. Therefore, they may borrow too little or too much in period 0 relative to the preferred choice of the region as a whole. If the divergence is very large, the post-intervention allocation may involve the region being worse off than it was in the laissez-faire equilibrium.

Panels III and IV of figure 6 illustrate the welfare impact of endogenizing $b_{1}^{S}$ for a given value of $H$, using the following two-step procedure. Firstly, we graph the period-0 regional welfares over all possible $b_{1}^{S}$, based on solving (28) subject to (18)-(23) and the period-0 equation:

$$
c_{T 0}^{S}=\frac{e^{T}}{2 y_{T 1}}\left(b_{1}^{S}+y_{T 1}(1-H)\right),
$$

which reflects household budget constraints and market clearing, but not period-0 household optimization. The constrained laissez-faire (i.e., $I=0)$ welfare is the welfare at the laissezfaire debt level:

$$
b_{1}^{S, C}=y_{T 1}\left(\frac{\phi(1+\nu)}{2+3 \phi+5 \phi \nu}+\frac{1+2 \phi+3 \phi \nu}{2+3 \phi+5 \phi \nu} H\right)
$$

and to the right of this point, panels III and IV trace out how welfares change as $b_{1}^{S}$ rises above $b_{1}^{S, C}$. Secondly, we identify the debt level $b_{1}^{S}$ corresponding to period-0 household optimization, which satisfies equation (44) and which we can read off the appropriate intersections in panels I and II. Using panels III and IV, we finally compare the welfare at that optimized debt level to the constrained laissez-faire welfare.

Panel III plots the Southern welfare levels $V^{S, \gamma^{N}=1}\left(b_{1}^{S}\right)$ and $V^{S, \gamma^{N}=0}\left(b_{1}^{S}\right)$ :

$$
V^{S, \gamma^{N}=1}\left(b_{1}^{S}\right)=\log \left\{\kappa\left(b_{1}^{S}+y_{T 1}(1-H)\right)\left(\frac{1+3 \phi+4 \phi \nu}{1+2 \phi+3 \phi \nu}-\frac{1+\phi+2 \phi \nu}{1+2 \phi+3 \phi \nu} \frac{b_{1}^{S}}{y_{T 1}}\right) \frac{1-\phi}{1+\phi \nu}\right\}
$$




$$
\begin{aligned}
V^{S, \gamma^{N}=0}\left(b_{1}^{S}\right) & =\log \left\{\kappa\left(b_{1}^{S}+y_{T 1}(1-H)\right)\right. \\
& \left.\times\left(2-\sqrt{\left(\frac{1+\phi+2 \phi \nu}{1+2 \phi+3 \phi \nu}+\frac{1+\phi+2 \phi \nu}{1+2 \phi+3 \phi \nu} \frac{b_{1}^{S}}{y_{T 1}}\right) \frac{1+\phi+2 \phi \nu}{1+\phi \nu}}\right)^{2}\right\},
\end{aligned}
$$

where $\kappa=\frac{e^{T}}{2} y_{T 2} \Pi_{t=\{0,1,2\}} y_{N T t}$ is a constant. Let us compare each to the laissez-faire welfare.

For a given level of $b_{1}^{S}$, if $\gamma^{N}=1$, then period-1 bargaining leaves the South indifferent between laissez-faire and the intervention over $t \in\{1,2\}$. Since fixing $b_{1}^{S}$ also fixes $c_{T 0}^{S}$, then for a given level of $b_{1}^{S}, \gamma^{N}=1$ means that the South's period-0 welfare is the same whether there is intervention or not. Therefore, the shape of $V^{S, \gamma^{N}=1}\left(b_{1}^{S}\right)$ reflects how the South's welfare varies with $b_{1}^{S}$ in the absence of intervention, and $V^{S, \gamma^{N}=1}\left(b_{1}^{S, C}\right)$ represents the constrained laissez-faire (i.e., $I=0$ ) welfare level.

Evaluated at the debt level $b_{1}^{S, C}$, the slope of $V^{S, \gamma^{N}=1}\left(b_{1}^{S}\right)$ is positive, which means that $V^{S, \gamma^{N}=1}\left(b_{1}^{S}\right)$ achieves a peak for some debt level higher than $b_{1}^{S, C}$. The reason is that increasing $b_{1}^{S}$ both increases $c_{T 0}^{S}$ and also pushes down $r_{2}$, which additionally shifts welfare from the North to the South. This interest rate effect is not internalized by Southern households, but does benefit the South as a whole. From panel I of figure 6, we know that $b_{1}^{S, \gamma^{N}=1}>b_{1}^{S, C}$. What panel III implies is that the increase in debt improves Southern welfare relative to laissez-faire if and only if $b_{1}^{S, \gamma^{N}=1} \in\left(b_{1}^{S, C},\left(b_{1}^{S}\right)^{M}\right)$, and worsens welfare if $b_{1}^{S, \gamma^{N}=1}>\left(b_{1}^{S}\right)^{M}$. Notice that $\left(b_{1}^{S}\right)^{M}$ is larger for levels of $H$ such that starting from the laissez-faire debt level $b_{1}^{S, C}$, an increase in debt benefits Southern welfare significantly more by depressing $r_{2}$ than it hurts welfare by tightening the Southern borrowing constraint.

$V^{S, \gamma^{N}=0}\left(b_{1}^{S}\right)$ represents the Southern welfare when all welfare gains from period-1 unionwide bargaining are given to the South instead of to the North. Its graph lies everywhere above $V^{S, \gamma^{N}=1}\left(b_{1}^{S}\right)$, and the gap between $V^{S, \gamma^{N}=0}\left(b_{1}^{S}\right)$ and $V^{S, \gamma^{N}=1}\left(b_{1}^{S}\right)$ at the debt level $b_{1}^{S, C}$ is higher the tighter is the constraint of the South at that debt level. The increase in $b_{1}^{S, \gamma^{N}=0}$ relative to the constrained laissez-faire level $b_{1}^{S, C}$, as depicted in panel I of figure 6 , is associated with a welfare improvement for the South if and only if $b_{1}^{S, \gamma^{N}=0} \in\left(b_{1}^{S, C},\left(b_{1}^{S}\right)^{N}\right)$ in panel III.

Panel IV plots the Northern welfare levels $V^{N, \gamma^{N}=0}\left(b_{1}^{S}\right)$ and $V^{N, \gamma^{N}=1}\left(b_{1}^{S}\right)$ :

$$
\begin{aligned}
V^{N, \gamma^{N}=0}\left(b_{1}^{S}\right)=\log \{ & \left.\kappa\left(y_{T 1}(1+H)-b_{1}^{S}\right)\left(\frac{1+\phi+2 \phi \nu}{1+2 \phi+3 \phi \nu}+\frac{1+\phi+2 \phi \nu}{1+2 \phi+3 \phi \nu} \frac{b_{1}^{S}}{y_{T 1}}\right) \frac{1+\phi+2 \phi \nu}{1+\phi \nu}\right\} \\
V^{N, \gamma^{N}=1}\left(b_{1}^{S}\right)= & \log \left\{\kappa\left(y_{T 1}(1+H)-b_{1}^{S}\right)\right. \\
& \left.\times\left(2-\sqrt{\left(\frac{1+3 \phi+4 \phi \nu}{1+2 \phi+3 \phi \nu}-\frac{1+\phi+2 \phi \nu}{1+2 \phi+3 \phi \nu} \frac{b_{1}^{S}}{y_{T 1}}\right) \frac{1-\phi}{1+\phi \nu}}\right)^{2}\right\} .
\end{aligned}
$$

Let us now compare each of these to the laissez-faire welfare. 
Applying analogous arguments to those for the Southern welfare graphs, we can establish that the shape of $V^{N, \gamma^{N}=0}\left(b_{1}^{S}\right)$ reflects how the North's welfare varies with $b_{1}^{S}$ in the absence of intervention, and that $V^{N, \gamma^{N}=0}\left(b_{1}^{S, C}\right)$ represents the North's constrained laissez-faire (i.e., $I=0)$ welfare level. Evaluated at the debt level $b_{1}^{S, C}$, the slope of $V^{N, \gamma^{N}=0}\left(b_{1}^{S}\right)$ is negative, which means that the peak of $V^{N, \gamma^{N}=0}\left(b_{1}^{S}\right)$ occurs at a level of debt lower than $b_{1}^{S, C}$. The reason is that increasing $b_{1}^{S}$ not only reduces $c_{T 0}^{N}$ but also, as we mentioned above, pushes down $r_{2}$. This interest rate effect is not internalized by Northern households, but does hurt the North as a whole as it is the saver region. The increase in $b_{1}^{S, \gamma} \gamma^{N}=0$ above $b_{1}^{S, C}$ from panel II therefore unambiguously reduces Northern welfare below its laissez-faire level in panel IV.

$V^{N, \gamma^{N}=1}\left(b_{1}^{S}\right)$ represents the Northern welfare when all welfare gains from period-1 bargaining are given to the North. Its graph lies everywhere above $V^{N, \gamma^{N}=0}\left(b_{1}^{S}\right)$, and the gap between $V^{N, \gamma^{N}=1}\left(b_{1}^{S}\right)$ and $V^{N, \gamma^{N}=0}\left(b_{1}^{S}\right)$ at the debt level $b_{1}^{S, C}$ is higher the tighter is the constraint of the South at that debt level. The increase in $b_{1}^{S, \gamma^{N}=1}$ relative to the constrained laissez-faire level $b_{1}^{S, C}$, as depicted in panel II of figure 6 , is associated with a welfare improvement for the North if and only if $b_{1}^{S, \gamma^{N}=1} \in\left(b_{1}^{S, C},\left(b_{1}^{S}\right)^{P}\right)$ in panel III.

Applying the experiment in panels III and IV of figure 6 over the entire set of pre-crisis heterogeneity levels $H \in[0,1]$, we derive the below proposition characterizing the set of Pareto-improving period-0 institutional designs $\left\{I, \gamma^{N}\right\}$ as a function of $H$.

Proposition 5 (Institutional design) Assume that $\phi$ is sufficiently low, i.e., $\phi \in[0, \tilde{\phi})$ for some $\tilde{\phi}>0$. Then we can define threshold levels $H_{1}$ and $H_{2}$ satisfying $H_{1} \in(\bar{H}, 1)$ and $H_{2} \in\left(H_{1}, 1\right)$ such that $(i)$ institutions are Pareto-improving in period 0 if and only if they are set up according to:

$$
I(H)= \begin{cases}0 & \text { for } H \in\left[0, H_{1}\right] \\ 1 & \text { for } H \in\left(H_{1}, 1\right],\end{cases}
$$

and (ii) the set of bargaining powers $\gamma^{N} \in\left[\gamma_{\min }^{N}(H), \gamma_{\max }^{N}(H)\right]$ consistent with a period-0 Pareto improvement follow:

$$
\begin{aligned}
& \gamma_{\min }^{N}(H)>0 \text { and } \gamma_{\max }^{N}(H)=1 \quad \text { for } H \in\left(H_{1}, H_{2}\right] \\
& \gamma_{\text {min }}^{N}(H)>0 \text { and } \gamma_{\max }^{N}(H)<1 \text { for } H \in\left(H_{2}, 1\right] \text {. }
\end{aligned}
$$

This proposition is illustrated by panels I and II of figure 7, which plot against $H$ the exponentials of the regional welfare levels $\left\{\exp \left(V^{i}\right)\right\}_{i \in\{N, S\}}$ for different institutional designs $\left\{I, \gamma^{N}\right\}$. In the figure, $H^{\max }=2 \frac{1+2 \phi+3 \phi \nu}{1+\phi+2 \phi \nu}$ lies above 1 , but if $\phi$ is sufficiently low, then $H_{1}$ and $H_{2}$ lie below 1 . We conclude this subsection by tracing out the connection between panels III and IV of figure 6 on the one hand, and panels I and II of figure 7 (and thereby, proposition 5) on the other.

When $H \in[0, \bar{H}]$, i.e., the financial union is reasonably homogeneous in its initial endowments across regions, it is known in period 0 that the Southern borrowing constraint will never bind. Following proposition 4, there is no argument for setting up institutions to 
facilitate union-wide bargaining, so $I=0$.

When $H \in\left(\bar{H}, H_{1}\right]$, i.e., the financial union is slightly heterogeneous, it is known that the Southern borrowing constraint will bind, but not very tightly. As a result, the Pareto gains from period-1 bargaining will be small. In panel III of figure $6, b_{1}^{S, \gamma^{N}=1} \in\left(b_{1}^{S, C},\left(b_{1}^{S}\right)^{M}\right)$ and $b_{1}^{S, \gamma^{N}=0} \in\left(b_{1}^{S, C},\left(b_{1}^{S}\right)^{N}\right)$ are both satisfied, as the South benefits from the increase in debt induced by the expectation of intervention. However, in panel IV of figure 6, the welfare result is more negative. Northern welfare is necessarily lower under $\gamma^{N}=0$ than for laissez-faire, and because the Pareto gains are small, the gap between $V^{N, \gamma^{N}=1}\left(b_{1}^{S}\right)$ and $V^{N, \gamma^{N}=0}\left(b_{1}^{S}\right)$ is small. Therefore, $\left(b_{1}^{S}\right)^{P}$ is low, which in turn means that $b_{1}^{S, \gamma^{N}=1}>\left(b_{1}^{S}\right)^{P}$. In other words, even if the North is allocated all the bargaining power in advance, i.e., $\gamma^{N}=1$, the North is still worse off from the period-0 perspective if $I=1$ is selected. These results are reflected in panels I and II of figure 7: for $H \in\left(\bar{H}, H_{1}\right]$, Southern welfares under $\left\{I=1, \gamma^{N} \in[0,1]\right\}$ are higher than under $I=0$, while Northern welfares are lower. There are no Pareto-improving allocations from the period- 0 perspective, so as proposition 5 states, the solution is $I=0$.

When $H \in\left(H_{1}, H_{2}\right]$, i.e., the financial union is moderately heterogeneous, the Pareto gains from period-1 bargaining become moderately large as well. In panel III of figure 6, $b_{1}^{S, \gamma^{N}=1} \in\left(b_{1}^{S, C},\left(b_{1}^{S}\right)^{M}\right)$ and $b_{1}^{S, \gamma^{N}=0} \in\left(b_{1}^{S, C},\left(b_{1}^{S}\right)^{N}\right)$ continue to hold as $V^{S, \gamma^{N}=0}\left(b_{1}^{S}\right)$ rises further above $V^{S, \gamma^{N}=1}\left(b_{1}^{S}\right)$, so the relative positions of the welfare lines in panel I of figure 7 remain unchanged. By contrast, there is a significant change in panel IV of figure 6 . As Pareto gains are now moderately large, $V^{N, \gamma^{N}=1}\left(b_{1}^{S}\right)$ rises substantially above $V^{N, \gamma^{N}=0}\left(b_{1}^{S}\right)$, so that $\left(b_{1}^{S}\right)^{P}$ becomes larger and $b_{1}^{S, \gamma^{N}=1} \in\left(b_{1}^{S, C},\left(b_{1}^{S}\right)^{P}\right)$ becomes satisfied. Therefore, in panel II of figure 7, the Northern welfare under $\left\{I=1, \gamma^{N}=1\right\}$ becomes higher than under $I=0$. Changing from $I=0$ to $I=1$ does generate a Pareto improvement from the period-0 perspective as long as $\gamma^{N}$ is sufficiently high (and definitely above 0 ).

When $H \in\left(H_{2}, 1\right]$, i.e., the financial union is highly heterogeneous, the Southern borrowing constraint becomes very tightly binding at the laissez-faire allocation and Pareto gains are very large. There is now a significant change in panel III of figure 6. The large Pareto gains continue to ensure that $b_{1}^{S, \gamma^{N}=0} \in\left(b_{1}^{S, C},\left(b_{1}^{S}\right)^{N}\right)$ is satisfied. However, the graph for $V^{S, \gamma^{N}=1}\left(b_{1}^{S}\right)$ reaches its peak much earlier and just above $b_{1}^{S, C}$, because for these levels of $H$, an increase in debt benefits Southern welfare a little by depressing $r_{2}$, but it hurts welfare substantially by tightening the constraint. Therefore, $b_{1}^{S, \gamma^{N}=1}>\left(b_{1}^{S}\right)^{M}$ becomes true. In panel I of figure 7, the Southern welfare under $\left\{I=1, \gamma^{N}=1\right\}$ dips below the welfare level under $I=0$. Regarding the North, the relative positions of the graphs in panel IV of figure 6 and panel II of figure 7 remain the same as for $H \in\left(H_{1}, H_{2}\right]$. In summary, changing from $I=0$ to $I=1$ now generates a Pareto improvement from the period-0 perspective if and only if $\gamma^{N}$ lies in an intermediate region: $\gamma^{N} \in\left[\gamma_{\min }^{N}(H), \gamma_{\max }^{N}(H)\right]$ with $\gamma_{\min }^{N}(H)>0$ and $\gamma_{\max }^{N}(H)<1$. Too much bargaining power must not be given to the North or to the South. 


\subsection{Discussion}

Overborrowing. Northern fears that setting up crisis-time bargaining institutions may induce the South to borrow more and thereby hurt the North are rationalized in our model for financial unions whose heterogeneity is low. The expectation of intervention does increase the level of Southern pre-crisis debt $b_{1}^{S}$, which makes the sudden stop more severe, reduces the union-wide interest rate $r_{2}$, and shifts welfare from the North to the South. This negative effect on the North cannot be overcome by the period-1 generation of Pareto gains, even if all the Pareto gains are given to the North.

However, when the financial union is moderately or highly heterogeneous, this overborrowing worry diminishes relative to the Pareto gains from crisis-time bargaining. These Pareto gains can be distributed between North and South in a manner to completely offset the negative impact on the North of higher pre-crisis Southern borrowing. In this context,

the higher $b_{1}^{S}$ generated by the anticipation of period-1 bargaining is actually a positive sign that the North and South are fully exploiting their respective comparative advantages (as savers and borrowers) in an unimpeded union-wide capital market.

In highly heterogeneous unions, care must be taken to limit the North's bargaining power $\gamma^{N}$, so that the South receives some of the Pareto gains during $t \in\{1,2\}$. Otherwise, the externality from household borrowing becomes very severe - Southern households borrow so much that the South as a whole has a very low outside option during the period-1 bargaining process - and as a result, the South's welfare is not improved from the period-0 perspective.

\section{A More Elaborate Financial Union}

Having proven our main results in a simple financially-closed union containing endowment economies, we now generalize the results above to a model with financial openness of the union to the rest of the world, and with production. The potential for Pareto-improving policies continues to hold, subject to modifications related to the presence of capital inflows from outside the union, and the intratemporally distortive effects of interventions.

\subsection{The Environment for Periods $t \in\{1,2\}$}

Our financial union $F$ still has the two regions $i \in\{N, S\}$, with each region continuing to be composed of a unit measure of countries $j \in[0,1]$. However, relative to the baseline model, each country now additionally contains a unit measure of firms in each of the tradable and nontradable sectors, who produce output by investing in capital. Both households and firms have access to loans from inside the union at interest rate $r_{2}$ and from the rest of the world $R O W$ at interest rate $r$. Households face limits on how much they can borrow both from inside the union and from $R O W$, while firms do not. Since capital inflows from $R O W$ to $F$ in period 1 are subject to borrowing limits while capital outflows from $F$ to $R O W$ are not, 
we must have $r_{2} \geq r$. Therefore, households borrow as much as they can from $R O W$ and the remainder from the intra-union loans market, while firms borrow everything they need from $R O W$ only.

All households within each region begin period 1 with the same inherited debt positions with respect to the intra-union market and to $R O W$, while all firms within each region begin with the same level of capital invested in each sector. Similarly to the baseline model, we again assume that all governments within each region pursue identical policies.

Households. The representative household in country $j$ of region $i$ has log preferences:

$$
U^{i, j}=\left(\log c_{T 1}^{i, j}+\nu \log c_{N T 1}^{i, j}\right)+\left(\log c_{T 2}^{i, j}+\nu \log c_{N T 2}^{i, j}\right),
$$

where $c_{T t}^{i, j}$ and $c_{N T t}^{i, j}$ are respectively the consumption of tradable and nontradable goods in country $j$ of region $i$ in period $t$, and $\nu$ captures the taste for nontradable goods. The amended budget and borrowing constraints are:

$$
\begin{gathered}
c_{T 1}^{i, j}+p_{1}^{i, j} c_{N T 1}^{i, j}+\frac{\left(1+\tau^{i}\right) c_{T 2}^{i, j}+\left(1-\eta^{i}\right) p_{2}^{i, j} c_{N T 2}^{i, j}}{r_{2}} \\
\leq-b_{1}^{i}-D_{1}^{i}+\pi_{T 1}^{i, j}+\pi_{N T 1}^{i, j}+x^{i}+\frac{D_{2}^{i, j}}{r}+\frac{\pi_{T 2}^{i, j}+\pi_{N T 2}^{i, j}+z^{i}-D_{2}^{i, j}}{r_{2}} \\
b_{2}^{i, j} \equiv r_{2}\left(c_{T 1}^{i, j}+p_{1}^{i, j} c_{N T 1}^{i, j}+b_{1}^{i}+D_{1}^{i}-\pi_{T 1}^{i, j}-\pi_{N T 1}^{i, j}-x^{i}-\frac{D_{2}^{i, j}}{r}\right) \leq \phi\left(\pi_{T 2}^{i, j}+\pi_{N T 2}^{i, j}+z^{i}\right) \\
D_{2}^{i, j} \leq \phi_{R O W}\left(\pi_{T 2}^{i, j}+z^{i}\right),
\end{gathered}
$$

where $p_{t}^{i, j}$ is the relative price of nontradable goods in country $j$ of region $i$ in period $t, \pi_{T t}^{i, j}$ and $\pi_{N T t}^{i, j}$ are respectively the profits of firms in the tradable and nontradable goods sectors in period $t, b_{t}^{i, j}$ is the inherited debt of each household in country $j$ of region $i$ at the beginning of period $t$ relative to the intra-union market (with $b_{1}^{i, j}=b_{1}^{i}$ for all $i, j$ ), $D_{t}^{i, j}$ is the inherited debt of that household at the beginning of period $t$ relative to $R O W$ (where $D_{1}^{i, j}=D_{1}^{i}$ for all $i, j), \phi \in(0,1)$ is the fraction of period-2 total income that is pledgable within the union $F$ as collateral against borrowing in period $1, \phi_{R O W} \in(0, \phi)$ is the fraction of period-2 tradable income that is pledgable to $R O W$ in period $1, x^{i}$ and $z^{i}$ are the lump-sum transfers or taxes provided by all governments in region $i$ to each household under its authority in periods 1 and 2 respectively, and $\tau^{i}$ and $\eta^{i}$ are respectively a tax on the consumption of tradable goods and a subsidy on the consumption of nontradable goods imposed by all governments in region $i$ in period 2 .

Nontradable outputs are pledgable only within the union $F$ and not to lenders in $R O W$. This assumption reflects that owing to common financial institutions within $F$, the pledgability of future outputs is likely superior within $F$ than between $F$ and $R O W$. It also clarifies the exposition: the main results below do hold even if nontradable outputs are partially pledgable to $R O W$, but the algebra is more cumbersome. Regarding household wealth, we 
assume that each household in country $j$ of region $i$ owns an equal share of the profits of all the firms within that country, but that households and firms have only an arms-length relationship: firms are not allowed to pass on borrowed resources to households.

The household's first-order conditions yield:

$$
\begin{gathered}
\left(1+\tau^{i}\right) c_{T 2}^{i, j} \geq r_{2} c_{T 1}^{i, j} \\
\nu c_{T 1}^{i, j}=p_{1}^{i, j} c_{N T 1}^{i, j} \\
\left(1+\tau^{i}\right) \nu c_{T 2}^{i, j}=\left(1-\eta^{i}\right) p_{2}^{i, j} c_{N T 2}^{i, j} \\
D_{2}^{i, j}\left\{\begin{array}{cc}
=\phi_{R O W}\left(\pi_{T 2}^{i, j}+z^{i}\right) & \text { if } r_{2}>r \text { or }(49) \text { is binding } \\
<\phi_{R O W}\left(\pi_{T 2}^{i, j}+z^{i}\right) & \text { otherwise. }
\end{array}\right.
\end{gathered}
$$

Firms. The profits of the representative firms in the tradable and nontradable sectors of country $j$ of region $i$ are:

$$
\begin{aligned}
\pi_{T 1}^{i, j} & =\left(1-\delta^{i}\right) y_{T 1}^{i, j}-r k_{T 2}^{i, j}, \text { where } y_{T 1}^{i, j}=A_{1}^{1-\alpha_{T}}\left(k_{T 0}^{i, j}\right)^{\alpha_{T}} \\
\pi_{T 2}^{i, j} & =\left(1-\xi^{i}\right) y_{T 2}^{i, j}-r k_{T 1}^{i, j}, \text { where } y_{T 2}^{i, j}=A_{2}^{1-\alpha_{T}}\left(k_{T 1}^{i, j}\right)^{\alpha_{T}} \\
\pi_{N T t}^{i, j} & =p_{t}^{i, j} y_{N T t}^{i, j}-r k_{N T, t-1}^{i, j}, \text { where } y_{N T t}^{i, j}=\left(k_{N T, t-1}^{i, j}\right)^{\alpha_{N T}},
\end{aligned}
$$

where $y_{T t}^{i, j}$ and $y_{N T t}^{i, j}$ are respectively the tradable and nontradable outputs in period $t, A_{t}^{1-\alpha_{T}}$ captures the level of tradable sector productivity in period $t, k_{T, t-1}^{i, j}$ and $k_{N T, t-1}^{i, j}$ are respectively the capital invested in the tradable and nontradable goods sectors in period $t-1$ for use in production in period $t$, and $\delta^{i}$ and $\xi^{i}$ are the taxes on the production of tradable goods in periods 1 and 2 respectively by all governments in region $i$.

In period 1, firms take capital levels $k_{T 0}^{i, j}$ and $k_{N T 0}^{i, j}$ as given (where $k_{T 0}^{i, j}=k_{T 0}^{i}$ and $k_{N T 0}^{i, j}=k_{N T 0}^{i}$ for all $\left.i, j\right)$, and they optimally select $k_{T 1}^{i, j}$ and $k_{N T 1}^{i, j}$ :

$$
\begin{gathered}
k_{T 1}^{i, j}=A_{2}\left(\frac{\left(1-\xi^{i}\right) \alpha_{T}}{r}\right)^{\frac{1}{1-\alpha_{T}}}=\frac{\left(1-\xi^{i}\right) \alpha_{T} y_{T 2}^{i, j}}{r}, \text { where } y_{T 2}^{i, j}=A_{2}\left(\frac{\left(1-\xi^{i}\right) \alpha_{T}}{r}\right)^{\frac{\alpha_{T}}{1-\alpha_{T}}} \\
k_{N T 1}^{i, j}=\left(\frac{\alpha_{N T} p_{2}^{i, j}}{r}\right)^{\frac{1}{1-\alpha_{N T}}}=\frac{\alpha_{N T} p_{2}^{i, j} y_{N T 2}^{i, j}}{r}, \text { where } y_{N T 2}^{i, j}=\left(\frac{\alpha_{N T} p_{2}^{i, j}}{r}\right)^{\frac{\alpha_{N T}}{1-\alpha_{N T}}}
\end{gathered}
$$

Government. We consider two interventions.

- Governmental loan $\left\{x^{i}, \delta^{i}, z^{i}, \xi^{i}\right\}_{i \in\{N, S\}}$ : Northern governments provide transfers to Southern governments in period 1 and get repaid in period 2, and all transfers are funded using production taxes:

$$
\left\{\begin{array}{c}
x^{S}=\delta^{N} \int_{0}^{1} y_{T 1}^{N, j} d j>0 \\
x^{N}=\delta^{S}=0
\end{array}\right\} \text { and }\left\{\begin{array}{c}
z^{N}=\xi^{S} \int_{0}^{1} y_{T 2}^{S, j} d j>0 \\
z^{S}=\xi^{N}=0
\end{array}\right\}
$$


This intervention requires governments to be able to commit to repay loans in period 2, getting around households' borrowing constraints.

- Tax-subsidy with debt relief $\left\{x^{i}, \delta^{i}, \tau^{i}, \eta^{i}\right\}_{i \in\{N, S\}}$ : Northern governments provide transfers to Southern governments in period 1 funded by production taxes, and Southern governments impose a budget-neutral combination of taxes and subsidies on consumption in period 2 :

$$
\begin{gathered}
\left\{\begin{array}{c}
x^{S}=\delta^{N} \int_{0}^{1} y_{T 1}^{N, j} d j>0 \\
x^{N}=\delta^{S}=0
\end{array}\right\} \text { and }\left\{\begin{array}{c}
\tau^{N}=\eta^{N}=0 \\
\tau^{S}, \eta^{S}>0
\end{array}\right\} \\
\text { where } \tau^{S} c_{T 2}^{S, j}=\eta^{S} p_{2}^{S, j} c_{N T 2}^{S, j} \text { for all } j .^{21}
\end{gathered}
$$

This intervention requires governments in period 1 to be able to commit to undertake specific fiscal policy actions in period 2 , but not to be able to commit to repay.

Resource constraints. Equations (60)-(62) already capture the notion of political closure, i.e., governments in $R O W$ have no influence on public transfers within the union. Our financial union is no longer financially closed to the rest of the world, but the intra-union loans market must still clear:

$$
b_{1}^{S}=-b_{1}^{N} \in\left(0,\left(b_{1}^{S}\right)^{\max }\right) \text { and } \sum_{i \in\{N, S\}} \int_{0}^{1} b_{2}^{i, j} d j=0 .
$$

where $\left(b_{1}^{S}\right)^{\max }$ is the highest value of debt consistent with non-negative Southern consumption in period 1 . The market for nontradable goods must clear within each country $j$ :

$$
c_{N T t}^{i, j}=y_{N T t}^{i, j} \text { for all } i, j, t .
$$

Combining the household budget constraint (48), production functions (55)-(57), government budget constraints (60)-(62), and market-clearing conditions (63)-(64), we establish the union-wide resource constraints on tradable goods:

$$
\begin{gathered}
\sum_{i \in\{N, S\}} \int_{0}^{1} c_{T 1}^{i, j} d j=-\left(D_{1}^{N}+D_{1}^{S}\right)+\sum_{i \in\{N, S\}}\left(A_{1}\left(k_{T 0}^{i}\right)^{\alpha_{T}}-r k_{T 0}^{i}-r k_{N T 0}^{i}\right)+\sum_{i \in\{N, S\}} \int_{0}^{1} \frac{D_{2}^{i, j}}{r} d j \\
\sum_{i \in\{N, S\}} \int_{0}^{1} c_{T 2}^{i, j} d j=-\sum_{i \in\{N, S\}} \int_{0}^{1} D_{2}^{i, j} d j+\sum_{i \in\{N, S\}} \int_{0}^{1}\left(A_{2}\left(k_{T 1}^{i, j}\right)^{\alpha_{T}}-r k_{T 1}^{i, j}-r k_{N T 1}^{i, j}\right) d j \\
\sum_{i \in\{N, S\}} \int_{0}^{1} D_{2}^{i, j} d j \leq \sum_{i \in\{N, S\}} \int_{0}^{1} \phi_{R O W}\left(A_{2}\left(k_{T 1}^{i, j}\right)^{\alpha_{T}}-r k_{T 1}^{i, j}\right) d j .
\end{gathered}
$$

${ }^{21}$ This equality is feasible because $\left\{c_{T 2}^{S, j}, p_{2}^{S, j}, c_{N T 2}^{S, j}\right\}$ turn out to be identical for all $j$ in equilibrium. 
Competitive equilibrium allocations. A rational expectations equilibrium is a set of prices and allocations $\left\{r_{2},\left\{p_{t}^{i, j}, c_{T t}^{i, j}, c_{N T t}^{i, j}, y_{T t}^{i, j}, y_{N T t}^{i, j}\right\}_{t \in\{1,2\}}, k_{T 1}^{i, j}, D_{2}^{i, j}\right\}_{i \in\{N, S\}, j \in[0,1]}$ which satisfy the households' constraints and first-order conditions (48)-(54), the production equations (55)(59), and the market-clearing conditions for the union (64)-(67), subject to the set of inherited debt levels and government policies $\left\{b_{1}^{i}, D_{1}^{i}, x^{i}, \delta^{i}, z^{i}, \xi^{i}, \tau^{i}, \eta^{i}\right\}_{i \in\{N, S\}}$ defined by (60)-(63).

As in the baseline model, the equilibrium values of all variables are identical for all countries $j$ within each region $i$, so we again suppress country superscripts in favor of regional superscripts. The amended system of equations is as follows:

$$
\begin{gathered}
\left(2+\alpha_{N T} \nu\right) c_{T 1}^{N}=\left(-B_{1}^{N}-\Phi_{T 1}^{N}\right)+\left(\frac{\phi_{R O W}}{r}+\frac{1-\phi_{R O W}}{r_{2}}\right)\left(\Pi_{2}+\Phi_{T 2}^{S}\right) \\
c_{T 1}^{S}+\left(1+\alpha_{N T}\left(\nu+\tau^{S}+\nu \tau^{S}\right)\right) \frac{c_{T 2}^{S}}{r_{2}} \\
=\left(-B_{1}^{S}+\Phi_{T 1}^{N}\right)+\left(\frac{\phi_{R O W}}{r}+\frac{1-\phi_{R O W}}{r_{2}}\right)\left(\Pi_{2}-\Delta_{T 2}^{S}\right) \\
R_{2}^{S} \equiv \frac{c_{T 2}^{S}}{c_{T 1}^{S}} \geq \frac{r_{2}}{1+\tau^{S}} \\
c_{T 1}^{S}-\phi\left(1-\alpha_{N T}\right)\left(\nu+\tau^{S}+\nu \tau^{S}\right) \frac{c_{T 2}^{S}}{r_{2}} \\
\leq\left(-B_{1}^{S}+\Phi_{T 1}^{N}\right)+\left(\frac{\phi_{R O W}}{r}+\frac{\phi}{r_{2}}\right)\left(\Pi_{2}-\Delta_{T 2}^{S}\right) \\
c_{T 1}^{N}+c_{T 1}^{S}=-\left(B_{1}^{N}+B_{1}^{S}\right)+\frac{\phi_{R O W}}{r}\left(\Pi_{2}-\Delta_{T 2}^{S}\right)+\frac{D_{2}^{N}}{r} \\
\left(1+\alpha_{N T} \nu\right) r_{2} c_{T 1}^{N}+\left(1+\alpha_{N T}\left(\nu+\tau^{S}+\nu \tau^{S}\right)\right) c_{T 2}^{S} \\
=\left(1-\phi_{R O W}\right)\left(\Pi_{2}-\Delta_{T 2}^{S}\right)+\left(\Pi_{2}+\Phi_{T 2}^{S}\right)-D_{2}^{N} \\
\Phi_{T 1}^{N} \leq\left(\Phi_{T 1}^{N}\right)^{\max }=y_{T 1}^{N} \text { and } \Phi_{T 2}^{S} \leq\left(\Phi_{T 2}^{S}\right) \phi_{R O W}^{\text {Laffer }}=\alpha_{T}^{\frac{\alpha}{1-\alpha}}\left(\Pi_{2}+\Phi_{T 2}^{S}\right) \text { and } r_{2} \geq r
\end{gathered}
$$

where $B_{1}^{i}=b_{1}^{i}+D_{1}^{i}+r k_{T 0}^{i}+r k_{N T 0}^{i}-y_{T 1}^{i}$ represents region $i$ 's inherited debts less its tradable output in period 1 (where $B_{1}^{N}+B_{1}^{S}$ is assumed to be a negative constant), $\Pi_{t}=$ $\left(1-\alpha_{T}\right) A_{t}\left(\frac{\alpha_{T}}{r}\right)^{\frac{\alpha_{T}}{1-\alpha_{T}}}$ represents the profits of tradable-sector firms in period $t$ in the absence of distortions, $\Phi_{T 1}^{i} \equiv \delta^{i} y_{T 1}^{i}$ and $\Phi_{T 2}^{i} \equiv \xi^{i} y_{T 2}^{i}$ are the revenues raised by region $i$ using taxes on tradable production in periods 1 and 2 respectively, and $\Delta_{T 2}^{S}=\Pi_{2}\left[1-\left(1-\xi^{S}\right)^{\frac{1}{1-\alpha_{T}}}\right]$ is the tax-induced reduction in Southern profits in period 2. $\left(\Phi_{T 1}^{N}\right)^{\max }=y_{T 1}^{N}$ because $\left\{k_{T 0}^{i}, k_{N T 0}^{i}\right\}_{i \in\{N, S\}}$ are exogenous. Owing to the distortive nature of the period-2 production tax, $\Delta_{T 2}^{S}$ is larger than $\Phi_{T 2}^{S}$, while the value of $\left(\Phi_{T 2}^{S}\right)^{\text {Laffer }}$ comes from the peak of the Laffer curve. Walras' Law means that one out of the equations (72) and (73) is redundant. 
There are now two sets of equations that hold with complementary slackness. The first set comprises equations (70) and (71), similarly to the baseline model. We assume that in the absence of the intra-union borrowing constraint (71), the interest rate within $F$ is strictly higher than $r$ :

$$
r_{2}^{*}=\frac{2\left(1-\phi_{R O W}\right) \Pi_{2}}{\left(1+\alpha_{N T} \nu\right)\left(-\left(B_{1}^{N}+B_{1}^{S}\right)+2 \frac{\phi_{R O W}}{r} \Pi_{2}\right)}>r .
$$

The only way that the intra-union interest rate $r_{2}$ can go below $r_{2}^{*}$, and possibly even touch $r$, is for the Southern constraint to be binding.

The second set of equations that hold with complementary slackness is given by equation (74). If $r_{2}>r$, then both North and South borrow the maximum possible from $R O W$, so $D_{2}^{N}=\phi_{R O W}\left(\Pi+\Phi_{T 2}^{S}\right)$. Our model's pattern of lending matches Chen et al. (2012): the South borrows from both the North and $R O W$, while the North lends to the South using both its own saving and also intermediated funds from $R O W$. In our model, the North earns a riskless premium $\left(r_{2}-r\right)>0$ on all the funds it intermediates from $R O W$. If $r_{2}=r$, then the Southern constraint continues to bind, implying that $D_{2}^{S}=\phi_{R O W}\left(\Pi-\Delta_{T 2}^{S}\right)$, but now $D_{2}^{N}$ lies below $\phi_{R O W}\left(\Pi+\Phi_{T 2}^{S}\right)$, and is given by the residual from equation (72).

Capital inflows from $R O W$ in period 1 allow the union as a whole to expand its tradable consumption in that period. The union's period-1 current account balance is given by:

$$
\begin{aligned}
\Psi_{1} & =\frac{1}{r}\left(B_{1}^{N}+B_{1}^{S}+y_{T 1}^{N}+y_{T 1}^{S}\right)-\frac{1}{r} \frac{\alpha_{T}}{1-\alpha_{T}}\left(2 \Pi_{2}-\Delta_{T 2}^{S}\right) \\
& -\frac{1}{r} \alpha_{N T}\left(\nu c_{T 2}^{N}+\left(\nu+\tau^{S}+\nu \tau^{S}\right) c_{T 2}^{S}\right)-\frac{1}{r}\left(\phi_{R O W}\left(\Pi_{2}-\Delta_{T 2}^{S}\right)+D_{2}^{N}\right) .
\end{aligned}
$$

The first sum in brackets is exogenous and represents the principal repayments of all inherited debts. The negative terms represent new borrowing from $R O W$ by tradable-sector firms, nontradable-sector firms, and households respectively.

\subsection{Pareto Efficiency of the Laissez-Faire Equilibrium}

First best. The first-best allocation maximizes $\sum_{i \in\{N, S\}} \int_{0}^{1} \lambda^{i, j} U^{i, j} d j$ subject to the marketclearing conditions (64)-(67) and the Pareto weights $\left\{\lambda^{i, j}=\lambda^{i}\right\}_{i \in\{N, S\}, j \in[0,1]}$, ignoring the borrowing constraint (49).

Lemma 7 (First-best allocation) Irrespective of $\left\{\lambda^{i}\right\}_{i \in\{N, S\}}$, the first-best allocation features $\frac{c_{T 2}^{i}}{c_{T 1}^{i}}=r_{2}^{*}, k_{T 1}^{i}=A_{2}\left(\frac{\alpha_{T}}{r}\right)^{\frac{1}{1-\alpha_{T}}}$, and $k_{N T 1}^{i}=\frac{\alpha_{N T} \nu c_{T 2}^{i}}{r}$ for all $i$, and the union-wide condition (67) holds with equality.

While the levels of consumption $\left\{c_{T t}^{i}\right\}_{i \in\{N, S\}, t \in\{1,2\}}$ do depend on the Pareto weights $\left\{\lambda^{i}\right\}_{i \in\{N, S\}}$, the intertemporal ratio $\frac{c_{T 2}^{i}}{c_{T 1}^{i}}$ does not. The difference from the baseline firstbest allocation is that there are now expressions for the optimal sectoral investment levels 
$\left\{k_{T 1}^{i}, k_{N T 1}^{i}\right\}_{i \in\{N, S\}}$. Each country's tradable production depends only on the $R O W$ interest rate $r$, and the resulting output is then either distributed among the regions according to the weights $\left\{\lambda^{i}\right\}_{i \in\{N, S\}}$, or repaid in interest to $R O W$. Since nontradable goods cannot be transported between countries, their production and consumption in each region depends not just on $r$ but also on $\left\{\lambda^{i}\right\}_{i \in\{N, S\}}$.

The union borrows up to its constraint from the rest of the world, which means that the period-1 current account balance $\Psi_{1}$ does not depend on the Pareto weights.

Laissez faire. The laissez-faire equilibrium follows equations (68)-(75), setting $\delta^{N}=\xi^{S}=$ $\tau^{S}=0$. The resulting allocations are indexed by $B_{1}^{S}$ (keeping the sum $B_{1}^{N}+B_{1}^{S}$ constant) and are shown by the solid lines in figure 8 . The dashed lines represent the unconstrained equilibrium, i.e., the equilibrium calculated ignoring condition (71). The unconstrained and constrained levels of tradable consumption in the South are:

$$
\begin{gathered}
c_{T 1}^{i *}=-\frac{1}{2+\alpha_{N T} \nu}\left(B_{1}^{i}+\frac{\left(1+\alpha_{N T} \nu\right)\left(B_{1}^{N}+B_{1}^{S}\right)}{2}\right)+\frac{\phi_{R O W}}{r} \Pi_{2} \text { and } c_{T 2}^{i *}=r_{2}^{*} c_{T 1}^{i *} \text { for all } i \\
c_{T 1}^{S, C}=\left\{\begin{array}{cc}
c_{T 1}^{S *} & \text { for } B_{1}^{S} \in\left[0, \bar{B}_{1}^{S}\right] \\
-\omega_{1} B_{1}^{S}-\omega_{2}\left(B_{1}^{N}+B_{1}^{S}\right)+\omega_{3} \frac{\phi_{R O W}}{r} \Pi_{2} & \text { for } B_{1}^{S} \in\left(\bar{B}_{1}^{S}, B_{1}^{S, r}\right) \\
-B_{1}^{S}+\frac{\phi_{R O W}+\phi}{r} \Pi_{2}+\phi\left(1-\alpha_{N T}\right) \nu \frac{\bar{c}_{T 2}^{S}}{r} & \text { for } B_{1}^{S} \geq B_{1}^{S, r}
\end{array}\right. \\
\text { and } c_{T 2}^{S, C}=\left\{\begin{array}{cc}
c_{T 2}^{S *} & \text { for } B_{1}^{S} \in\left[0, \bar{B}_{1}^{S}\right] \\
\bar{c}_{T 2}^{S} & \text { for } B_{1}^{S}>\bar{B}_{1}^{S},
\end{array}\right.
\end{gathered}
$$

where $\left\{\omega_{k}\right\}_{k \in\{1,2,3\}}>0, \omega_{1} \in\left(\frac{1}{2+\alpha_{N T} \nu}, 1\right), \bar{c}_{T 2}^{S}=\frac{\left(1-\phi_{R O W}-\phi\right) \Pi_{2}}{1+\left(\alpha_{N T}+\phi\left(1-\alpha_{N T}\right)\right) \nu}$, and there exist $\bar{B}_{1}^{S}$ and $B_{1}^{S, r}$ satisfying $B_{1}^{S, r}>\bar{B}_{1}^{S}>0$ (we assume that $r$ is below $r_{2}^{*}$, as stated above, but also high enough so that $c_{T 1}^{S, C}$ does not go to zero to the left of $\left.B_{1}^{S}=B_{1}^{S, r}\right)$. The equilibrium is defined up to $\left(B_{1}^{S}\right)^{\max }=\frac{\phi_{R O W}\left(1+\alpha_{N T} \nu\right)+\phi(1+\nu)}{1+\left(\alpha_{N T}+\phi\left(1-\alpha_{N T}\right)\right) \nu} \frac{\Pi_{2}}{r}$, which also implicitly defines $\left(b_{1}^{S}\right)^{\text {max }}$.

Panels I and III of figure 8 illustrate that the constraint becomes binding when $B_{1}^{S}>\bar{B}_{1}^{S}$. Panel II shows that as in the baseline model, $r_{2}$ and $R_{2}^{S}$ diverge for $B_{1}^{S}>\bar{B}_{1}^{S}$. The difference from the baseline model is that for $B_{1}^{S} \geq B_{1}^{S, r}$, the intra-union interest rate $r_{2}$ cannot decline below $r$ without leading to unlimited capital outflows from $F$ to $R O W$, so instead it stays fixed at $r$. Since the decline in $r_{2}$ as $B_{1}^{S}$ increases within $\left(\bar{B}_{1}^{S}, B_{1}^{S, r}\right)$ cushions Southern consumption from the tightening constraint, the absence of a continued interest rate decline means that $c_{T 1}^{S, C}$ falls more steeply with $B_{1}^{S}$ when $B_{1}^{S} \geq B_{1}^{S, r}$ (i.e., the slope magnitude 1 is greater than $\omega_{1}$ ), and $R_{2}^{S}$ increases more steeply as a result.

Panel IV compares the constrained regional welfares $\left\{U^{i, j}=U^{i}\right\}_{i \in\{N, S\}, j \in[0,1]}$ to their unconstrained levels $\left\{U^{i *}\right\}_{i \in\{N, S\}}$. While the relative behavior of the graphs mostly echoes the baseline model, there is a difference for $B_{1}^{S} \geq B_{1}^{S, r}$ : since $r_{2}$ is fixed and can play no cushioning effect for these high debt levels, constrained Southern welfare falls more steeply 
with $B_{1}^{S}$ while Northern welfare increases more steeply. Therefore, the graphs for both regions have a kink at $B_{1}^{S}=B_{1}^{S, r}$.

Panels V and VI illustrate the behavior of variables which are important in our generalized model but were missing from the baseline model. Panel V shows the Southern tradable and nontradable outputs in period 2, which are determined by the corresponding period-1 investment levels, $k_{T 1}^{i}=A_{2}\left(\frac{\alpha_{T}}{r}\right)^{\frac{1}{1-\alpha_{T}}}$ and $k_{N T 1}^{i}=\frac{\alpha_{N T} \nu c_{T 2}^{i}}{r}$ for all $i$. Tradable production does not vary with $B_{1}^{S}$, while nontradable production moves in line with the value of $c_{T 2}^{S}$ from panel I. Panel VI shows the period-1 current account position of the union, which is flat for $B_{1}^{S} \in\left[0, B_{1}^{S, r}\right]$ but increases when $B_{1}^{S}>B_{1}^{S, r}$. In the latter region, the North chooses to borrow less from $R O W$ than its borrowing constraint allows, so tradable consumption inside the union declines. Even though the union as a whole is able to borrow more from $R O W$, and the South values consumption highly at the margin, the North does not intermediate funds from $R O W$ to the South because the latter region is borrowing-constrained in the intra-union loans market and cannot absorb more funds.

The above results are summarized in the proposition below.

Proposition 6 (Laissez-faire equilibrium) The laissez-faire equilibrium is a first-best allocation for some Pareto weights $\left\{\lambda^{i}\right\}_{i \in\{N, S\}}$ when $B_{1}^{S} \in\left[0, \bar{B}_{1}^{S}\right]$, but lies in the interior of the first-best frontier when $B_{1}^{S}>\bar{B}_{1}^{S}$. In the latter region, $c_{T 2}^{S, C}=\bar{c}_{T 2}^{S}$ and $R_{2}^{S}>r_{2}^{*}>r_{2} . \Psi_{1}$ is flat for $B_{1}^{S} \in\left[0, B_{1}^{S, r}\right]$, but $\frac{d \Psi_{1}}{d B_{1}^{S}}=\frac{1}{2+\alpha_{N T} \nu}>0$ when $B_{1}^{S}>B_{1}^{S, r}$. There exists $\widehat{B}_{1}^{S}<\left(B_{1}^{S}\right)^{\max }$ such that welfare levels follow:

$$
U^{N}\left\{\begin{array} { c c } 
{ = U ^ { N * } } & { \text { for } B _ { 1 } ^ { S } \in [ 0 , \overline { B } _ { 1 } ^ { S } ] } \\
{ < U ^ { N * } } & { \text { for } B _ { 1 } ^ { S } > \overline { B } _ { 1 } ^ { S } }
\end{array} \quad \text { and } U ^ { S } \left\{\begin{array}{cc}
=U^{S *} & \text { for } B_{1}^{S} \in\left[0, \bar{B}_{1}^{S}\right] \\
>U^{S *} & \text { for } B_{1}^{S} \in\left(\bar{B}_{1}^{S}, \widehat{B}_{1}^{S}\right) \\
<U^{S *} & \text { for } B_{1}^{S}>\widehat{B}_{1}^{S},
\end{array}\right.\right.
$$

where $\widehat{B}_{1}^{S}<B_{1}^{S, r}$ iff $r$ is sufficiently low. Define $U^{i, C F}$ as the counterfactual welfare for region $i$ when we use equations (68)-(75) and fix $D_{2}^{N}=\phi_{R O W}\left(\Pi+\Phi_{T 2}^{S}\right)$, even if the result of doing so is the infeasible configuration of interest rates $r_{2}<r$. Then for $B_{1}^{S}>B_{1}^{S, r}$, $U^{N}>U^{N, C F}$ and $U^{S}<U^{S, C F}$.

\subsection{Pareto-improving Interventions}

Echoing our approach for the baseline model, we start at a constrained equilibrium, i.e., $B_{1}^{S}>\bar{B}_{1}^{S}$, and select policy tools $\left\{\delta^{N}, \xi^{S}, \tau^{S}\right\}$ to maximize the Nash product (28) subject to equations (68)-(75). We again assume that all the governments within each region $i$ bargain as a coalition, with bargaining powers satisfying $\gamma^{N}=1-\gamma^{S} \in[0,1]$.

The impact of small changes in the interventions can be analyzed using the same steps as in the baseline model. We analyze the configuration $B_{1}^{S} \in\left(\bar{B}_{1}^{S}, B_{1}^{S, r}\right]$ to begin with and return later to $B_{1}^{S}>B_{1}^{S, r}$. In order to focus in this section on those results that are new relative to the baseline model, let us go straight to the expression for the Pareto gains: 


$$
\begin{aligned}
& \left.d U^{i}\left(\delta^{N}, \xi^{S}, \tau^{S}\right)\right|_{d U^{-i}\left(\delta^{N}, \xi^{S}, \tau^{S}\right)=0} \\
& =\frac{1}{c_{T 1}^{i}} \frac{1}{r_{2}}\left(1-\frac{r_{2}}{R_{2}^{S}} \frac{1+\alpha_{N T} \nu}{1+\alpha_{N T}\left(\nu+\tau^{S}+\nu \tau^{S}\right)}\right) \frac{\left(1-\phi_{R O W}-\phi\right)\left(1+\alpha_{N T}\left(\nu+\tau^{S}+\nu \tau^{S}\right)\right)}{1+\left(\alpha_{N T}+\phi\left(1-\alpha_{N T}\right)\right)\left(\nu+\tau^{S}+\nu \tau^{S}\right)} d \Phi_{T 2}^{S} \\
& -\frac{1}{c_{T 1}^{i}} \frac{1}{r_{2}}\left(-\left(1-\frac{r_{2}}{R_{2}^{S}} \frac{\left.\left.1+\alpha_{R O W} \frac{r_{2}}{1+\alpha_{N T}\left(\nu+\tau^{S}+\nu \tau^{S}\right)}\right) \frac{\left(1-\phi_{R O W}-\phi\right)\left(1+\alpha_{N T}\left(\nu+\tau^{S}+\nu \tau^{S}\right)\right)}{1+\left(\alpha_{N T}+\phi\left(1-\alpha_{N T}\right)\right)\left(\nu+\tau^{S}+\nu \tau^{S}\right)}\right) \frac{\xi^{S} \alpha_{T}}{1-\xi^{S}-\alpha_{T}} d \Phi_{T 2}^{S}}{-}-\frac{c_{T 2}^{S} \phi(1+\nu)\left(1-\alpha_{N T}\right)}{c_{T 1}^{i}} \frac{1}{r_{2}}\left(1-\frac{r_{2}}{R_{2}^{S}} \frac{1+\alpha_{N T} \nu}{1+\alpha_{N T}\left(\nu+\tau^{S}+\nu \tau^{S}\right)}\right) \frac{1+\left(\alpha_{N T}+\phi\left(1-\alpha_{N T}\right)\right)\left(\nu+\tau^{S}+\nu \tau^{S}\right)}{1+\alpha_{N T} \nu}\right.\right. \\
& -\frac{c_{T 1}^{S}}{c_{T 1}^{i}} \alpha_{N T}(1+\nu)\left(\frac{\nu}{1+\alpha_{N T}\left(\nu+\tau^{S}+\nu \tau^{S}\right)}-\frac{\nu}{\nu+\tau^{S}+\nu \tau^{S}}\right) d \tau^{S}
\end{aligned}
$$

where $d \Phi_{T 1}^{N}$ has been set to satisfy $d U^{-i}\left(\delta^{N}, \xi^{S}, \tau^{S}\right)=0$ conditional on arbitrary values of $\left\{d \Phi_{T 2}^{S}=\frac{1-\xi^{S}-\alpha_{T}}{\left(1-\xi^{S}\right)\left(1-\alpha_{T}\right)} y_{T 2}^{S} d \xi^{S}, d \tau^{S}\right\}$. At the laissez-faire equilibrium, $R_{2}^{S}>r_{2}$ and $\delta^{N}=\xi^{S}=$ $\tau^{S}=0$, so there are positive Pareto gains from regional bargaining and interventions.

In the baseline model, regional bargaining was able to achieve allocations on the first-best frontier: interventions reduced $R_{2}^{S}$ and increased $r_{2}$ until they eliminated the intertemporal distortion arising from the borrowing constraint. In our more elaborate financial union, only distortive interventions are available, so the interventions generate new intratemporal distortions as they mitigate the existing intertemporal distortions.

In the above expression, the two terms indexed by $d \Phi_{T 2}^{S}$ capture the effects of the governmental loan. The first term indicates a reduction in the intertemporal distortion similar to that in the baseline model, but the second term is negative, indicating that the tax-induced decrease in period-2 Southern tradable output hurts union-wide consumption and welfare. The two terms indexed by $d \tau^{S}$ capture the effects of the tax-subsidy intervention with debt relief. The first term indicates a reduction in the intertemporal distortion similar to that in the baseline model, but the second term is negative, indicating that the tax-induced increase in period-2 Southern nontradable output hurts union-wide welfare. The welfare benefits from the additional Southern consumption of nontradable goods fall short of the welfare losses owing to higher repayments to $R O W$ by Southern nontradable-sector firms.

Distortive interventions are not used all the way until the intertemporal distortion is eliminated, but rather until the marginal reduction in the constraint-induced intertemporal distortion is equal to the marginal increase in the policy-induced intratemporal distortion. Therefore, regional bargaining is no longer able to bring the union to the first-best frontier, and it traces out a second-best frontier instead. ${ }^{22}$

Figure 9 illustrates the effects of Pareto-improving interventions for $B_{1}^{S} \in\left(\bar{B}_{1}^{S}, B_{1}^{S, r}\right]$, with the governmental loan indexed by $\Phi_{T 2}^{S}$, and the tax-subsidy intervention with debt relief indexed by $\tau^{S}$. The qualitative effects of these interventions in panels I through IV are similar

\footnotetext{
${ }^{22}$ The desire to equalize the marginal changes in the intertemporal and intratemporal distortions means that the condition $\Phi_{T 2}^{S} \leq\left(\Phi_{T 2}^{S}\right)^{\text {Laffer }}$ never binds. On the other hand, the condition $\Phi_{T 1}^{N} \leq\left(\Phi_{T 1}^{N}\right)^{\max }$ may bind - and if it does so, the first-best frontier goes further out of reach.
} 
to those in the baseline model, but the Pareto-efficient magnitudes of both interventions are smaller owing to the distortions that they generate.

The new results from our extended model are shown in panels V and VI. The interventions now affect period- 2 output, because firms base their period- 1 investment decisions on period- 2 taxes and prices. The governmental loan reduces Southern tradable and nontradable output, while the tax-subsidy intervention with debt relief increases Southern nontradable output:

$$
\frac{d y_{T 2}^{S}}{d \Phi_{T 2}^{S}}<0, \frac{d y_{N T 2}^{S}}{d \Phi_{T 2}^{S}}<0 \text { and } \frac{d y_{T 2}^{S}}{d \tau^{S}}=0, \frac{d y_{N T 2}^{S}}{d \tau^{S}}>0
$$

The interventions have opposite effects on the current account balance. The governmental loan causes the balance to increase toward surplus, because it reduces period-1 borrowing: the reduction in Southern period-2 tradable output tightens the borrowing constraint of Southern households, while the reduction in tradable and nontradable output in the South reflects lower investment by Southern firms in both sectors. The tax-subsidy intervention causes the current account balance to decrease toward deficit, because the higher $p_{2}^{S}$ generates higher investment by Southern nontradable-sector firms. Summarizing these results:

$$
\frac{d \Psi_{1}}{d \Phi_{T 2}^{S}}>0 \text { and } \frac{d \Psi_{1}}{d \tau^{S}}<0
$$

The Pareto gain expression above continues to apply for the configuration $B_{1}^{S}>B_{1}^{S, r}$, if we set $r_{2}=r$. The qualitative results in figure 9 also continue to apply, with two exceptions. Firstly, the interest rate $r_{2}$ remains fixed at $r$ instead of increasing at the beginning of the interventions. As we increase the size of the interventions, it is possible - but not certainthat $r_{2}$ eventually rises above $r$. Secondly, when $B_{1}^{S}>B_{1}^{S, r}$, the laissez-faire current account balance is higher than the first-best level, which in turn may alter the sign of $\frac{d \Psi_{1}}{d \Phi_{T 2}^{S}}$ from positive to negative for small values of the governmental loan. The reason is that this intervention causes the North to borrow more from $R O W$ in order to pass on the capital flows, packaged as governmental loans, to the South.

The above results are summarized in the proposition below, which characterizes the outcome of regional bargaining when only distortive interventions are available.

Proposition 7 (Second-best frontier) When $B_{1}^{S}>\bar{B}_{1}^{S}$, each intervention achieves a Pareto improvement relative to the laissez-faire equilibrium, but each has different effects on $\left\{y_{T 2}^{S}, y_{N T 2}^{S}, \Psi_{1}\right\}$. Bargaining between North and South achieves an allocation on the secondbest frontier, defined by the condition $\left.d U^{i}\left(\delta^{N}, \xi^{S}, \tau^{S}\right)\right|_{d U^{-i}\left(\delta^{N}, \xi^{S}, \tau^{S}\right)=0}=0$ for $i \in\{N, S\}$. If both interventions are available, then both are used at the frontier, i.e., $\xi^{S}>0$ and $\tau^{S}>0$. The condition $\Phi_{T 2}^{S} \leq\left(\Phi_{T 2}^{S}\right)^{\text {Laffer }}$ never binds, but the condition $\Phi_{T 1}^{N} \leq\left(\Phi_{T 1}^{N}\right)^{\max }$ may do so.

Combining the interventions. The availability of the two distortive interventions depends on different political factors: the governmental loan depends on the ability of the South 
to commit to repay, while the tax-subsidy intervention requires the North to offer up-front debt relief. If only one out of the two interventions is available, then that is what regional bargaining should focus on. However, if both interventions are available, then both should be used. Each marginal reduction in the intertemporal distortion is less costly in terms of marginal intratemporal distortions if the latter distortions are spread out throughout the economy, rather than focused on one sector.

Deviating from the second-best combination of interventions reduces the welfare gains for both North and South, as Pareto gains remain unexploited. Excessive use of the governmental loan causes an excessive reduction in Southern tradable output in period 2, and an excessively large union-wide current account surplus in period 1. Excessive use of the taxsubsidy intervention with debt relief causes an excessive stimulus to Southern nontradable output in period 2, and an excessively large union-wide current account deficit in period 1.

\subsection{The Environment for Period $t=0$}

Having shown that the potential for Pareto improvements during $t \in\{1,2\}$ carries over from our baseline model to our more elaborate financial union, we next explore whether regional bargaining during crises continues to be Pareto-improving from the pre-crisis perspective, as it was in the baseline model under some conditions.

Echoing the approach in section 3.1, we again add a pre-crisis period labeled as $t=0$, but there are two differences. Firstly, there is a unit measure of firms in each of the tradable and nontradable sectors which invest capital in period 0 to produce output in period 1. Secondly, in addition to the intra-union loans market with interest rate $r_{1}$, loans from $R O W$ are available at interest rate $r \leq r_{1}$. As in section 4.1, households face borrowing constraints, while firms do not.

Households. The representative household in country $j$ of region $i$ has the amended $\log$ preferences:

$$
V^{i, j}=\left(\log c_{T,-1}^{i, j}+\nu \log c_{N T,-1}^{i, j}\right)+\left(\log c_{T 0}^{i, j}+\nu \log c_{N T 0}^{i, j}\right)+U^{i, j}
$$

where $c_{T t}^{i, j}$ and $c_{N T t}^{i, j}$ are respectively the consumption of tradable and nontradable goods in country $j$ of region $i$ in period $t$, and $U^{i, j}$ follows equation (47). The new equations for household debt and the borrowing constraint are:

$$
\begin{gathered}
b_{1}^{i, j} \equiv r_{1}\left(c_{T 0}^{i, j}+p_{0}^{i, j} c_{N T 0}^{i, j}-e^{i, j}-p_{0}^{i, j} y_{N T 0}-\frac{D_{1}^{i, j}}{r}\right) \\
D_{1}^{i, j} \leq \phi_{R O W}\left(\pi_{T 1}^{i, j}+x^{i, j}\right),
\end{gathered}
$$

where $e^{i, j}$ is the tradable endowment of each household in country $j$ of region $i$ in period 0 (with $e^{i, j}=e^{i}$ for all $j$ ), $y_{N T 0}$ is the nontradable endowment common to all countries in

period $0, p_{0}^{i, j}$ is the price of nontradable goods in country $j$ of region $i$ in period 0 , and the 
other variables are as defined in section 4.1. The equations (48)-(50) continue to apply.

In addition to the conditions (51)-(54), the household's consumption choices now also satisfy the following conditions for period 0 :

$$
\begin{gathered}
c_{T 1}^{i, j}=r_{1}^{i, j} c_{T 0}^{i, j} \\
\nu c_{T 0}^{i, j}=p_{0}^{i, j} c_{N T 0}^{i, j},
\end{gathered}
$$

while equation (81) holds with equality.

Firms. The period-1 profits of the representative firms in the tradable and nontradable sectors are given by equations (55) and (57). Therefore, the period-0 investment decisions take the following form:

$$
\begin{gathered}
k_{T 0}^{i, j}=A_{1}\left(\frac{\left(1-\delta^{i}\right) \alpha_{T}}{r}\right)^{\frac{1}{1-\alpha_{T}}}=\frac{\left(1-\delta^{i}\right) \alpha_{T} y_{T 1}^{i, j}}{r}, \text { where } y_{T 1}^{i, j}=A_{1}\left(\frac{\left(1-\delta^{i}\right) \alpha_{T}}{r}\right)^{\frac{\alpha_{T}}{1-\alpha_{T}}} \\
k_{N T 0}^{i, j}=\left(\frac{\alpha_{N T} p_{1}^{i, j}}{r}\right)^{\frac{1}{1-\alpha_{N T}}}=\frac{\alpha_{N T} p_{1}^{i, j} y_{N T 1}^{i, j}}{r}, \text { where } y_{N T 1}^{i, j}=\left(\frac{\alpha_{N T} p_{1}^{i, j}}{r}\right)^{\frac{\alpha_{N T}}{1-\alpha_{N T}}} .
\end{gathered}
$$

Resource constraints. The additional market-clearing conditions for the union are:

$$
\begin{gathered}
c_{N T 0}^{i, j}=y_{N T 0} \text { for all } i, j \\
\sum_{i \in\{N, S\}} \int_{0}^{1} c_{T 0}^{i, j} d j=e^{T}+\sum_{i \in\{N, S\}} \int_{0}^{1} \frac{D_{1}^{i, j}}{r} d j \\
\sum_{i \in\{N, S\}} \int_{0}^{1} D_{1}^{i, j} d j \leq \sum_{i \in\{N, S\}} \int_{0}^{1} \phi_{R O W}\left(A_{1}\left(k_{T 0}^{i, j}\right)^{\alpha_{T}}-r k_{T 0}^{i, j}\right) d j
\end{gathered}
$$

where $e^{T} \equiv \sum_{i \in\{N, S\}} \int_{0}^{1} e^{i, j} d j$ is the total period-0 tradable endowment within the union. As in section 3.1, we assume that $e^{S} \in\left[0, \frac{e^{T}}{2}\right]$, and we define $H \equiv \frac{e^{N}-e^{S}}{e^{T}}=1-2 \frac{e^{S}}{e^{T}} \in[0,1]$.

Competitive equilibrium allocations. Building on the definition of the rational expectations equilibrium in section 4.1, we expand the set of prices and allocations to include $\left\{r_{0}, p_{0}^{i, j}, c_{T 0}^{i, j}, c_{N T 0}^{i, j}, k_{T 0}^{i, j}, D_{1}^{i, j}\right\}_{i \in\{N, S\}, j \in[0,1]}$, and we expand the set of equilibrium conditions to include equations (80)-(88). We solve the system of equations subject to the degree of heterogeneity $H$ and the government policies $\left\{x^{i}, \delta^{i}, z^{i}, \xi^{i}, \tau^{i}, \eta^{i}\right\}_{i \in\{N, S\}}$ defined by (60)-(62).

Again suppressing country superscripts in favor of regional superscripts, we can solve for the tradable consumption levels in period 0 and the implied levels of household debt:

$$
\begin{gathered}
c_{T 0}^{i}=\frac{c_{T 1}^{i}}{r_{1}} \text { for all } i \\
b_{1}^{S}=c_{T 1}^{S}-r_{1}\left[\frac{e^{T}}{2}(1-H)+\frac{\phi_{R O W}}{r}\left(\Pi_{1}+\Phi_{T 1}^{N}\right)\right]=-b_{1}^{N} .
\end{gathered}
$$


Combining these expressions with the firms' optimization conditions and the union's resource constraints, we derive the formulae for $B_{1}^{S}$ and $B_{1}^{N}+B_{1}^{S}$ :

$$
\begin{gathered}
B_{1}^{S}=\left(1+\alpha_{N T} \nu\right) c_{T 1}^{S}-r_{1} \frac{e^{T}}{2}(1-H)-\phi_{R O W}\left(\frac{r_{1}}{r}-1\right)\left(\Pi_{1}+\Phi_{T 1}^{N}\right)-\Pi_{1} \\
B_{1}^{S}+B_{1}^{N}=\alpha_{N T} \nu\left(c_{T 1}^{S}+c_{T 1}^{N}\right)-\left(1-\phi_{R O W}\right)\left(2 \Pi_{1}-\Delta_{T 1}^{N}+\Phi_{T 1}^{N}\right), \\
\text { where } r_{1}=\frac{c_{T 1}^{S}+c_{T 1}^{N}}{e^{T}+\frac{\phi_{R O W}}{r}\left(2 \Pi_{1}-\Delta_{T 1}^{N}+\Phi_{T 1}^{N}\right)} \text { and } \Phi_{T 1}^{N} \leq\left(\Phi_{T 1}^{N}\right)^{\text {Laffer }}=\alpha_{T}^{\frac{\alpha_{T}}{1-\alpha_{T}}} \Pi_{1} .
\end{gathered}
$$

Therefore, the union-wide equilibrium can be reduced to the set of prices and allocations $\left\{r_{2}, p_{2}^{S}, c_{T 1}^{S}, c_{T 2}^{S}, c_{T 1}^{N}, D_{2}^{N}\right\}$ as a function of $\left\{H, \delta^{N}, \xi^{S}, \tau^{S}\right\}$, subject to the equations (68)-(74) and (89)-(91). The new limit $\left(\Phi_{T 1}^{N}\right)^{\text {Laffer }}$ allows period-0 investment to adjust according to expectations of the period-1 production tax, so $\Phi_{T 1}^{N} \leq\left(\Phi_{T 1}^{N}\right)^{\text {Laffer }}$ is a tighter condition than $\Phi_{T 1}^{N} \leq\left(\Phi_{T 1}^{N}\right)^{\max }$.

Using the amended system of equations, we find that the borrowing constraint of Southern households becomes binding when the degree of pre-crisis heterogeneity is high:

$$
\begin{aligned}
H & >\bar{H}=\left(3+2 \alpha_{N T} \nu\right)\left(1+\frac{\phi_{R O W}}{r} \frac{2 \Pi_{1}}{e^{T}}\right) \frac{\phi\left(1+\left(\alpha_{N T}+\left(1-\phi_{R O W}\right)\left(1-\alpha_{N T}\right)\right) \nu\right)}{\left(1-\phi_{R O W}\right)\left(1+\left(\alpha_{N T}+\phi\left(1-\alpha_{N T}\right)\right) \nu\right)} \\
& \Leftrightarrow B_{1}^{S}>\bar{B}_{1}^{S} .
\end{aligned}
$$

For $H \in(\bar{H}, 1]$, the laissez-faire equilibrium lies strictly in the interior of the first-best frontier, and the question of whether to allow crisis-time intervention becomes relevant. For

very high values of $H$, the condition $\Phi_{T 1}^{N} \leq\left(\Phi_{T 1}^{N}\right)^{\text {Laffer }}$ may bind, because large interventions are chosen in periods $t \in\{0,1\}$ to combat the large intertemporal distortions afflicting the union under laissez-faire.

Institutional design. As in section 3.1, regional coalitions of Northern and Southern governments must decide at the beginning of period 0 on the values of $I \in\{0,1\}$ and $\gamma^{N} \in[0,1]$. As the above equations make clear, the expectation of intervention affects the optimization conditions for households and firms in period 0, so the choice of $\left\{I, \gamma^{N}\right\}$ helps to determine the equilibrium levels of $B_{1}^{S}$ and $B_{1}^{S}+B_{1}^{N}$ for any given value of $H$. For $I=0$, no crisis-time interventions are allowed; for $I=1$, regional coalitions bargain in period 1 over unlimited interventions $\left\{\delta^{N}, \xi^{S}, \tau^{S}\right\}$, while taking $B_{1}^{S}$ and $\gamma^{N}$ as given.

\subsection{Pareto-improving Institutional Design}

An advantage of our baseline model was that we could derive closed-form solutions for final allocations as a function of the pre-crisis degree of heterogeneity $H$ and the choice of $\left\{I, \gamma^{N}\right\}$. Therefore, in section 3.3, we were able to analytically prove that regional bargaining during crises was Pareto-improving from the pre-crisis perspective for some values of $H$ and $\gamma^{N}$. In our more elaborate financial union, the second-best nature of the post-intervention frontier 
means that we cannot derive closed-form solutions for all the final allocations, so for the analysis of pre-crisis welfare changes, we go straight to illustrative simulations.

Our simulations are designed to demonstrate the existence of Pareto improvements from the pre-crisis perspective, not to approximate any specific real-world financial union. To construct figures 10 and 11, we have chosen parameters to facilitate comparisons to the proofs and graphs from section 3.3. ${ }^{23}$ We plot the unconstrained allocation, the constrained laissez-faire allocation (corresponding to $I=0$ ), and then the post-intervention allocations (corresponding to $I=1$ ) for two values of the bargaining parameter, $\gamma^{N}=0$ and $\gamma^{N}=1$. We focus on a union with enough pre-crisis heterogeneity that the Southern borrowing constraint is expected to bind, i.e., $H>\bar{H}=0.28$.

Figure 10 illustrates how the level of $B_{1}^{S}$ and regional welfares change as we move from the unconstrained allocation to the constrained laissez-faire allocation. Panel I shows that the expectation of the binding Southern borrowing constraint reduces the level of $B_{1}^{S}$, because Southern households consume less and nontradable-sector firms invest less when they expect lower tradable and nontradable consumption in period 1.

Panel II plots the change in regional welfares, $\left\{V^{i}-V^{i *}\right\}_{i \in\{N, S\}}$. The numerical findings from our elaborate financial union follow closely the predictions of proposition 4 from the baseline model. When $H$ is such that the constraint is just binding, the constraint benefits the South and hurts the North because it tilts the "intertemporal terms of trade" in favor of the former; but when $H$ is larger, the constraint hurts the South as well, because the intertemporal transfer of consumption away from period 1 becomes more and more painful.

Figure 11 focuses on how union-wide allocations change when crisis-time bargaining is allowed. Panel I shows that the expectation of intervention increases $B_{1}^{S}$ above its laissez-faire level, because the increase in Southern consumption in period 1 stimulates higher Southern consumption and nontradable-sector investment in the previous period as well. The postintervention level of $B_{1}^{S}$ is higher when the South expects to have more bargaining power in crisis-time bargaining.

As in the baseline model, the union-wide sum of the inherited debts of households, $b_{1}^{S}+b_{1}^{N}$, is equal to zero. However, equations (72) and (90) establish that in our more elaborate financial union, the sum $B_{1}^{S}+B_{1}^{N}$ changes in response to expected interventions, because the interventions generate distortions to tradable output in periods 1 and 2 . Period- 1 distortions reduce both of the terms in equation (90), while period-2 distortions reduce only the first term. Panel II of figure 11 shows that for our chosen parameters, the post-intervention value of $B_{1}^{S}+B_{1}^{N}$ increases above its laissez-faire level. Therefore, the impact of period-1 distortions on the second term of equation (90) turns out to be the dominant influence.

\footnotetext{
${ }^{23}$ The parameters are: $\phi=0.05, \phi_{R O W}=0.01, \alpha_{T}=0.5, \alpha_{N T}=0.2, \nu=1, r=1, e^{T}=0.5, A_{1}=2$, and $A_{2}=4$. Therefore, $\Pi_{1}=0.5, \Pi_{2}=1, \bar{H}=0.28$, and the unconstrained interest rates are $r_{1}^{*}=1.96$ and $r_{2}^{*}=1.65$. Our simulation strategy is: (i) firstly, for any $B_{1}^{S}$ and $B_{1}^{S}+B_{1}^{N}$, find the unconstrained allocation, the constrained allocation, and the two post-intervention allocations indexed by $\left\{d U^{i}=0\right\}_{i \in\{N, S\}}$, the latter drawing on the proof of proposition 7 ; and (ii) secondly, endogenize both $B_{1}^{S}$ and $B_{1}^{S}+B_{1}^{N}$ for a given $H$.
} 
Finally, panels III and IV demonstrate that for some parameter configurations, Pareto improvements may exist from the pre-crisis perspective. The lines in these panels show the change in regional welfares from the laissez-faire allocation to the post-intervention al-

locations, $\left\{V^{i, \gamma^{N}}-V^{i}\right\}_{i \in\{N, S\}, \gamma^{N} \in\{0,1\}}$. Relative to the baseline model, our more elaborate financial union has new economic mechanisms in action. The interventions generate distortions in tradable and nontradable output in periods 1 and 2, which affect investment levels as well as the pledgability of union-wide output to $R O W$ in periods 0 and 1 . In addition, welfare gains from the pre-crisis perspective are hampered by the fact that period-1 distortions are not taken into account during regional bargaining in period 1, because that bargaining process treats $\left\{k_{T 0}^{i}, k_{N T 0}^{i}\right\}_{i \in\{N, S\}}$ as exogenous.

Nevertheless, for our chosen parameters, our numerical findings yield no surprises relative to the baseline model, and in fact the results from our more elaborate financial union are best understood by comparing them to proposition 5 and figure $7 . V^{S, \gamma^{N}=0}$ always lies above the laissez-faire level $V^{S}$, while $V^{S, \gamma^{N}=1}$ lies above $V^{S}$ for $H \in\left(\bar{H}=0.28, H_{2}=0.80\right]$. $V^{N, \gamma^{N}=0}$ lies everywhere below the laissez-faire level $V^{N}$, while $V^{N, \gamma^{N}=1} \operatorname{dips}$ below $V^{N}$ for $H \in\left(\bar{H}=0.28, H_{1}=0.43\right)$ and then exceeds $V^{N}$ for $H \in\left(H_{1}=0.43,1\right]$. Therefore, in our more elaborate financial union, there exist values of $H$ and $\gamma^{N}$ such that regional bargaining during crises continues to be Pareto-improving from the pre-crisis perspective.

\section{Conclusion}

The financial integration of heterogenous regions of countries generates novel economic problems. Over and above the risk-sharing concerns that lay at the heart of the literature on optimal currency areas, we need to think about designing institutions which facilitate the efficient flow of capital from the core to the periphery, and which mitigate the financial crises that arise when the flows turn out to have been misdirected and/or excessive. Waves of financial integration mediated by asymmetric debt flows are especially subject to sudden stops when financial frictions bind, and lessons from the emerging markets literature may become surprisingly relevant - and indeed exacerbated via an endogenous interest rate - even if the member countries of the union are all advanced. The key element is that the institutions to efficiently manage capital flows may exist within but not between such countries, both because the cross-border flows are new and because political sovereignty constraints limit the creation of supranational entities until crises occur.

We have designed a model with the above environment in mind. We identify two interventions - governmental loans and/or tax-subsidy packages with debt relief - which could be used to tackle union-wide financial imperfections, going beyond the standard toolkit of monetary and fiscal policies. We focus on generating Pareto improvements so as to respect political sovereignty constraints. We analyze changes in pre-crisis welfare as well, so as to address the real fear that crisis-time bargaining may generate pre-crisis overborrowing; we

CInternational Monetary Fund. Not for Redistribution 
find that such concerns are dominated by the size of crisis-time Pareto gains when the degree of heterogeneity of the financial union is sufficiently high.

Our baseline model and more elaborate financial union provide complementary messages. The baseline model captures our fundamental mechanisms while being simple enough to generate all final allocations, with and without intervention, in closed form. As a result, we are able to prove all of our main results and trace through all the relevant economic channels.

The more elaborate financial union preserves the result that Pareto improvements are possible, while also showing that the final allocations move from first-best to second-best, and the two interventions have quite different effects on tradable and nontradable output. In addition, we show that the current account balance of the union as a whole becomes excessively large when the governmental loan is overused relative to tax-subsidies and debt relief. The results for pre-crisis welfares do not follow closed-form solutions in the more elaborate financial union, but the numerical simulation results can be easily understood via comparison with the proofs from the baseline model.

For sufficiently heterogeneous financial unions, our main lesson holds for both the baseline model and the more elaborate financial union, and from both crisis-time and pre-crisis perspectives: inter-regional lending and debt relief institutions need to be built.

\section{References}

Bayoumi, Tamim, and Barry Eichengreen. 1993. "Shocking Aspects of European Monetary Unification," in Adjustment and Growth in the European Monetary Union, Francisco Torres and Francesco Giavazzi (eds.), Cambridge: Cambridge University Press.

Bayoumi, Tamim, and Paul R. Masson. 1995. "Fiscal Flows in the United States and Canada: Lessons for Monetary Union in Europe," European Economic Review, Vol. 39 (2), 253-274.

Beetsma, Roel M. W. J., and Henrik Jensen. 2005. "Monetary and Fiscal Policy Interactions in a Micro-Founded Model of a Monetary Union," Journal of International Economics, Vol. 67 (2), 320-352.

Benigno, Gianluca, Huigang Chen, Christopher Otrok, Alessandro Rebucci, and Eric R. Young. 2013. "Financial Crises and Macro-prudential Policies," Journal of International Economics, Vol. 89, 453-470.

Benigno, Gianluca, Huigang Chen, Christopher Otrok, Alessandro Rebucci, and Eric R. Young. 2016. "Optimal Capital Controls and Real Exchange Rate Policies: A Pecuniary Externality Perspective," Journal of Monetary Economics, Vol. 84, 147-165.

Benigno, Pierpaulo, and Federica Romei. 2014. "Debt Deleveraging and the Exchange Rate," Journal of International Economics, Vol. 93, 1-16.

Bianchi, Javier. 2010. "Credit Externalities: Macroeconomic Effects and Policy Implications," American Economic Review: Papers and Proceedings, Vol. 100 (2), 398-402.

C)International Monetary Fund. Not for Redistribution 
Bianchi, Javier. 2011. "Overborrowing and Systematic Externalities in the Business Cycle," American Economic Review, Vol. 101 (7), 3400-3426.

Blanchard, Olivier, Christopher J. Erceg, and Jesper Lindé. 2015. "Jump Starting the Euro Area Recovery: Would a Rise in Core Fiscal Spending Help the Periphery?," NBER Working Paper No. 21426.

Blanchard, Olivier, and Francesco Giavazzi. 2002. "Current Account Deficits in the Euro Area: The End of the Feldstein-Horioka Puzzle?," Brookings Papers on Economic Activity, Vol. 33 (2), 147-210.

Bolton, Patrick, and Olivier Jeanne. 2011. "Sovereign Default Risk and Bank Fragility in Financially Integrated Economies," IMF Economic Review, Vol. 59 (2), 162-194.

Broner, Fernando, Aitor Erce, Alberto Martin, and Jaume Ventura. 2014. "Sovereign Debt Markets in Turbulent Times: Creditor Discrimination and Crowding-Out Effects, Journal of Monetary Economics, Vol. 61, 114-142.

Caballero, Ricardo J., and Arvind Krishnamurthy. 2001. "International and Domestic Collateral Constraints in a Model of Emerging Market Crises," Journal of Monetary Economics, Vol. 48 (3), 513-548.

Calvo, Guillermo A. 1998. "Capital Flows and Capital Market Crises: The Simple Economics of Sudden Stops," Journal of Applied Economics, Vol. 1 (1), 35-54.

Calvo, Guillermo A., Alejandro Izquierdo, and Luis-Fernando Mejia. 2004. "On the Empirics of Sudden Stops: The Relevance of Balance-Sheet Effects," NBER Working Paper No. 10520.

Chen, Ruo, Gian Maria Milesi-Ferretti, and Thierry Tressel. 2012. "External Imbalances in the Euro Area," IMF Working Paper No. 12/236.

Cremers, Emily T., and Partha Sen. 2009. "Transfers, the Terms of Trade, and Capital Accumulation," The Canadian Journal of Economics, Vol. 42 (4), 1599-1616.

de Grauwe, Paul. 1993. "The Political Economy of Monetary Union in Europe," The World Economy, Vol. 16 (6), 653-661.

de Grauwe, Paul. 1996. "Monetary Union and Convergence Economics," European Economic Review, Vol. 40 (3-5), 1091-1101.

de Grauwe, Paul. 2012. "The Governance of a Fragile Eurozone," Australian Economic Review, Vol. 45 (3), 255-268.

Djajić, Slobodan, Sajal Lahiri, and Pascalis Raimondos-Møller. 1998. "The Transfer Problem and the Intertemporal Terms of Trade," The Canadian Journal of Economics, Vol. 31 (2), 427-436.

Dogra, Keshav. 2014. Optimal Debt Restructuring and Lending Policy in a Monetary Union," Mimeo, Columbia University.

Dornbusch, Rudiger, Ilan Goldfajn, and Rodrigo O. Valdés. 1995. "Currency Crises and Collapses," Brookings Papers on Economic Activity, 219-293. 
Eggertsson, Gauti B., and Michael Woodford. 2003. "The Zero Bound on Interest Rates and Optimal Monetary Policy," Brookings Papers on Economic Activity, Vol. 34, Issue 1, 139-235.

Farhi, Emmanuel, and Iván Werning. 2012. "Dealing with the Trilemma: Optimal Capital Controls with Fixed Exchange Rates," NBER Working Paper No. 18199.

Farhi, Emmanuel, and Iván Werning. 2013a. "Fiscal Unions," NBER Working Paper No. 18280.

Farhi, Emmanuel, and Iván Werning. 2013b. "Fiscal Multipliers: Liquidity Traps and Currency Unions," NBER Working Paper No. 18381.

Fornaro, Luca. 2015. "International Debt Deleveraging," CEPR Discussion Paper No. DP10469.

Galí, Jordi, and Tommaso Monacelli. 2008. "Optimal Monetary and Fiscal Policy in a Currency Union," Journal of International Economics, Vol. 76 (1), 116-132.

Giavazzi, Francesco, and Luigi Spaventa. 2010. "Why the Current Account May Matter in a Monetary Union: Lessons from the Financial Crisis in the Euro Area," CEPR Discussion Paper No. 8008.

Goyal, Rishi, Petya Koeva Brooks, Mahmood Pradhan, Thierry Tressel, Giovanni Dell'Ariccia, Ross Leckow, and Ceyla Pazarbasioglu. 2013. "A Banking Union for the Euro Area," IMF Staff Discussion Note No. 13/01.

Gourinchas, Pierre-Olivier, Thomas Philippon, and Dimitri Vayanos. 2016. "The Analytics of the Greek Crisis," NBER Working Paper No. 22370.

Guerrieri, Veronica, and Guido Lorenzoni. 2011. "Credit Crises, Precautionary Savings, and the Liquidity Trap," NBER Working Paper No. 17583.

Hale, Galina. 2013. "Balance of Payments in the European Periphery," FRBSF Economic Letter, 2013-01.

Iacoviello, Matteo. 2005. "House Prices, Borrowing Constraints, and Monetary Policy in the Business Cycle," American Economic Review, Vol. 95 (3), 739-764.

Jeanne, Olivier, and Anton Korinek. 2010. "Excessive Volatility in Capital Flows: A Pigouvian Taxation Approach," American Economic Review, Vol. 100 (2), 403-07.

Jeanne, Olivier, and Anton Korinek. 2013. "Macroprudential Regulation Versus Mopping Up After the Crash," NBER Working Paper No. 18675.

Kenen, Peter. 1969. "The Theory of Optimum Currency Areas: An Eclectic View," in Monetary Problems of the International Economy, Robert A. Mundell and Alexander K. Swoboda (eds.), Chicago: University of Chicago Press.

Keynes, John M. 1929. "The German Transfer Problem," The Economic Journal, Vol. 39, $1-7$.

Korinek, Anton. 2011. "The New Economics of Prudential Capital Controls," IMF Economic Review, Vol. 59 (3), 523-561.

C)International Monetary Fund. Not for Redistribution 
Korinek, Anton, and Enrique G. Mendoza. 2014. "From Sudden Stops to Fisherian Deflation: Quantitative Theory and Policy," Annual Review of Economics, Vol. 6, 299-332.

Lane, Philip R.. 2012. "The European Sovereign Debt Crisis," Journal of Economic Perspectives, Vol. 26 (3), 49-68.

Martin, Philippe, and Thomas Philippon. 2014. "Inspecting the Mechanism: Leverage and the Great Recession in the Eurozone," NBER Working Paper No. 20572.

Midrigan, Virgiliu, and Thomas Philippon. 2011. "Household Leverage and the Recession," NBER Working Paper No. 18675.

McKinnon, Ronald. 1963. "Optimum Currency Areas," The American Economic Review, Vol. 53, 717-724.

Mendoza, Enrique G. 2002. "Credit, Prices and Crashes: Business Cycles with a Sudden Stop," in Preventing Currency Crises in Emerging Markets, S. Edwards and J. Frankel (eds.), Chicago: University of Chicago Press.

Mendoza, Enrique G. 2006. "Lessons from the Debt-Deflation Theory of Sudden Stops," American Economic Review, Vol. 96 (2), 411-416.

Mendoza, Enrique G. and Katherine A. Smith. 2006. "Quantitative Implications of a DebtDeflation Theory of Sudden Stops and Asset Prices," Journal of International Economics, Vol. 70, 82-114.

Mendoza, Enrique G., Linda L. Tesar, and Jing Zhang. 2014. "Saving Europe?: The Unpleasant Arithmetic of Fiscal Austerity in Integrated Economies," NBER Working Paper No. 20200.

Merler, Silvia, and Jean Pisani-Ferry. 2012. "Sudden Stops in the Euro Area," Bruegel Policy Contribution No. 2012/06.

Mundell, Robert A. 1961. "A Theory of Optimum Currency Areas," The American Economic Review, Vol. 51 (4), 657-665.

Mundell, Robert A. 1973. "Uncommon Arguments for Common Currencies," in The Economics of Common Currencies, H. G. Johnson and A. K. Swoboda (eds.), London: Allen and Unwin Limited.

Obstfeld, Maurice. 2013. "Finance at Center Stage: Some Lessons of the Euro Crisis," CEPR Discussion Papers 9415, C.E.P.R. Discussion Papers.

Ohlin, Bertil. 1929. "The Reparation Problem: A Discussion," The Economic Journal, Vol. 39, 172-173.

Reis, Ricardo. 2013. "The Portuguese Slump and Crash and the Euro Crisis," Brookings Papers on Economic Activity, Vol. 46 (1), 143-210.

Shambaugh, Jay C. 2012. "The Euro's Three Crises," Brookings Papers on Economic Activity, Spring 2012, 157-231.

Waysand, Claire, Kevin Ross, and John C. De Guzman. 2010. "European Financial Linkages: A New Look at Imbalances," IMF Working Paper No. 10/295.

CInternational Monetary Fund. Not for Redistribution 


\section{Proofs}

Lemma 1. Take first-order conditions of the first-best maximization problem and rearrange:

$$
c_{T t}^{i, j}=2 y_{T t} \frac{\lambda^{i, j}}{\sum_{i \in\{N, S\}} \int_{0}^{1} \lambda^{i, j} d j} \Rightarrow \frac{c_{T 2}^{i, j}}{c_{T 1}^{i, j}}=\frac{y_{T 2}}{y_{T 1}} \text { for all } i, j .
$$

Setting $\lambda^{i, j}=\lambda^{i}$ for all $i, j$, we obtain the desired result.

Proposition 1. The arguments in subsection 2.2 establish that the laissez-faire equilibrium is Pareto efficient if and only if $b_{1}^{S} \in\left[0, \bar{b}_{1}^{S}\right]$. Equation (26) and the market-clearing conditions establish the consumption levels for $b_{1}^{S}>\bar{b}_{1}^{S}$. The market and shadow interest rates are:

$$
r_{2}=\frac{y_{T 2}\left(\frac{1}{2}+\frac{\phi(1+\nu)}{1+\phi \nu}\right)}{\frac{1}{2} b_{1}^{S}+\frac{1}{2} y_{T 1}} \text { and } R_{2}^{S}=\frac{y_{T 2} \frac{1-\phi}{1+\phi \nu}\left(\frac{1}{2}+\frac{\phi(1+\nu)}{1+\phi \nu}\right)}{-b_{1}^{S}\left(\frac{1}{2}+\frac{1}{2} \frac{\phi(1+\nu)}{1+\phi \nu}\right)+y_{T 1}\left(\frac{1}{2}+\frac{3}{2} \frac{\phi(1+\nu)}{1+\phi \nu}\right)} .
$$

We derive the required welfare results by substituting equations (25) and (26), along with the market-clearing conditions, into the expression (1).

Proposition 2. The arguments in subsection 2.3 establish the existence of Pareto improvements starting from $b_{1}^{S}>\bar{b}_{1}^{S}$. As the intervention continues, we know from the text that $d r_{2}>0$. In addition:

$$
\begin{gathered}
d c_{T 2}^{S}=-\frac{1-\phi}{1+\phi \nu} d z^{N}<0 \text { and } d c_{T 1}^{S}=\frac{2 \rho^{x z}\left(\gamma^{N}\right)-1}{r_{2}} \frac{1-\phi}{1+\phi \nu} d z^{N}>0 \Rightarrow d R_{2}^{S}<0 \\
d p_{2}^{S}=-\frac{1}{y_{N T 2}} \frac{(1-\phi) \nu}{1+\phi \nu} d z^{N}<0 \text { and } d b_{2}^{S}=-\frac{\phi(1+\nu)}{1+\phi \nu} d z^{N}<0 .
\end{gathered}
$$

As $r_{2}$ increases and $R_{2}^{S}$ decreases, eventually we achieve $R_{2}^{S}=r_{2}$. This condition combined with the union's resource constraint (12) establishes that $R_{2}^{S}=r_{2}=\frac{c_{T 2}^{i}}{c_{T 1}^{i}}=\frac{y_{T 2}}{y_{T 1}}$ for all $i$, which means that the union is restored to the first-best frontier. Substituting this equality into equations (19) and (21)-(22), we derive the expression for the frontier, equation (29).

We derive the formulae (30)-(31) for consumption at the ends of the Pareto frontier by observing that $U^{S}\left(x^{S}, z^{N}, 0\right)=U^{S}(0,0,0)$ for $\gamma^{N}=1$ and that $U^{N}\left(x^{S}, z^{N}, 0\right)=U^{N}(0,0,0)$ for $\gamma^{N}=0$. In other words, using equations (1), (23), and (26):

$$
\begin{gathered}
\log \left\{\left(c_{T 1}^{S, \gamma^{N}=1}\right)^{2} \frac{y_{T 2}}{y_{T 1}}\right\}=\log \left\{\left(\frac{1+3 \phi+4 \phi \nu}{1+2 \phi+3 \phi \nu} y_{T 1}-\frac{1+\phi+2 \phi \nu}{1+2 \phi+3 \phi \nu} b_{1}^{S}\right)\left(y_{T 2} \frac{1-\phi}{1+\phi \nu}\right)\right\} \\
\log \left\{\left(c_{T 1}^{N, \gamma^{N}=0}\right)^{2} \frac{y_{T 2}}{y_{T 1}}\right\}=\log \left\{\left(\frac{1+\phi+2 \phi \nu}{1+2 \phi+3 \phi \nu} y_{T 1}+\frac{1+\phi+2 \phi \nu}{1+2 \phi+3 \phi \nu} b_{1}^{S}\right)\left(y_{T 2} \frac{1+\phi+2 \phi \nu}{1+\phi \nu}\right)\right\} .
\end{gathered}
$$

Substituting equations (30)-(31) into the expression $c_{T 2}^{S}=\left(y_{T 2}-z^{N}\right) \frac{1-\phi}{1+\phi \nu}$ from the text, we can characterize the set $\left[z^{N, \gamma^{N}=0}, z^{N, \gamma^{N}=1}\right]$ : 


$$
\begin{aligned}
z^{N, \gamma^{N}=0}= & y_{T 2} \frac{1+\phi \nu}{1-\phi} \sqrt{\left(\frac{1+\phi+2 \phi \nu}{1+2 \phi+3 \phi \nu}+\frac{1+\phi+2 \phi \nu}{1+2 \phi+3 \phi \nu} \frac{b_{1}^{S}}{y_{T 1}}\right) \frac{1+\phi+2 \phi \nu}{1+\phi \nu}}-y_{T 2} \frac{1+\phi+2 \phi \nu}{1-\phi} \\
& z^{N, \gamma^{N}=1}=y_{T 2}-y_{T 2} \frac{1+\phi \nu}{1-\phi} \sqrt{\left(\frac{1+3 \phi+4 \phi \nu}{1+2 \phi+3 \phi \nu}-\frac{1+\phi+2 \phi \nu}{1+2 \phi+3 \phi \nu} \frac{b_{1}^{S}}{y_{T 1}}\right) \frac{1-\phi}{1+\phi \nu}}
\end{aligned}
$$

The properties $z^{N, \gamma^{N}=0}<z^{N, \gamma^{N}=1}$ and $\frac{d z^{N}}{d \gamma^{N}}>0$ follow by inspection. Using equation (29), we can back out the corresponding bounds for the set $\left[x^{S, \gamma^{N}=0}, x^{S, \gamma^{N}=1}\right]$.

Suppose that $\phi<\frac{1}{2+\nu}$, so that panel I of figure 5 is the relevant configuration. The upper end of frontier (29) may be bounded by $z^{N} \leq\left(z^{N}\right)^{\max }$. If so, then while $z^{N}$ cannot be increased further, welfare can still be transferred from South to North by reducing $x^{S}$ until $U^{S}\left(x^{S}, z^{N}, 0\right)=U^{S}(0,0,0)$. The lower end of frontier (29) may be bounded by $x^{S} \leq$ $\left(x^{S}\right)^{\text {max }}$. If so, then while $x^{S}$ cannot be increased further, welfare can still be transferred from North to South by reducing $z^{N}$ until $U^{N}\left(x^{S}, z^{N}, 0\right)=U^{N}(0,0,0)$.

Next, suppose that $\phi<\frac{1}{2+\nu}$, so that panel II is the relevant configuration. Then both the bounds $z^{N} \leq\left(z^{N}\right)^{\text {max }}$ and $x^{S} \leq\left(x^{S}\right)^{\text {max }}$ only bound the upper end of the frontier (29), and the frontier kinks at the point corresponding to the tighter of the bounds. At that point, welfare can still be transferred from South to North by reducing $x^{S}$ until $U^{S}\left(x^{S}, z^{N}, 0\right)=$ $U^{S}(0,0,0)$.

In all these cases, moving away from the blue frontier means moving inside the first-best frontier.

Proposition 3. The arguments in subsection 2.3 establish the existence of Pareto improvements starting from $b_{1}^{S}>\bar{b}_{1}^{S}$. As the intervention continues, we know from the text that $d r_{2}>0$. In addition:

$$
\begin{gathered}
d c_{T 2}^{S}=-\frac{c_{T 2}^{S} \phi(1+\nu)}{1+\phi\left(\nu+\tau^{S}+\nu \tau^{S}\right)} d \tau^{S}<0 \text { and } d c_{T 1}^{S}=\frac{2 \rho\left(\gamma^{N}\right)-1}{r_{2}} \frac{c_{T 2}^{S} \phi(1+\nu)}{1+\phi\left(\nu+\tau^{S}+\nu \tau^{S}\right)} d \tau^{S}>0 \\
\Rightarrow d R_{2}^{S}<0 \\
d p_{2}^{S}=\frac{1}{y_{N T 2}} \frac{c_{T 2}^{S}(1+\nu)}{1+\phi\left(\nu+\tau^{S}+\nu \tau^{S}\right)} d \tau^{S}>0 \text { and } d b_{2}^{S}=\frac{c_{T 2}^{S} \phi(1+\nu)}{1+\phi\left(\nu+\tau^{S}+\nu \tau^{S}\right)} d \tau^{S}>0 .
\end{gathered}
$$

As $r_{2}$ increases and $R_{2}^{S}$ decreases, again we achieve $R_{2}^{S}=r_{2}=\frac{c_{T 2}^{i}}{c_{T 1}^{i}}=\frac{y_{T 2}}{y_{T 1}}$ for all $i$. Substituting this equality into equations (19) and (21)-(22), we derive the expression for the frontier, equation (32). The same formulae (30)-(31) apply. Substituting them into the expression $c_{T 2}^{S}=y_{T 2} \frac{1-\phi}{1+\phi\left(\nu+\tau^{S}+\nu \tau^{S}\right)}$ from the text, we can characterize the set $\left[\tau^{S, \gamma^{N}=0}, \tau^{S, \gamma^{N}=1}\right]$ :

$$
\frac{1-\phi}{1+\phi\left(\nu+(1+\nu) \tau^{S, \gamma^{N}=0}\right)}=2-\sqrt{\left(\frac{1+\phi+2 \phi \nu}{1+2 \phi+3 \phi \nu}+\frac{1+\phi+2 \phi \nu}{1+2 \phi+3 \phi \nu} \frac{b_{1}^{S}}{y_{T 1}}\right) \frac{1+\phi+2 \phi \nu}{1+\phi \nu}}
$$




$$
\frac{1-\phi}{1+\phi\left(\nu+(1+\nu) \tau^{S, \gamma^{N}=1}\right)}=\sqrt{\left(\frac{1+3 \phi+4 \phi \nu}{1+2 \phi+3 \phi \nu}-\frac{1+\phi+2 \phi \nu}{1+2 \phi+3 \phi \nu} \frac{b_{1}^{S}}{y_{T 1}}\right) \frac{1-\phi}{1+\phi \nu}} .
$$

The properties $\tau^{S, \gamma^{N}=0}<\tau^{S, \gamma^{N}=1}$ and $\frac{d \tau^{S}}{d \gamma^{N}}>0$ follow by inspection. Using equation (32), we can back out the corresponding bounds for the set $\left[x^{S, \gamma^{N}=0}, x^{S, \gamma^{N}=1}\right]$.

Panels III, IV, and V of figure 5 show the frontiers corresponding to different levels of $b_{1}^{S}$. The upper end of frontier (32) may be bounded by $\tau^{S} \leq\left(\tau^{S}\right)^{\max }$. If so, then while $\tau^{S}$ cannot be increased further, welfare can still be transferred from South to North by reducing $x^{S}$ until $U^{S}\left(x^{S}, z^{N}, 0\right)=U^{S}(0,0,0)$. The lower end of frontier (29) may be bounded by $x^{S} \leq\left(x^{S}\right)^{\text {max }}$. If so, then while $x^{S}$ cannot be increased further, welfare can still be transferred from North to South by reducing $\tau^{S}$ until $U^{N}\left(x^{S}, z^{N}, 0\right)=U^{N}(0,0,0)$. Again, moving away from the blue frontier means moving inside the first-best frontier.

Lemma 2. The arguments in subsection 2.4 establish that a tax on the non-collateralizable nontradable good, $\theta^{S}<0$, can generate a Pareto improvement starting from $b_{1}^{S}>\bar{b}_{1}^{S}$. However, when the policy tools $\left(x^{S}, \tau^{S}\right)$ are unlimited, the final post-intervention allocation is already at the first-best frontier, so the additional tax instrument is redundant. On the other hand, if the policy tools $\left(x^{S}, \tau^{S}\right)$ are limited, then the post-intervention allocation may be in the shaded gray zone inside the blue frontier in figure 5, and Pareto gains are not exhausted using $\left(x^{S}, \tau^{S}\right)$ alone. Since $R_{2}^{S}>r_{2}$, we can use the arguments in the text to generate additional Pareto improvements using the $\operatorname{tax} \theta^{S}<0$. The amended Pareto frontier is:

$$
x^{S}=b_{1}^{S}-2 y_{T 1} \frac{\phi\left(1+\nu+\tau^{S}+\nu \tau^{S}-\frac{\theta}{1-\theta}\left(\gamma+\gamma \tau^{S}\right)\right)}{1+\phi\left(\nu+\tau^{S}+\nu \tau^{S}-\frac{\theta}{1-\theta}\left(\gamma+\gamma \tau^{S}\right)\right)} .
$$

Lemma 3. This result follows directly from substituting $d x^{S}>0$ and $d z^{N}=d \tau^{S}=0$ into the equations in subsection 2.3.

Lemma 4. The arguments in subsection 3.2 establish that for $H>\bar{H}$, the Southern debt level is given by the intersection of the black line and the appropriate gray line in panel I of figure 6. Let us compare the expressions (25), (26), (30) and (31):

$$
\begin{gathered}
c_{T 1}^{S *}\left(\bar{b}_{1}^{S}\right)=c_{T 1}^{S, C}\left(\bar{b}_{1}^{S}\right)=c_{T 1}^{S, \gamma \gamma^{N}=1}\left(\bar{b}_{1}^{S}\right)=c_{T 1}^{S, \gamma^{N}=0}\left(\bar{b}_{1}^{S}\right) \\
\frac{d c_{T 1}^{S *}}{d b_{1}^{S}}=-\frac{1}{2} \text {, while } \frac{d c_{T 1}^{S, C}}{d b_{1}^{S}}=-\frac{1+\phi+2 \phi \nu}{1+2 \phi+3 \phi \nu}<-\frac{1}{2} \\
\left.\frac{d c_{T 1}^{S, \gamma^{N}=1}}{d b_{1}^{S}}\right|_{b_{1}^{S}=\bar{b}_{1}^{S}}=-\frac{1}{2} \frac{1+\phi+2 \phi \nu}{1+2 \phi+3 \phi \nu}>-\frac{1}{2} \text { and } \frac{d^{2} c_{T 1}^{S, \gamma^{N}=1}}{d\left(b_{1}^{S}\right)^{2}}<0 \\
c_{T 1}^{S, \gamma^{N}=1}=c_{T 1}^{S, C} \text { for } b_{1}^{S}=\bar{b}_{1}^{S} \text { and } b_{1}^{S}=\left(b_{1}^{S}\right)^{\max }=\frac{1+3 \phi+4 \phi \nu}{1+\phi+2 \phi \nu} y_{T 1}
\end{gathered}
$$




$$
\left.\frac{d c_{T 1}^{S, \gamma^{N}=0}}{d b_{1}^{S}}\right|_{b_{1}^{S}=\bar{b}_{1}^{S}}=-\frac{1}{2} \frac{1+\phi+2 \phi \nu}{1+2 \phi+3 \phi \nu}>-\frac{1}{2} \text { and } \frac{d^{2} c_{T 1}^{S, \gamma^{N}=0}}{d\left(b_{1}^{S}\right)^{2}}>0 .
$$

Combined, these expressions establish that $b_{1}^{S, C}<b_{1}^{S *}$ and $b_{1}^{S, \gamma^{N}=0}>b_{1}^{S, \gamma^{N}=1}>b_{1}^{S, C}$. Next, we turn to the maximization of (28) subject to (18)-(23), which implies:

$$
\begin{aligned}
& \max _{c_{T 1}^{S}}\left(\log \left(c_{T 1}^{S, \gamma^{N}}\right)^{2} \frac{y_{T 2}}{y_{T 1}}-\log \left\{\left(\frac{1+3 \phi+4 \phi \nu}{1+2 \phi+3 \phi \nu} y_{T 1}-\frac{1+\phi+2 \phi \nu}{1+2 \phi+3 \phi \nu} b_{1}^{S}\right) y_{T 2} \frac{1-\phi}{1+\phi \nu}\right\}\right)^{1-\gamma^{N}} \\
& \times\left(\log \left(2 y_{T 1}-c_{T 1}^{S, \gamma^{N}}\right)^{2} \frac{y_{T 2}}{y_{T 1}}-\log \left\{\left(\frac{1+\phi+2 \phi \nu}{1+2 \phi+3 \phi \nu} y_{T 1}+\frac{1+\phi+2 \phi \nu}{1+2 \phi+3 \phi \nu} b_{1}^{S}\right) y_{T 2} \frac{1+\phi+2 \phi \nu}{1+\phi \nu}\right\}\right)^{\gamma^{N}} .
\end{aligned}
$$

Substituting (44) into the first-order condition of the above problem:

$$
\begin{aligned}
Q & =\left(1-\gamma^{N}\right) \frac{2}{c_{T 1}^{S}}\left(\begin{array}{c}
\log \left(2 y_{T 1}-c_{T 1}^{S, \gamma^{N}}\right)^{2} \frac{y_{T 2}}{y_{T 1}} \\
-\log \left(\frac{1+\phi+2 \phi \nu}{1+2 \phi+3 \phi \nu} y_{T 1}+\frac{1+\phi+2 \phi \nu}{1+2 \phi+3 \phi \nu}\left(c_{T 1}^{S, \gamma^{N}}-y_{T 1}(1-H)\right)\right) y_{T 2} \frac{1+\phi+2 \phi \nu}{1+\phi \nu}
\end{array}\right) \\
& -\gamma^{N} \frac{2}{2 y_{T 1}-c_{T 1}^{S}}\left(\begin{array}{c}
\log \left(c_{T 1}^{S, \gamma^{N}}\right)^{2} \frac{y_{T 2}}{y_{T 1}} \\
-\log \left(\frac{1+3 \phi+4 \phi \nu}{1+2 \phi+3 \phi \nu} y_{T 1}-\frac{1+\phi+2 \phi \nu}{1+2 \phi+3 \phi \nu}\left(c_{T 1}^{S, \gamma^{N}}-y_{T 1}(1-H)\right)\right) y_{T 2} \frac{1-\phi}{1+\phi \nu}
\end{array}\right)=0 .
\end{aligned}
$$

Then for a fixed degree of heterogeneity $H$, we derive:

$$
\frac{d c_{T 1}^{S, \gamma^{N}}}{d \gamma^{N}}=-\frac{\partial Q / \partial \gamma^{N}}{\partial Q / \partial c_{T 1}^{S}}<0 \text { since } \frac{\partial Q}{\partial \gamma^{N}}<0 \text { and } \frac{\partial Q}{\partial c_{T 1}^{S}}<0
$$

Combining with equation (44), we establish that $\frac{d b_{1}^{S, \gamma} \gamma^{N}}{d \gamma^{N}}<0$.

Lemma 5. Take first-order conditions of the first-best maximization problem, rearrange, and set $\lambda^{i, j}=\lambda^{i}$ for all $i, j$, as in the proof of lemma 1 .

Proposition 4. The arguments in subsection 3.2 establish that the laissez-faire equilibrium is Pareto efficient if and only if $H \in[0, \bar{H}]$. When $H \in(\bar{H}, 1]$, it must be that $b_{1}^{S, C}>\bar{b}_{1}^{S}$, so $c_{T 2}^{S, C}=\bar{c}_{T 2}^{S}$ and $R_{2}^{S}>\frac{y_{T 2}}{y_{T 1}}>r_{2}$; while $\frac{c_{T 1}^{i}}{c_{T 0}^{i}}=\frac{2 y_{T 1}}{e^{T}}$ holds because there is no borrowing constraint between periods 0 and 1 . The unconstrained and constrained consumption levels from the intersections of the lines in panel I of figure 5 are:

$$
\begin{gathered}
c_{T 1}^{S *}=y_{T 1}\left(1-\frac{1}{3} H\right) \text { and } c_{T 2}^{S *}=\frac{y_{T 2}}{y_{T 1}} c_{T 1}^{S *}, c_{T 0}^{S *}=\frac{e^{T}}{2 y_{T 1}} c_{T 1}^{S *} \\
c_{T 1}^{S, C}=y_{T 1}\left(\frac{2+4 \phi+6 \phi \nu}{2+3 \phi+5 \phi \nu}-\frac{1+\phi+2 \phi \nu}{2+3 \phi+5 \phi \nu} H\right) \text { and } c_{T 1}^{S, C}=\bar{c}_{T 2}^{S},, c_{T 0}^{S, C}=\frac{e^{T}}{2 y_{T 1}} c_{T 1}^{S, C} .
\end{gathered}
$$

We derive the required welfare results by substituting these equations into the expression (33). 
Lemma 6. This result follows from substituting the applying the analysis of section 2 to the model in section 3, applying not just (18)-(23) but also $c_{T 0}^{i}=\frac{e^{T}}{2 y_{T 1}} c_{T 1}^{i}$ for all $i$, the relation (44), and the utility expression (33).

Proposition 5. In addition to the unconstrained and constrained consumption levels above, we can also write the post-intervention consumption levels for $\gamma^{N}=1$ and $\gamma^{N}=0$, again using the intersections of the lines in panel I of figure 5 :

$$
\begin{aligned}
c_{T 1}^{S, \gamma^{N}=1}= & \frac{1}{2} y_{T 1} \sqrt{\left(\frac{1+\phi+2 \phi \nu}{1+2 \phi+3 \phi \nu} \frac{1-\phi}{1+\phi \nu}\right)^{2}+4\left(2-\frac{1+\phi+2 \phi \nu}{1+2 \phi+3 \phi \nu} H\right) \frac{1-\phi}{1+\phi \nu}} \\
& -\frac{1}{2} \frac{1+\phi+2 \phi \nu}{1+2 \phi+3 \phi \nu} \frac{1-\phi}{1+\phi \nu} y_{T 1} \\
c_{T 1}^{S, \gamma^{N}=0}= & \frac{1}{2}\left(4+\frac{1+\phi+2 \phi \nu}{1+2 \phi+3 \phi \nu} \frac{1+\phi+2 \phi \nu}{1+\phi \nu}\right) y_{T 1} \\
- & \frac{1}{2} y_{T 1} \sqrt{4 \frac{1+\phi+2 \phi \nu}{1+2 \phi+3 \phi \nu} \frac{1+\phi+2 \phi \nu}{1+\phi \nu}(2+H)+\left(\frac{1+\phi+2 \phi \nu}{1+2 \phi+3 \phi \nu} \frac{1+\phi+2 \phi \nu}{1+\phi \nu}\right)^{2}} .
\end{aligned}
$$

Substituting the above equations into the expression (33), we derive the welfare expressions as a function of $H$ :

$$
\begin{aligned}
& V^{S *}=\log \left\{\kappa y_{T 1}\left(1-\frac{1}{3} H\right)^{3}\right\} \\
& V^{S, C}=\log \left\{\kappa y_{T 1}\left(\frac{2+4 \phi+6 \phi \nu}{2+3 \phi+5 \phi \nu}-\frac{1+\phi+2 \phi \nu}{2+3 \phi+5 \phi \nu} H\right)^{2} \frac{1-\phi}{1+\phi \nu}\right\} \\
& V^{S, \gamma^{N}=1}=\log \left\{\kappa y_{T 1}\left(\begin{array}{c}
\frac{1}{2} \sqrt{\left(\frac{1+\phi+2 \phi \nu}{1+2 \phi+3 \phi \nu} \frac{1-\phi}{1+\phi \nu}\right)^{2}+4\left(2-\frac{1+\phi+2 \phi \nu}{1+2 \phi+3 \phi \nu} H\right) \frac{1-\phi}{1+\phi \nu}} \\
-\frac{1}{2} \frac{1+\phi+2 \phi \nu}{1+2 \phi+3 \phi \nu} \frac{1-\phi}{1+\phi \nu}
\end{array}\right)^{3}\right\}
\end{aligned}
$$

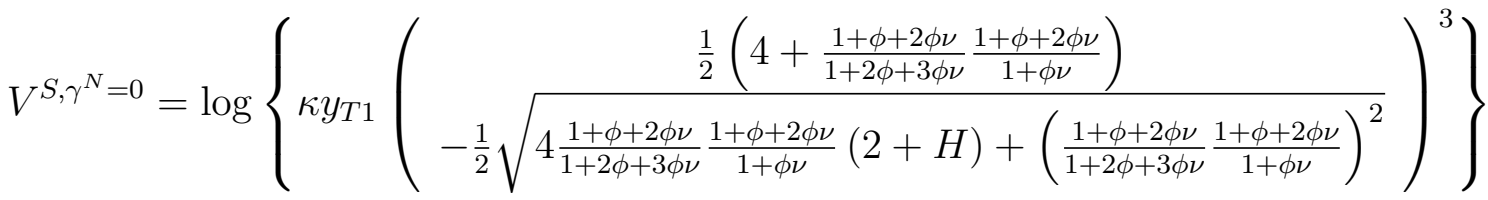

$$
\begin{aligned}
& V^{N *}=\log \left\{\kappa y_{T 1}\left(1+\frac{1}{3} H\right)^{3}\right\} \\
& V^{N, C}=\log \left\{\kappa y_{T 1}\left(\frac{2+2 \phi+4 \phi \nu}{2+3 \phi+5 \phi \nu}+\frac{1+\phi+2 \phi \nu}{2+3 \phi+5 \phi \nu} H\right)^{2} \frac{1+\phi+2 \phi \nu}{1+\phi \nu}\right\}
\end{aligned}
$$

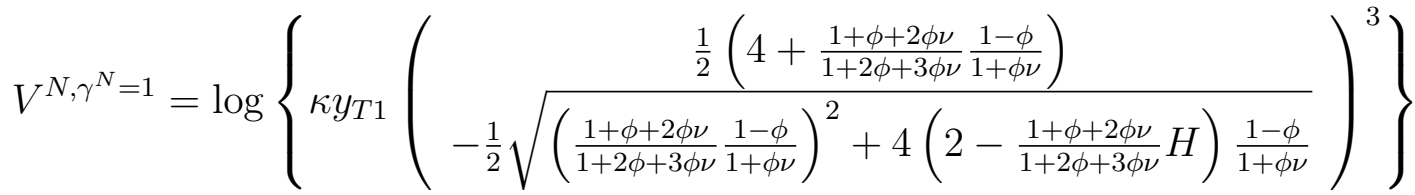




$$
V^{N, \gamma^{N}=0}=\log \left\{\kappa y_{T 1}\left(\begin{array}{c}
\frac{1}{2} \sqrt{4 \frac{1+\phi+2 \phi \nu}{1+2 \phi+3 \phi \nu} \frac{1+\phi+2 \phi \nu}{1+\phi \nu}(2+H)+\left(\frac{1+\phi+2 \phi \nu}{1+2 \phi+3 \phi \nu} \frac{1+\phi+2 \phi \nu}{1+\phi \nu}\right)^{2}} \\
-\frac{1}{2} \frac{1+\phi+2 \phi \nu}{1+2 \phi+3 \phi \nu} \frac{1+\phi+2 \phi \nu}{1+\phi \nu}
\end{array}\right)^{3}\right\}
$$

where $\kappa=\frac{e^{T}}{2} y_{T 2} \Pi_{t=\{0,1,2\}} y_{N T t}$. We compare the levels and slopes of these expressions at $H=\bar{H}$ and at $H=H^{\max }=2 \frac{1+2 \phi+3 \phi \nu}{1+\phi+2 \phi \nu}$. We also assess how many times $V^{i, C}$ and $V^{i, \gamma^{N}}$ must intersect with each other within $H \in\left[\bar{H}, H^{\max }\right]$, using the following auxiliary variables where appropriate to convert the welfare formulae into expressions with integer exponents:

$$
\begin{aligned}
\epsilon_{1} & =\sqrt{\left(\frac{1+\phi+2 \phi \nu}{1+2 \phi+3 \phi \nu} \frac{1-\phi}{1+\phi \nu}\right)^{2}+4\left(2-\frac{1+\phi+2 \phi \nu}{1+2 \phi+3 \phi \nu} H\right) \frac{1-\phi}{1+\phi \nu}} \\
\text { and } \epsilon_{2} & =\sqrt{4 \frac{1+\phi+2 \phi \nu}{1+2 \phi+3 \phi \nu} \frac{1+\phi+2 \phi \nu}{1+\phi \nu}(2+H)+\left(\frac{1+\phi+2 \phi \nu}{1+2 \phi+3 \phi \nu} \frac{1+\phi+2 \phi \nu}{1+\phi \nu}\right)^{2}}
\end{aligned}
$$

Notice that the use of auxiliary variables may generate additional non-feasible roots which must in turn be ruled out. This process produces the correct number of intersections within $H \in\left[\bar{H}, H^{\max }\right]$ and the correct sign of $\left\{V^{i, C} \lesseqgtr V^{i, \gamma^{N}}\right\}_{i \in\{N, S\}}$ around the intersections.

We then prove that $H_{1}<H_{2}$ by observing that since interventions move the union to the first-best frontier, it must be that at least one region must be better off as a result of the intervention, no matter the value of $H$. For $\phi$ small enough, $H_{2}$ must be smaller than 1 , which means that both $H_{1}$ must also be smaller than 1 .

Finally, the finding from lemma 4 that $\frac{d c_{T 1}^{S, \gamma^{N}}}{d \gamma^{N}}<0$ and $\frac{d b_{1}^{S, \gamma^{N}}}{d \gamma^{N}}<0$ establishes that the set of bargaining powers consistent with a period-0 Pareto improvement is always compact.

Lemma 7. Take first-order conditions of the first-best maximization problem and rearrange:

$$
\begin{gathered}
c_{T 1}^{i, j}=\left(-\left(B_{1}^{N}+B_{1}^{S}\right)+2 \frac{\phi_{R O W}}{r} \Pi_{2}\right) \frac{\lambda^{i, j}}{\sum_{i \in\{N, S\}} \int_{0}^{1} \lambda^{i, j} d j} \\
\left.c_{T 2}^{i, j}=\frac{2\left(1-\phi_{R O W}\right) \Pi_{2}}{1+\alpha_{N T} \nu} \frac{\lambda^{i, j}}{\sum_{i \in\{N, S\}} \int_{0}^{1} \lambda^{i, j} d j}\right\} \Rightarrow \frac{c_{T 2}^{i, j}}{c_{T 1}^{i, j}}=r_{2}^{*} \text { for all } i, j \\
k_{T 1}^{i, j}=A_{2}\left(\frac{\alpha_{T}}{r}\right)^{\frac{1}{1-\alpha_{T}}} \text { and } k_{N T 1}^{i, j}=\frac{\alpha_{N T} \nu c_{T 2}^{i, j}}{r} \text { for all } i, j,
\end{gathered}
$$

and our assumption that $r_{2}^{*}>r$ establishes that condition (67) holds with equality. Setting $\lambda^{i, j}=\lambda^{i}$ for all $i, j$, we obtain the desired result.

Proposition 6. The arguments in subsection 4.2 establish that the laissez-faire equilibrium is Pareto efficient if and only if $B_{1}^{S} \in\left[0, \bar{B}_{1}^{S}\right]$. Equation (77) establishes the Southern tradable consumption levels for $B_{1}^{S}>\bar{B}_{1}^{S}$, while the Northern tradable consumption levels are given by: 


$$
c_{T 1}^{N, C}=\frac{1}{2+\alpha_{N T} \nu}\left(-B_{1}^{N}+\left(\frac{\phi_{R O W}}{r}+\frac{1-\phi_{R O W}}{r_{2}}\right) \Pi_{2}\right) \text { and } c_{T 2}^{N, C}=r_{2} c_{T 1}^{N, C} .
$$

From these formulae, the market and shadow interest rates can be derived. We derive the required welfare results by substituting the first-best and constrained formulae for tradable and nontradable consumption (the latter given by the output consistent with investment level $k_{N T 1}^{i}=\frac{\alpha_{N T} \nu c_{T 2}^{i}}{r}$ for each $i$ ) into the expression (47).

Proposition 7. We proceed in four steps. In the first step, we use the Pareto gains formula (78) to find the Pareto-optimal choice for each intervention given a fixed value of other intervention, along the two boundaries of the Pareto set, $\left\{d U^{i}=0\right\}_{i \in\{N, S\}}$. Notice that the two conditions $\left.d U^{i}\right|_{d U^{-i=0}}=0$ for $i \in\{N, S\}$ are multiples of each other, so they boil down to just one Pareto gains condition. Rearranging, the conditions for positive Pareto gains for the governmental loan and tax-subsidy interventions are, respectively:

$$
\begin{gathered}
\frac{R_{2}^{S}}{r_{2}}>\frac{\frac{\left(1+\alpha_{N T} \nu\right)\left(1-\phi_{R O W}-\phi\right)}{1+\left(\alpha_{N T}+\phi\left(1-\alpha_{N T}\right)\right)\left(\nu+\tau^{S}+\nu \tau^{S}\right)}\left(1+\frac{\xi^{S} \alpha_{T}}{1-\xi^{S}-\alpha_{T}}\right)}{\frac{\left(1+\alpha_{N T}\left(\nu+\tau^{S}+\nu \tau^{S}\right)\right)\left(1-\phi_{R O W}-\phi\right)}{1+\left(\alpha_{N T}+\phi\left(1-\alpha_{N T}\right)\right)\left(\nu+\tau^{S}+\nu \tau^{S}\right)}\left(1+\frac{\xi^{S} \alpha_{T}}{1-\xi^{S}-\alpha_{T}}\right)-\left(\phi_{R O W} \frac{r_{2}}{r}+\left(1-\phi_{R O W}\right)\right) \frac{\xi^{S} \alpha_{T}}{1-\xi^{S}-\alpha_{T}}} \\
\frac{R_{2}^{S}}{r_{2}}>\frac{\phi\left(1-\alpha_{N T}\right)\left(\nu+\tau^{S}+\nu \tau^{S}\right)+\alpha_{N T}(1+\nu) \tau^{S}}{\phi\left(1-\alpha_{N T}\right)\left(\nu+\tau^{S}+\nu \tau^{S}\right)} .
\end{gathered}
$$

Taking derivatives of the consumption levels and the interest rate from the system of equations, we can establish that if we start from a constrained laissez-faire allocation, interventions along the two boundaries of the Pareto set generate:

$$
d c_{T 2}^{S}<0, d c_{T 1}^{S}>0 \text {, and if } r_{2}>r \text {, then } d r_{2}>0
$$

In fact, such interventions strictly decrease $\frac{R_{2}^{S}}{r_{2}}$ and strictly increase the right hand sides of the above inequalities until the two sides become equalized. As a result, given a fixed value of one intervention, there is a unique Pareto-optimal choice for the other intervention along each of the two boundaries $\left\{d U^{i}=0\right\}_{i \in\{N, S\}}$. This reasoning produces the second-best reaction functions $\xi^{S, S B}\left(\tau^{S}\right)$ and $\tau^{S, S B}\left(\xi^{S}\right)$ for each $B_{1}^{S}>\bar{B}_{1}^{S}$.

In the second step, continuing to stick to the two Pareto boundaries, $\left\{d U^{i}=0\right\}_{i \in\{N, S\}}$, we prove the existence of intervention combinations achieving the second-best frontier. Specifically, we plot the reaction functions in $\left(\xi^{S}, \tau^{S}\right)$ space and showing that they intersect. The crucial elements to prove are: (i) $\xi^{S, S B}\left(\tau^{S}\right)>0$ for all $\tau^{S} \in\left[0, \tau^{S, S B}\left(\xi^{S}=0\right)\right]$, where $\tau^{S, S B}\left(\xi^{S}=0\right)>0$; (ii) $\xi^{S, S B}\left(\tau^{S}\right)$ is defined for all $\tau^{S}$, which means as a corollary that it is defined for $\tau^{S}>\max _{\xi^{S}} \tau^{S, S B}\left(\xi^{S}\right)$; (iii) $\tau^{S, S B}\left(\xi^{S}\right)>0$ for all $\xi^{S} \in\left[0, \xi^{S, S B}\left(\tau^{S}=0\right)\right]$, where $\xi^{S, S B}\left(\tau^{S}=0\right)>0$; and (iv) $\tau^{S, S B}\left(\xi^{S}\right)$ is defined for some $\xi^{S}>\max _{\tau^{S}} \xi^{S, S B}\left(\tau^{S}\right)$. The last condition comes from the observations that, firstly, $\tau^{S, S B}\left(\xi^{S}\right)$ is defined at least up to the 
point where marginal changes in $\xi^{S}$ have no effect on $c_{T 1}^{S}$, and secondly, that $\max _{\tau^{S}} \xi^{S, S B}\left(\tau^{S}\right)$ lies to the left of this point.

In the third step, we extend the above two steps to interventions in the interior of the boundaries of the Pareto set, $\left\{d U^{i}=0\right\}_{i \in\{N, S\}}$. Consider intervention paths which satisfy the following formula for the period-1 transfer $d \Phi_{T 1}^{N}$ as a function of the changes in the production tax and the tax-subsidy combination:

$$
\begin{aligned}
d \Phi_{T 1}^{N}\left(d \xi^{S}, d \tau^{S} ; \xi^{S}, \tau^{S}\right) & =\left.\theta\left(\xi^{S}, \tau^{S}\right) d \Phi_{T 1}^{N}\left(d \xi^{S}, d \tau^{S} ; \xi^{S}, \tau^{S}\right)\right|_{d U^{N}=0} \\
& +\left.\left(1-\theta\left(\xi^{S}, \tau^{S}\right)\right) d \Phi_{T 1}^{N}\left(d \xi^{S}, d \tau^{S} ; \xi^{S}, \tau^{S}\right)\right|_{d U^{S}=0}
\end{aligned}
$$

where $\theta\left(\xi^{S}, \tau^{S}\right)$ is a continuously differentiable function, and we have suppressed the dependence of the intervention on the non-policy variables of the problem. Notice that we can go from one boundary of the Pareto set to the other by altering the value of the transfer. We can prove that the set of transfers $d \Phi_{T 1}^{N}$ corresponding to Pareto improvements from a specific allocation is compact, and that its boundaries move in a continuous fashion as the allocation gradually changes. Then the first two steps of this proof apply equally to all such intervention paths.

Finally, in the fourth step, we note that since the above steps apply whether $r_{2}>r$ or $r_{2}=r$, they continue to apply in the cases when the economy starts in the $r_{2}=r$ region and interventions move the economy into the $r_{2}>r$ region. 


\section{Figures}

Figure 1. Laissez-faire equilibrium

- Constrained --- Unconstrained
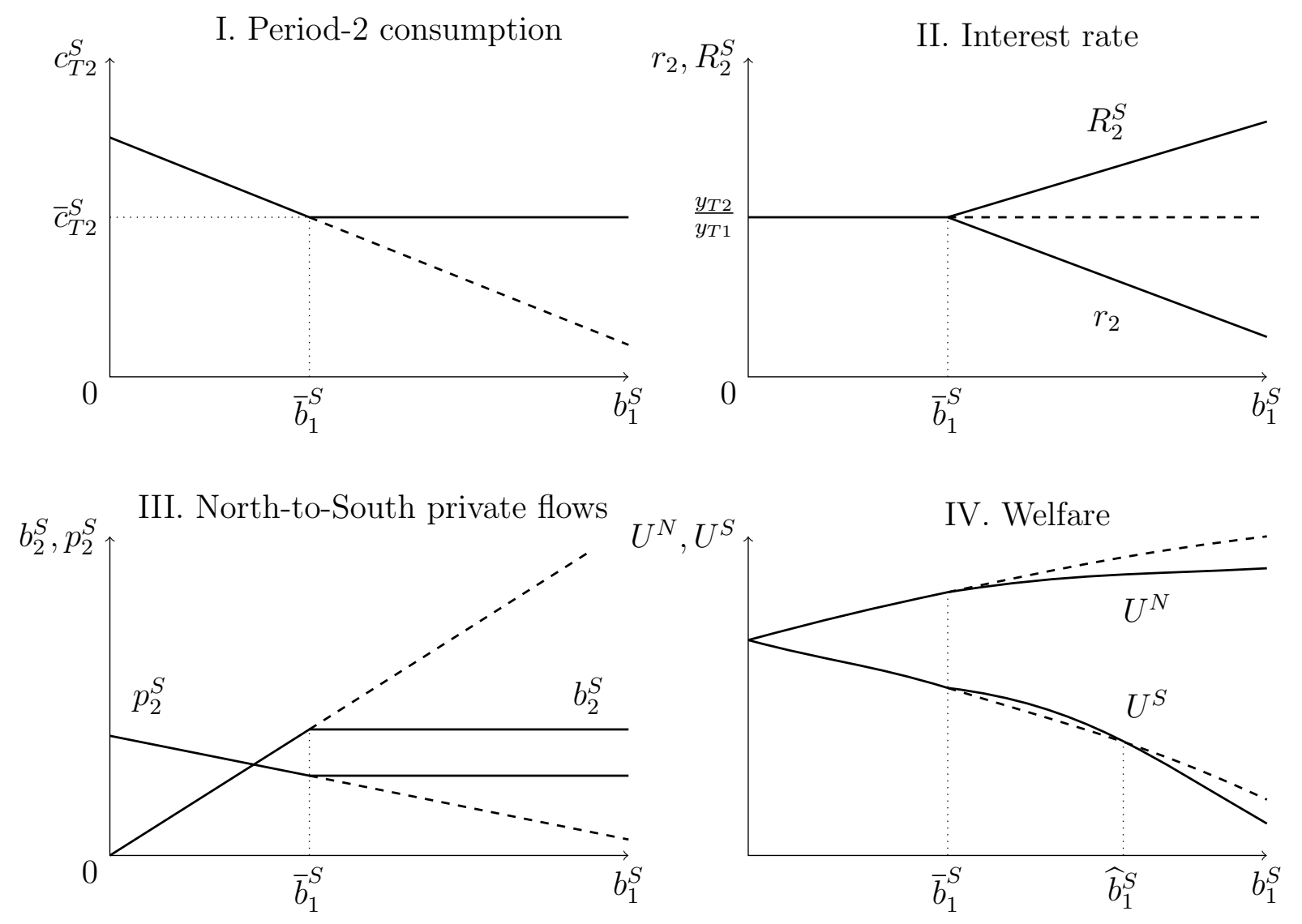

Figure 2. Laissez-faire welfare
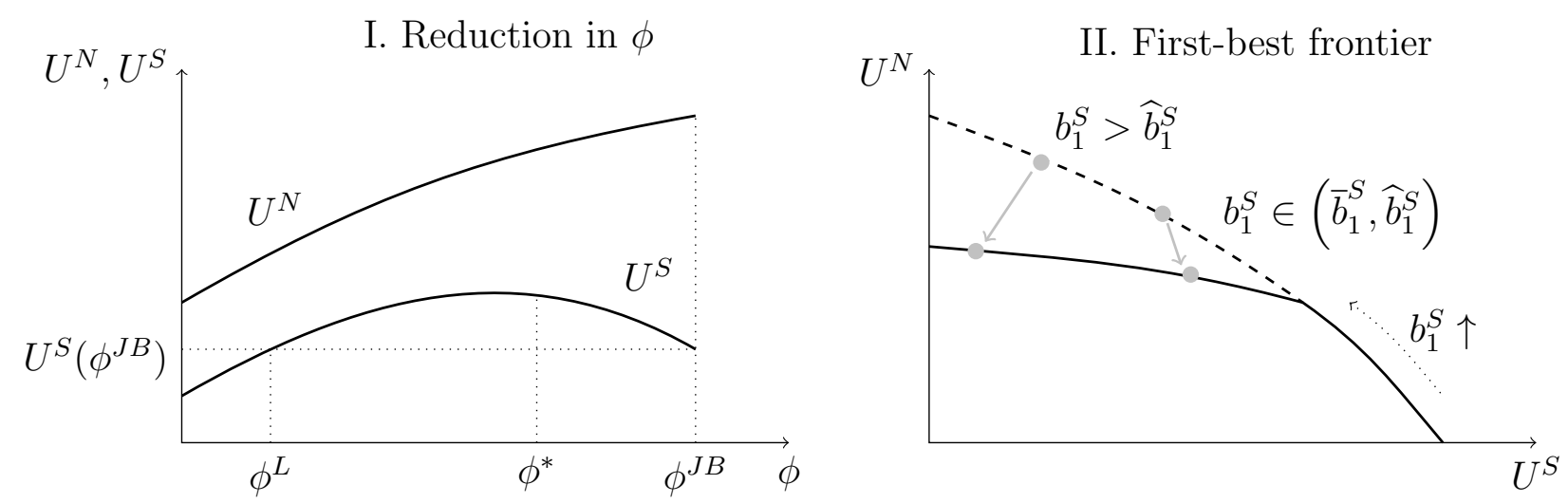
Figure 3. Impact of intervention

- Governmental loan _ - - Tax-subsidy with debt relief
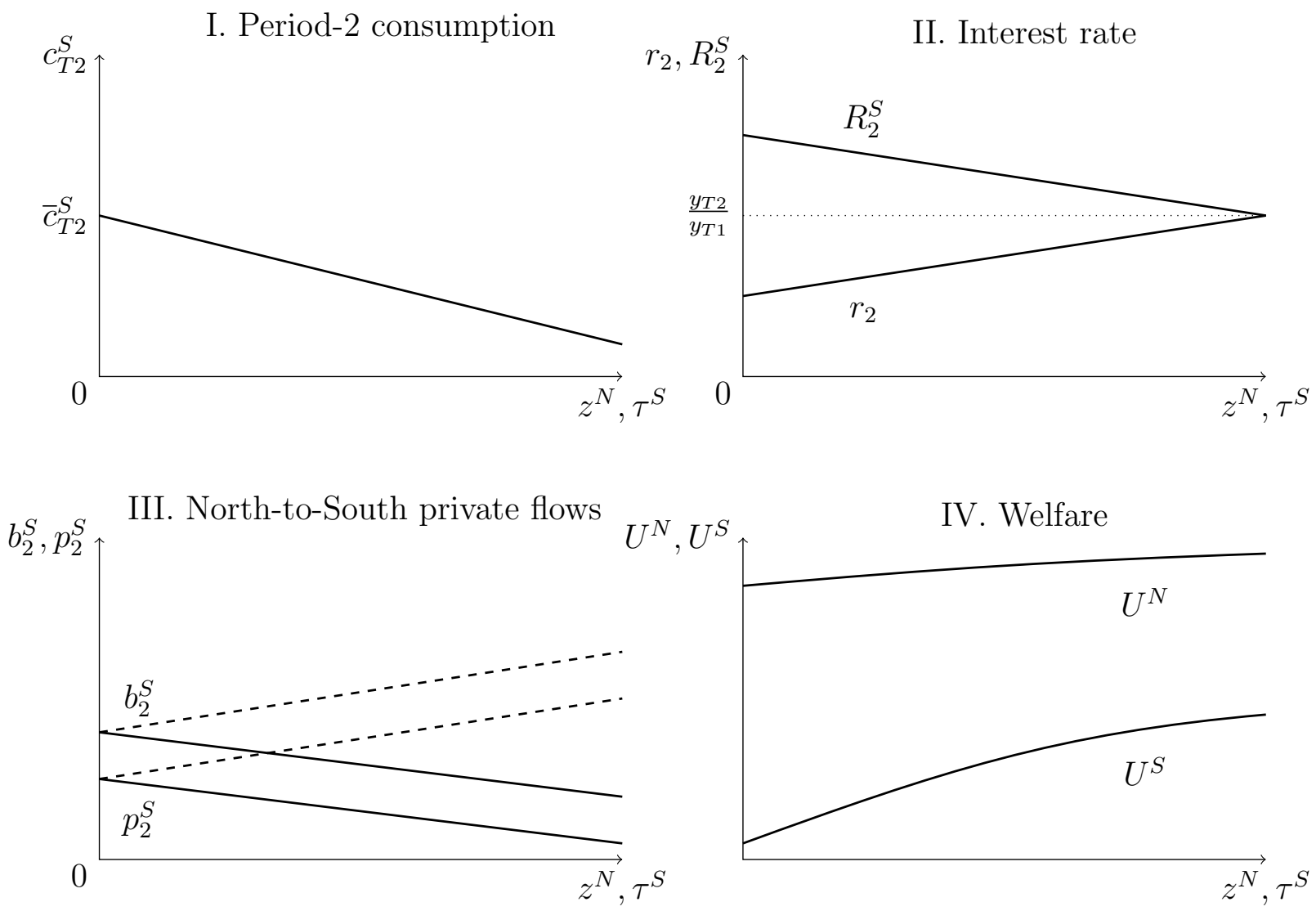

IV. Welfare

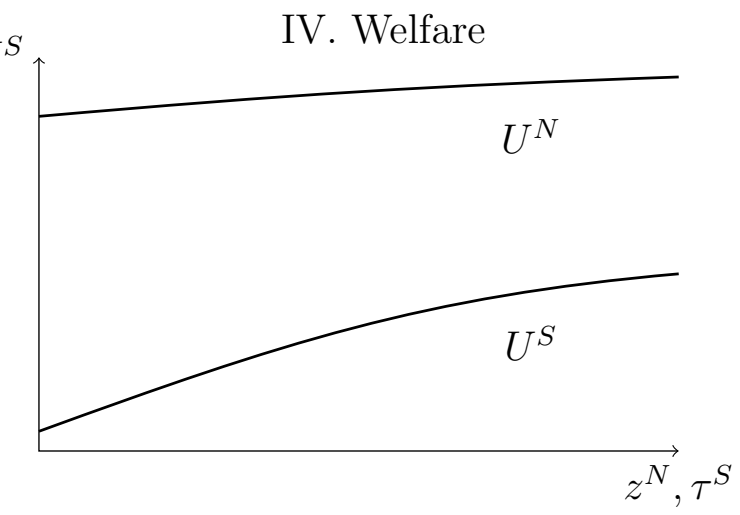

Figure 4. How intervention begins
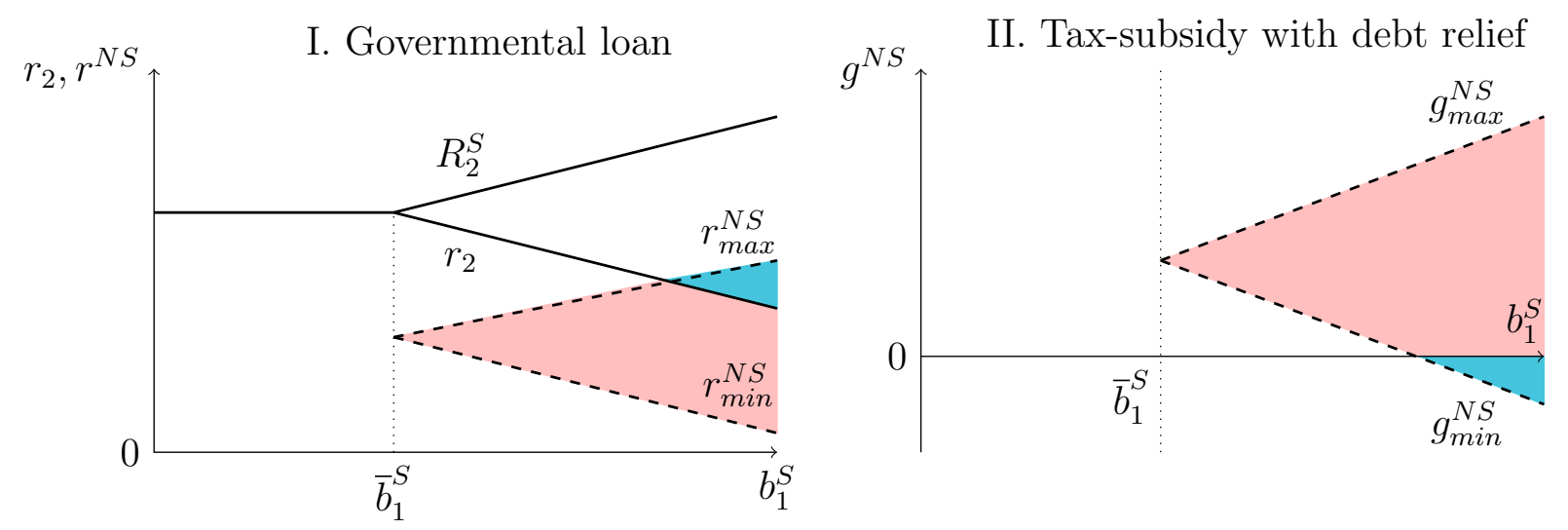
Figure 5. How intervention ends

- Unlimited intervention --- Limited intervention

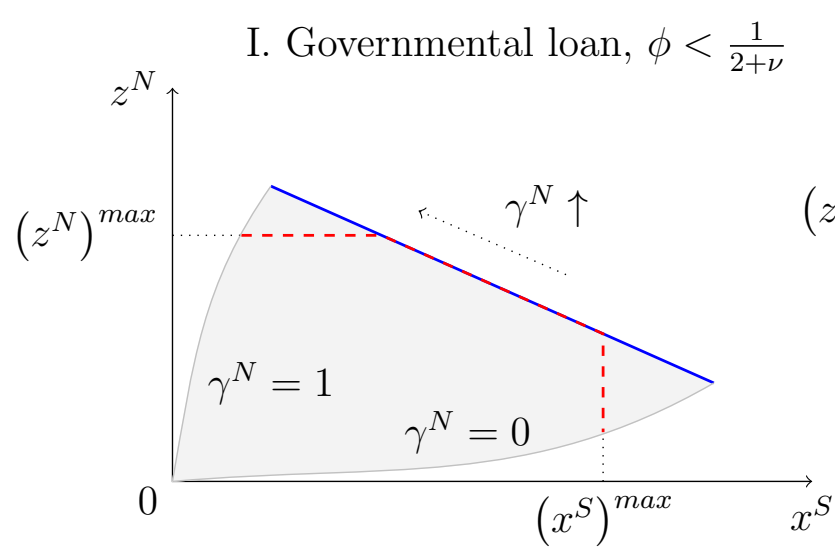

III. Tax-subsidy, $b_{1}^{S} \in\left(\bar{b}_{1}^{S}, \widetilde{b}_{1}^{S}\right)$

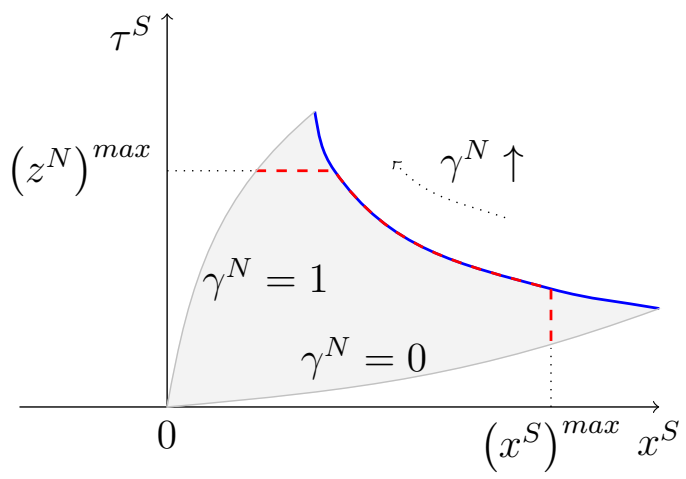

V. Tax-subsidy, $b_{1}^{S}>\widehat{b}_{1}^{S}$

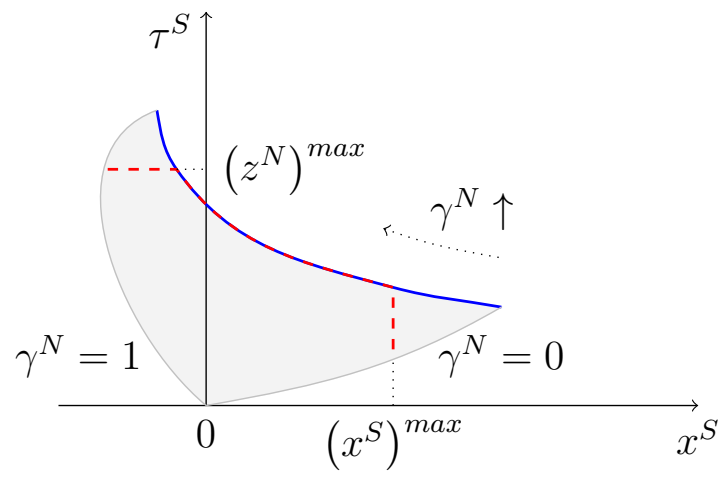

II. Governmental loan, $\phi>\frac{1}{2+\nu}$

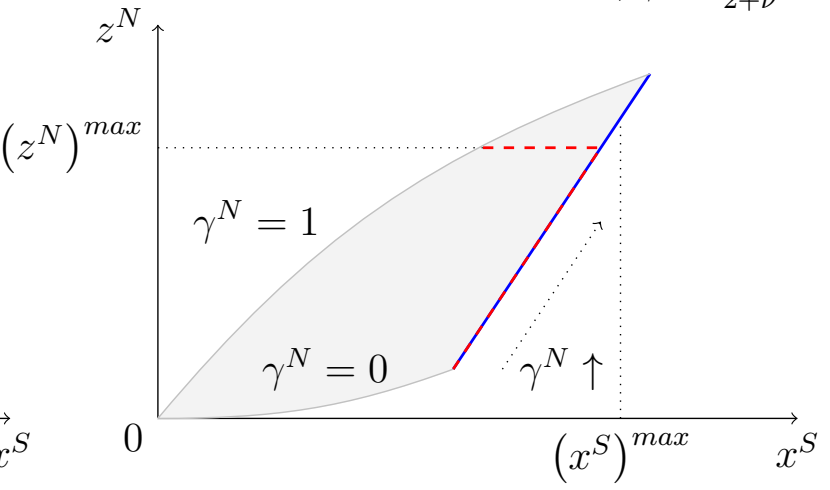

IV. Tax-subsidy, $b_{1}^{S} \in\left(\widetilde{b}_{1}^{S}, \widehat{b}_{1}^{S}\right)$

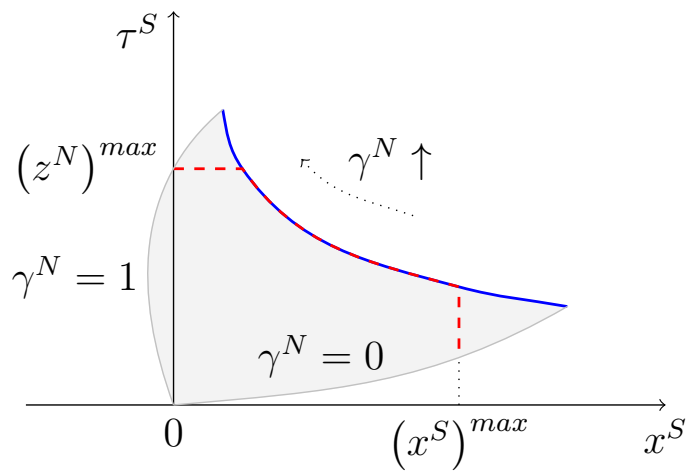


Figure 6. Endogenizing the debt level $b_{1}^{S}$

I. Determination of $b_{1}^{S}$ and $c_{T 1}^{S}$

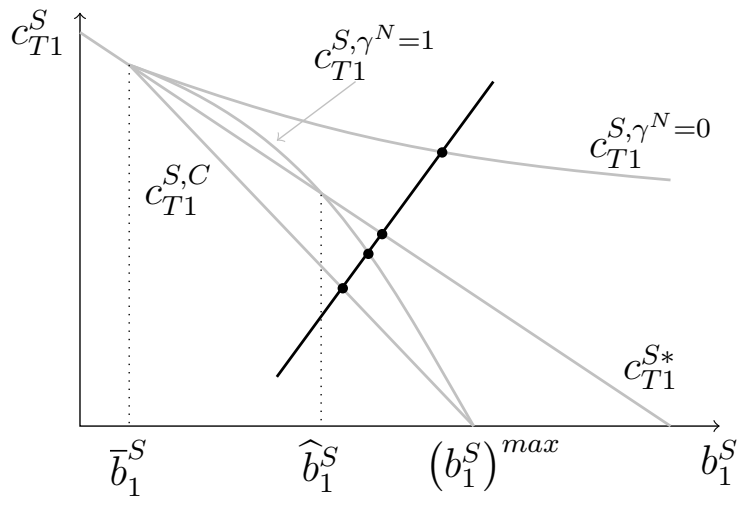

II. Determination of $b_{1}^{S}$ and $c_{T 1}^{N}$

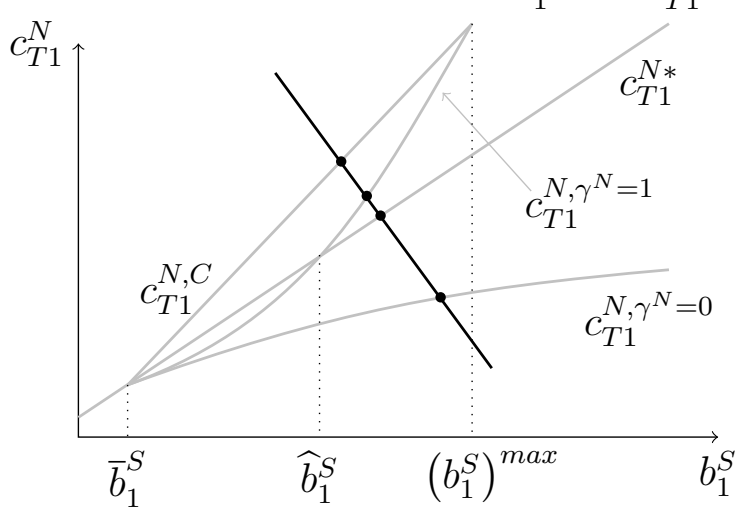

III. Impact on $V^{S}$
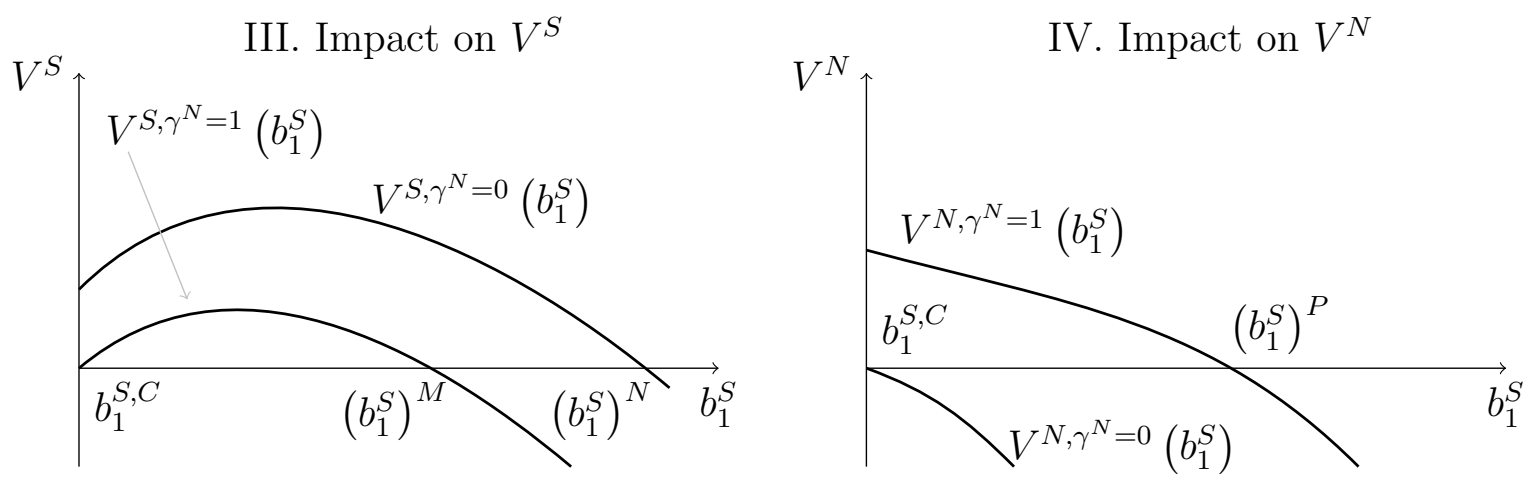

Figure 7. Institutional design

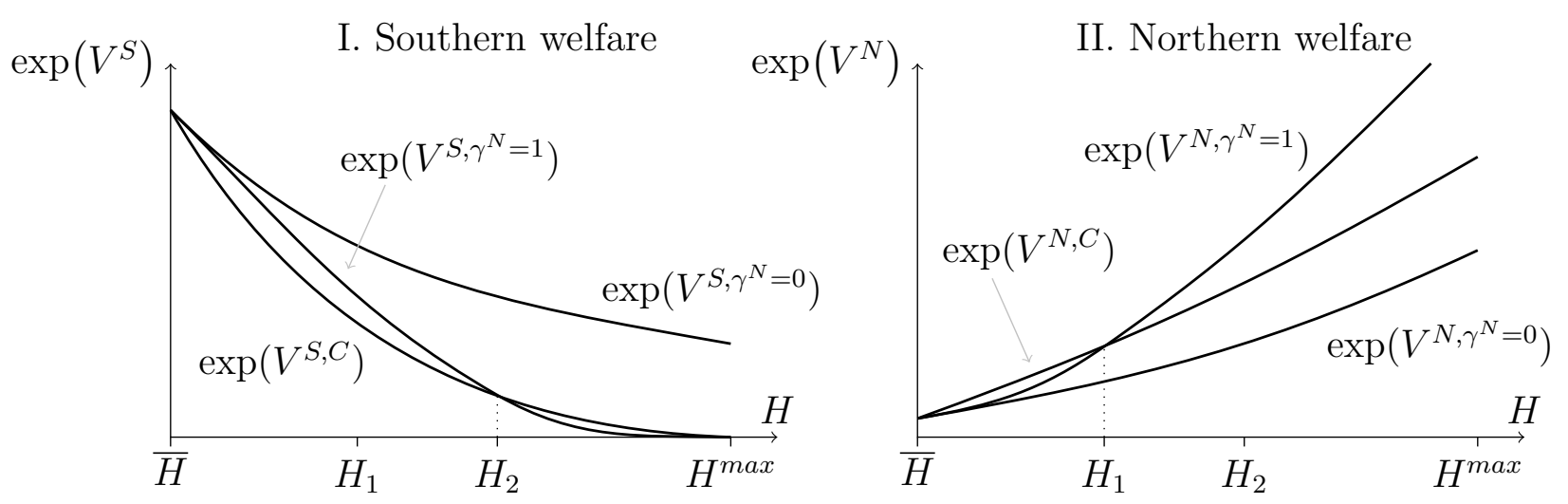


Figure 8. Laissez-faire equilibrium with $R O W$ and production

- Constrained -- Unconstrained
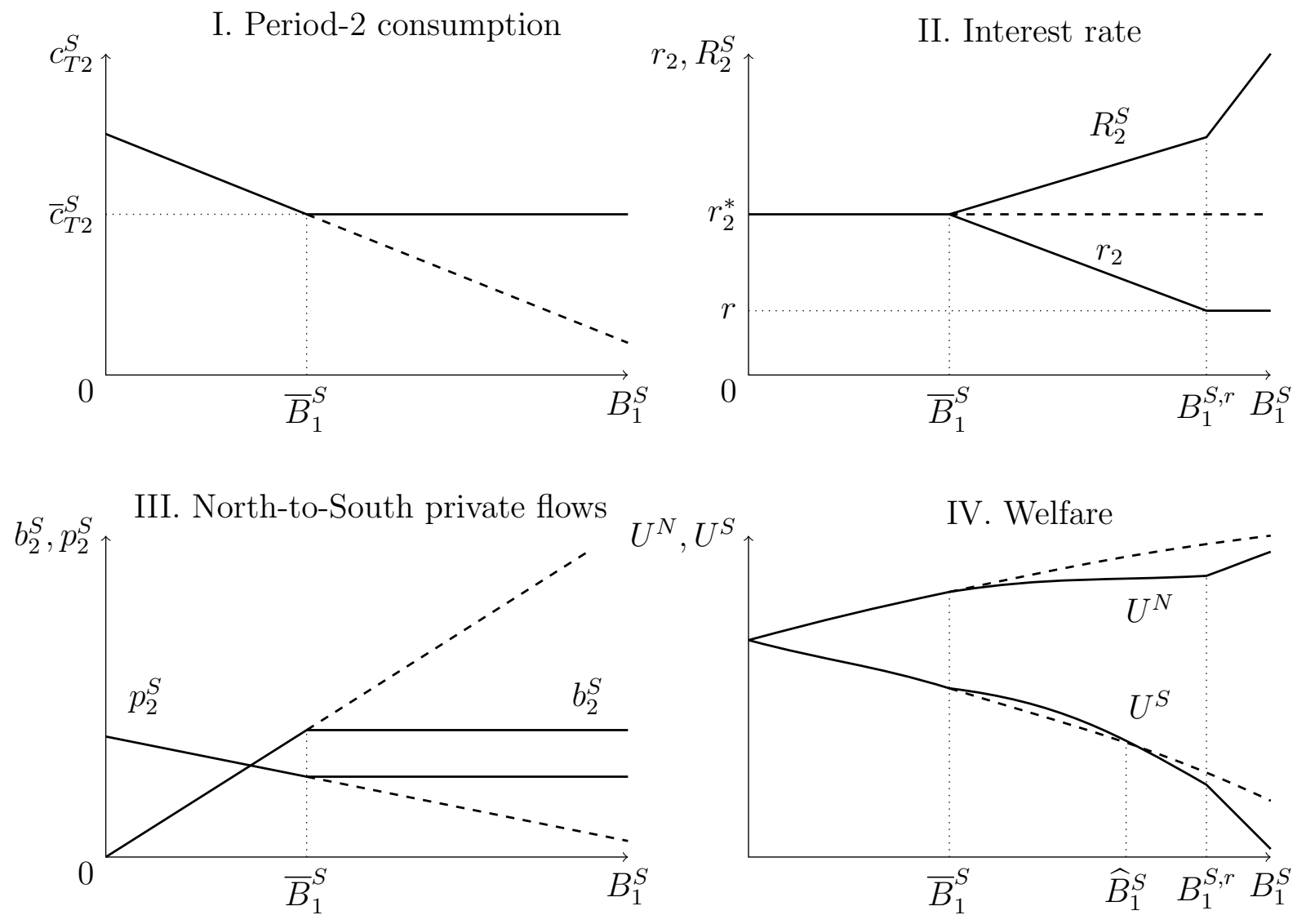

IV. Welfare
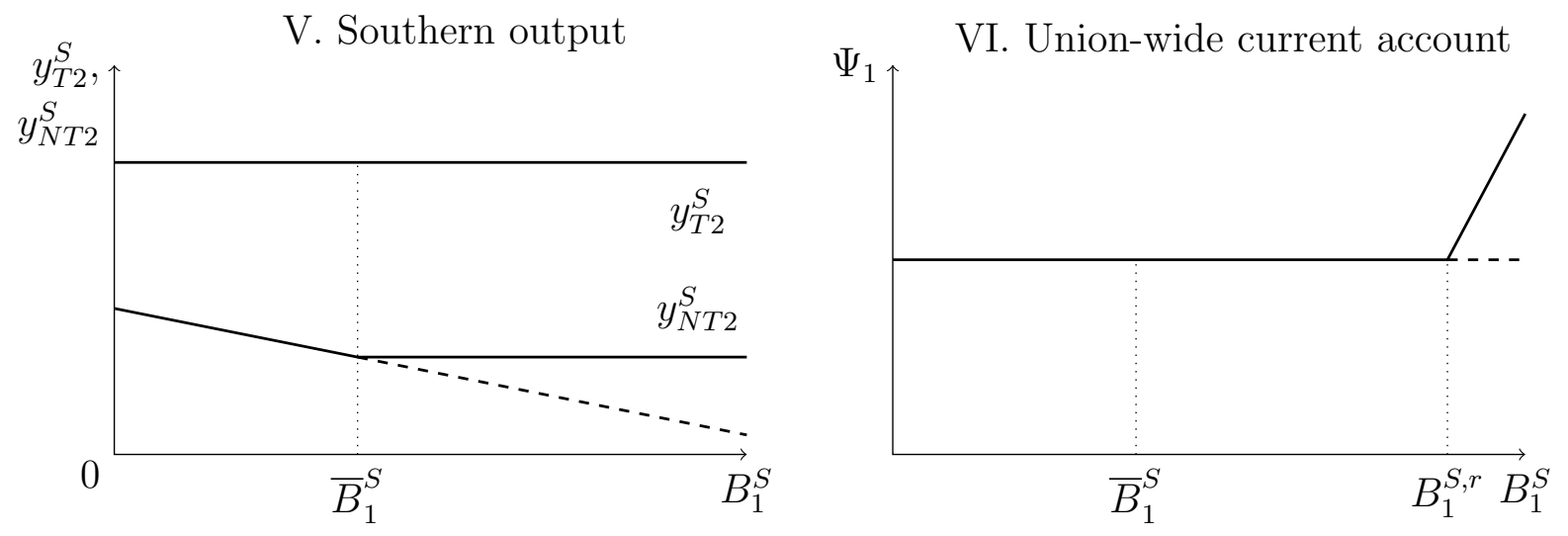
Figure 9. Impact of intervention with $R O W$ and production for $B_{1}^{S} \in\left(\bar{B}_{1}^{S}, B_{1}^{S, r}\right]$

— Governmental loan - - - Tax-subsidy with debt relief
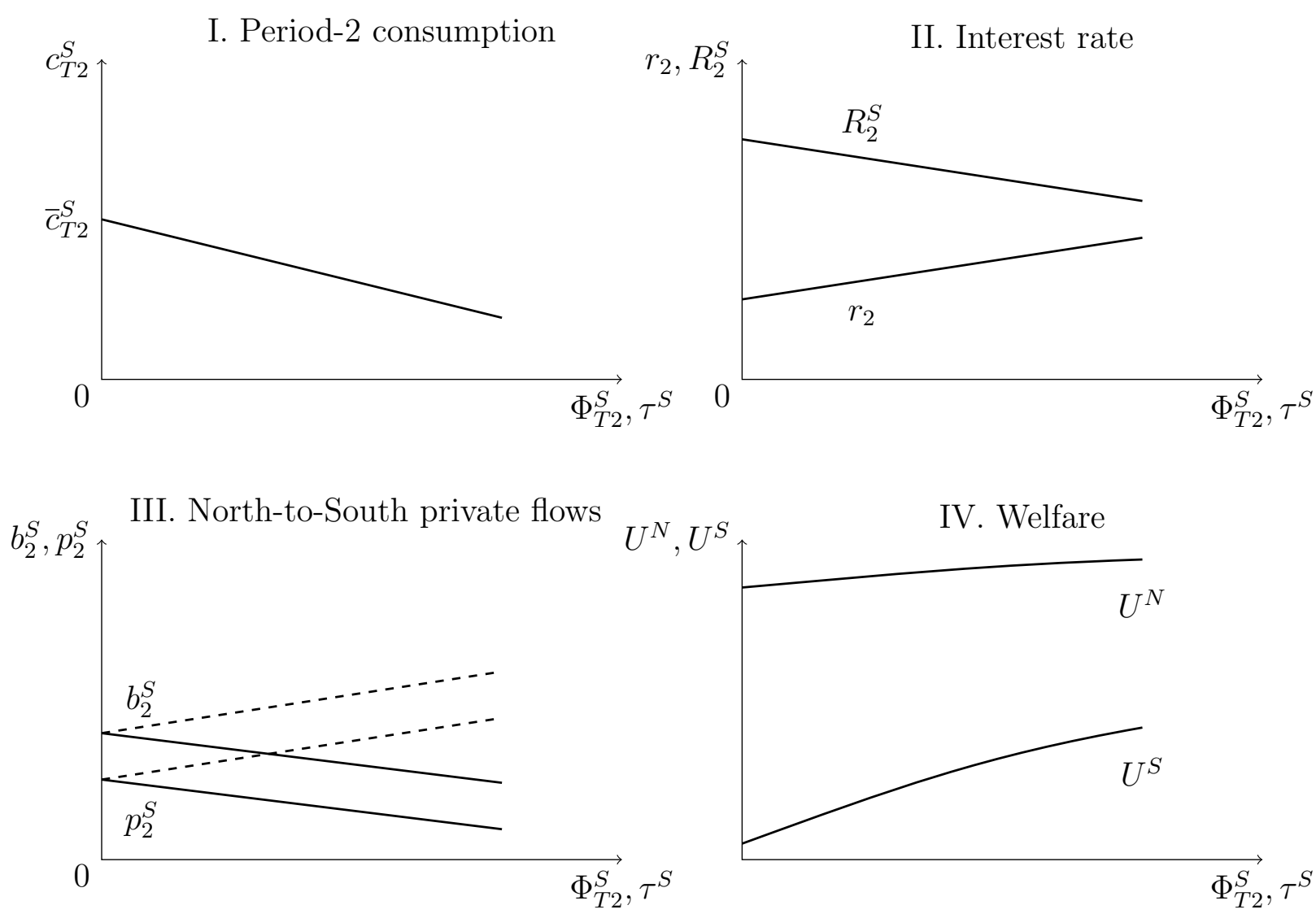

IV. Welfare
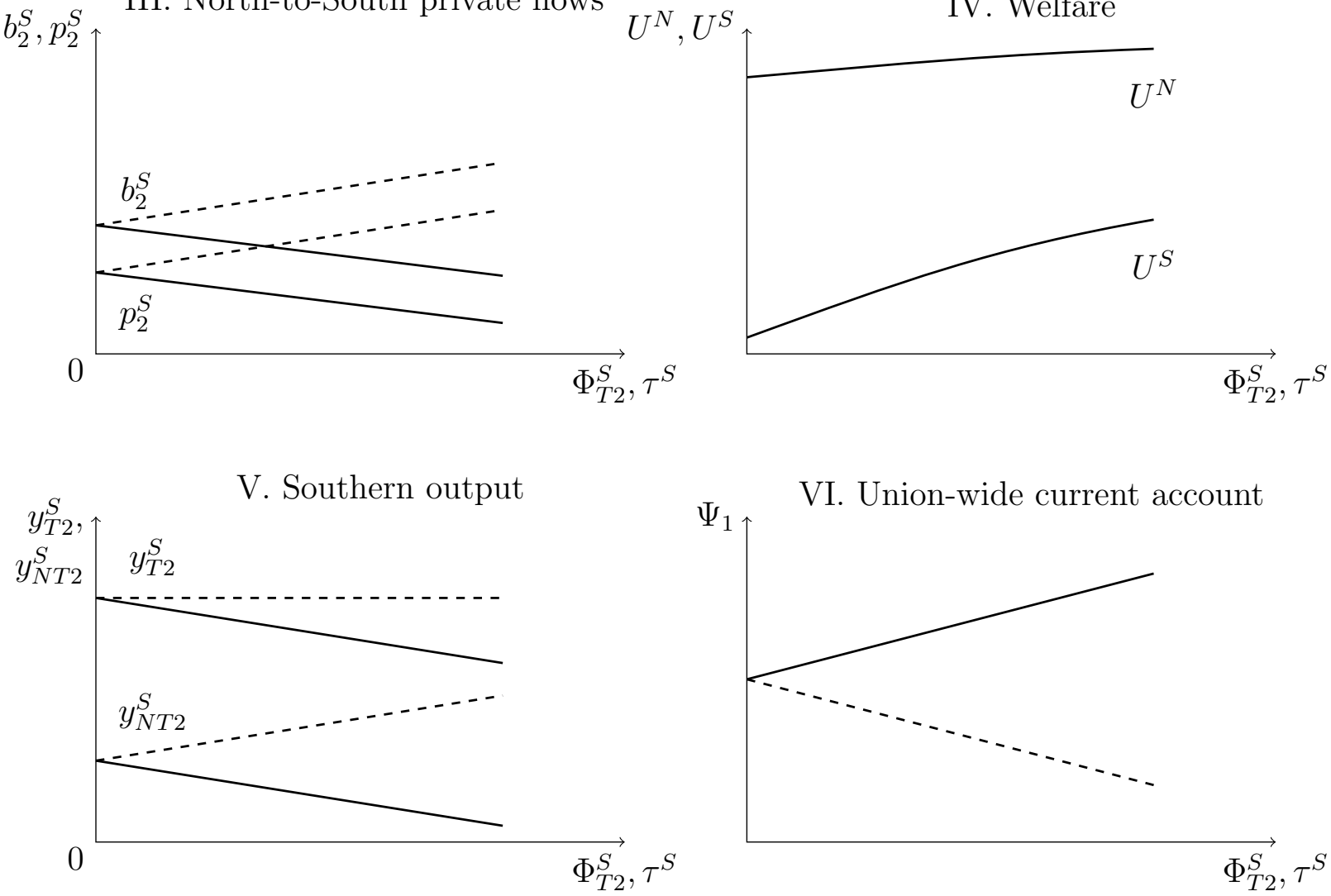
Figure 10. Simulation: impact of constraint on pre-crisis welfare
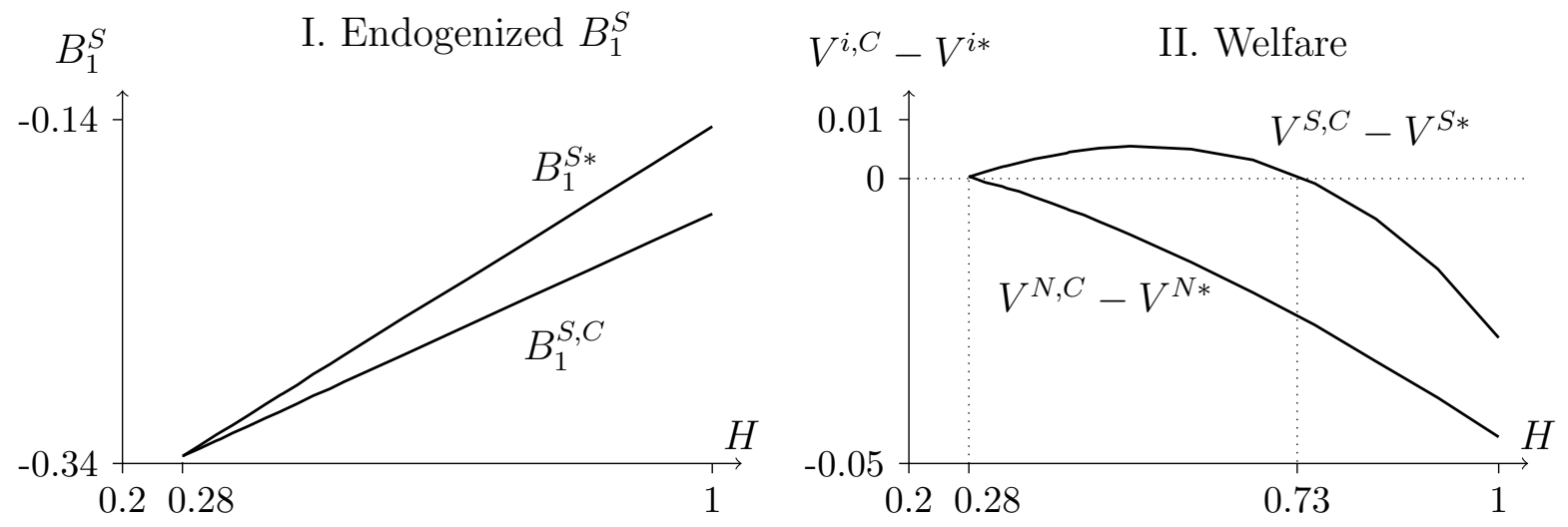

Figure 11. Simulation: institutional design
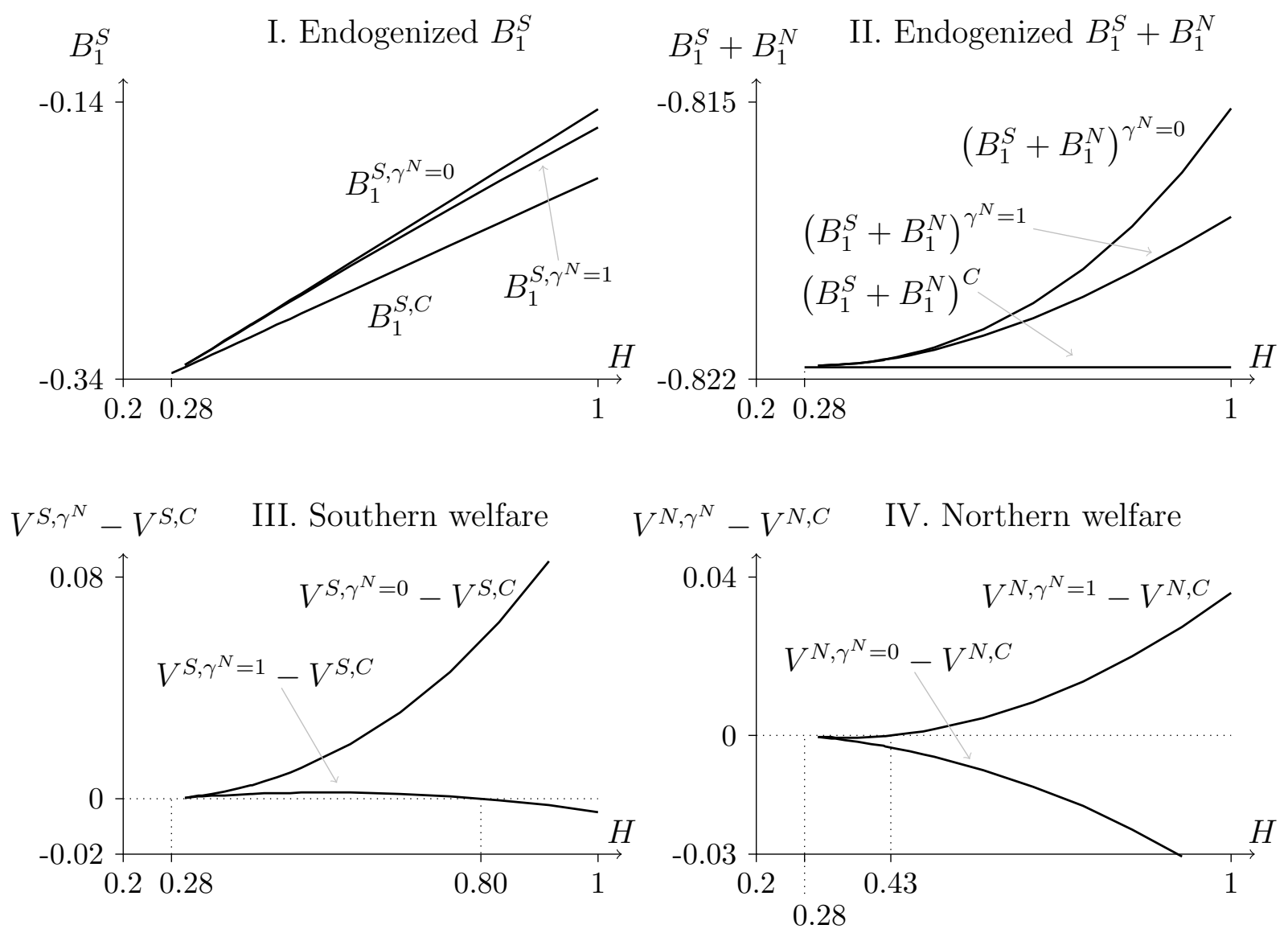

Parameters: $\phi=0.05, \phi_{R O W}=0.01, \alpha_{T}=0.5, \alpha_{N T}=0.2, \nu=1, r=1, e^{T}=0.5, A_{1}=2, A_{2}=4$. 